\title{
Larval Ecology and Synchronous Reproduction of Two Crustacean Species: \\ Semibalanus balanoides in New England, USA and \\ Gecarcinus quadratus in Veraguas, Panama
}

\author{
by \\ Joanna Gyory \\ B.A., Cornell University, 2001 \\ M.Sc., Stony Brook University, 2005 \\ Submitted to the MIT Department of Biology and the WHOI Biology Department \\ in partial fulfillment of the requirements for the degree of \\ Doctor of Philosophy \\ at the \\ MASSACHUSETTS INSTITUTE OF TECHNOLOGY \\ and the \\ WOODS HOLE OCEANOGRAPHIC INSTITUTION
}

February 2011

(C) 2010 Joanna Gyory. All rights reserved.

The author hereby grants to MIT and WHOI permission to reproduce and to distribute publicly paper and electronic copies of this thesis document in whole or in part in any medium now known or hereafter created.

Signature of Author

Joint Program in Oceanography/Applied Ocean Science and Engineering Massachusetts Institute of Technology and Woods Hole Oceanographic Institution

December 15, 2010

Certified by

Dr. Jesús Pineda Thesis supervisor

Accepted by

Dr. Simon Thorrold Chair, Joint Committee for Biological Oceanography

Woods Hole Oceanographic Institution 


\title{
Larval Ecology and Synchronous Reproduction of Two Crustacean Species: Semibalanus balanoides in New England, USA and Gecarcinus quadratus in Veraguas, Panama
}

\author{
by \\ Joanna Gyory \\ Submitted to the MIT Department of Biology and the WHOI Biology Department on \\ December 15, 2010, in partial fulfillment of the requirements for the degree of \\ Doctor of Philosophy
}

\begin{abstract}
The environmental cues for synchronous reproduction were investigated for two highly abundant, ecologically important crustacean species: the temperate acorn barnacle, Semibalanus balanoides, and the tropical terrestrial crab, Gecarcinus quadratus. Larval ecology of these two species was also studied to determine potential sources of larval mortality and recruitment success. High-frequency observations revealed that early-stage larval abundance of $S$. balanoides was related to storms, and possibly turbidity. Field observations and experiments studied the effect of turbidity and phytoplankton on larval release response. Release coincided with increased turbidity at three sites along the northeast coast of the United States. A three-year time series of phytoplankton and zooplankton data showed that larval release was not consistently related to phytoplankton abundance (total or single species). When gravid barnacles were exposed to phytoplankton or synthetic beads, they released in response to both, suggesting that presence of particles is more important than identity of particles. Feeding experiments showed that adult cannibalism on newly released larvae is lower in highly turbid conditions. It is suggested here that $S$. balanoides synchronizes its reproduction with the onset of phytoplankton blooms, but turbidity may fine-tune the timing if it provides predation refuge for larvae. Adult G. quadratus females undertake synchronized breeding migrations to the ocean after the first rains of the rainy season, presumably when the risk of desiccation is lowest. They wait for darkness and an ebbing tide before releasing their eggs into the water. First-stage zoeas have dark pigmentation, long dorsal and rostral spines, and a pair of lateral spines. Hatching in darkness may help zoeas avoid predation from planktivorous diurnal fish, and the zoeal spines may deter predation from planktivorous nocturnal fish. In the laboratory, a G. quadratus zoea reached the megalopa stage in 21 days. A mass migration of megalopae and juveniles out of the water was observed 30 days after adult females released their eggs. Plankton pump samples taken near the island suggest that zoea abundance and distribution may be related to the phase of the internal tide. Synchronous reproduction in these two species appears to be the result of predator avoidance behaviors.
\end{abstract}

Thesis Supervisor: Jesús Pineda

Associate Scientist with Tenure

Woods Hole Oceanographic Institution 


\section{ACKNOWLEDGEMENTS}

I wish to thank many people for their help, support, and encouragement during the time I worked on this dissertation. I am very grateful to my advisor, Jesús Pineda. He taught me many practical skills, including programming CTDs, soldering cables for plankton pumps, deploying and recovering temperature moorings successfully, and many more. He imprinted in me the importance of being a good naturalist and observing my study systems carefully. From him I also learned a great deal about the philosophy of science and what it means to be a good scientist. I thank the rest of my thesis committee: Carin Ashjian, Peter Wiebe, and Thomas Peacock. They provided useful and valuable feedback throughout the process of designing and implementing experiments and interpreting the results.

My funding was provided by a National Science Foundation Graduate Research Fellowship, three WHOI Ocean Life Institute grants (Grant \# 27071337, 27071342, and 25051361), two WHOI Coastal Ocean Institute grants (Grant \# 32031022 and 27040136), and financial support from the WHOI Academic Programs Office.

I thank many people for their field assistance, especially Hazel Levine. She worked carefully, cheerfully, and tenaciously under difficult conditions to help me gather data at the Liquid Jungle Lab in Panama. The light trap work would have been impossible without her help. I thank the staff at the Liquid Jungle Lab, including Luis Camilli, Elvia, Elida, Juan, Benito, Pacho, Bernabé, Johnny, Dra. Bertha, Juan Carlos, Juancho, Lina, Jorge, Dre, and others for helping me carry out my work there. I am also deeply grateful to my fellow Joint Program students who helped with the high-frequency sampling of barnacle larvae. They include Luc Mehl, Erin Banning, Christopher Waters, Michael Holcomb, Meredith White, Christine Thompson, and Kate Buckman. John Ahern was invaluable in helping with logistics, setup, and execution of experiments in Woods Hole, Rhode Island, and New Hampshire. I thank the staff at the University of Rhode Island Graduate School of Oceanography and the University of New Hampshire, who allowed me to use their piers and laboratories.

Andrew Solow and Victoria Starczak provided many helpful discussions and suggestions for the statistical analysis of data. This thesis also benefited from discussions with Molly Jacobs, Kristen Davis, Jonathan Blythe, and Nathalie Reyens. Heidi Sosik and David Ralston kindly lent me their fluorometers and turbidimeters and showed me how to use them.

I thank Marsha Armando, Julia Westwater, Ronni Schwartz, Ellen Bailey, Susan Tomeo, and Kate Davis for their tremendous help with administrative matters. The WHOI carpenters, electricians, facilities workers, and media office were also very helpful.

Finally, I would like to thank my family and friends for cheering me on. Their love and support were key to my success. 


\section{Table of Contents}

Chapter 1: Introduction ....................................................................................... 7

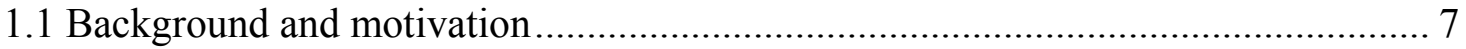

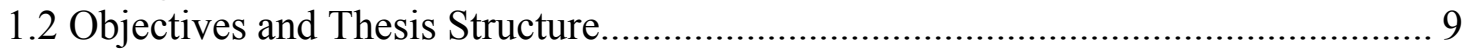

Chapter 2: High-frequency observations of early-stage larval abundance: Do storms trigger synchronous larval release in Semibalanus balanoides? ...................................... 13

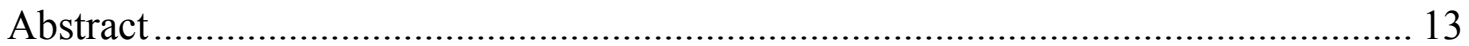

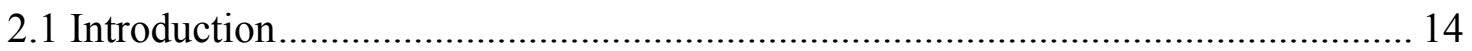

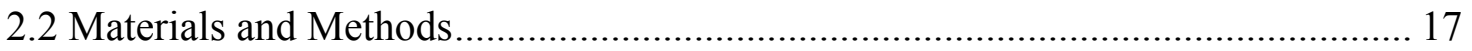

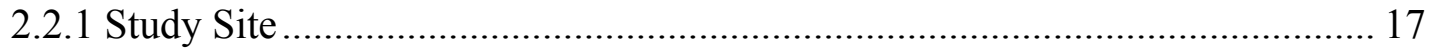

2.2.2 Timing of larval release in relation to environmental variables ...................... 18

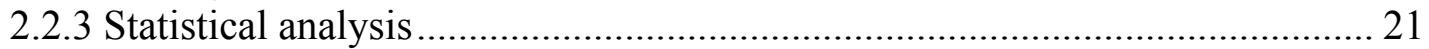

2.2.4 Vertical distribution of Barnacle Larvae.................................................... 25

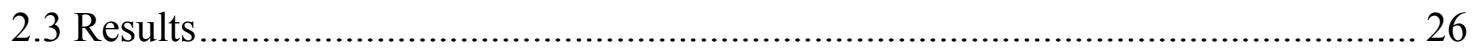

2.3.1 Timing of larval release in relation to environmental variables ...................... 26

2.3.2 Vertical distribution of Barnacle Larvae....................................................... 30

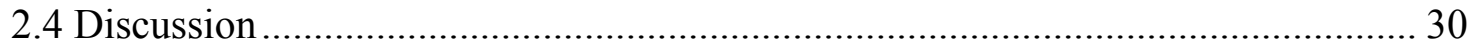

Chapter 3: Does turbidity trigger larval release by the intertidal barnacle Semibalanus balanoides? A test of the hypothesis............................................................................... 35

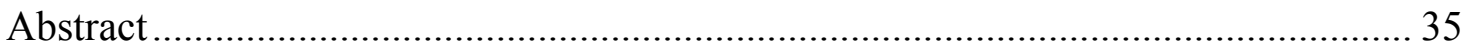

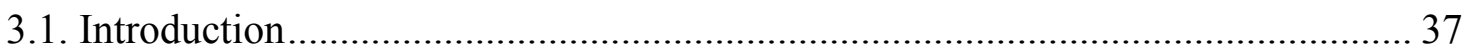

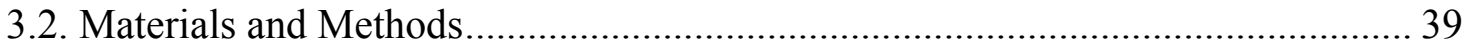

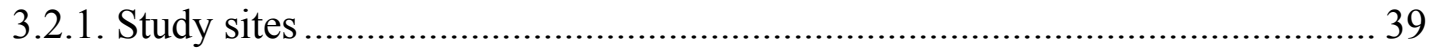

3.2.2. Field observations of larval release.............................................................. 40

3.2.3. Experiments - Larval release in response to phytoplankton, turbidity, and control conditions............................................................................................... 43

3.2.4. Experiments - Predation rate of adults on newly released larvae under turbid and normal conditions......................................................................................... 49 3.2.5. Analysis of time series from Rhode Island: Does larval release coincide with

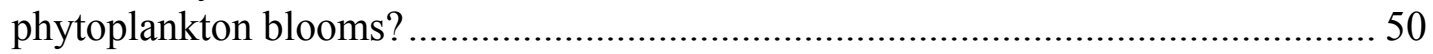

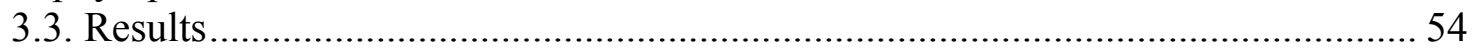

3.3.1. Field observations of larval release............................................................ 54

3.3.2. Experiments - Larval release in response to phytoplankton, turbidity, and

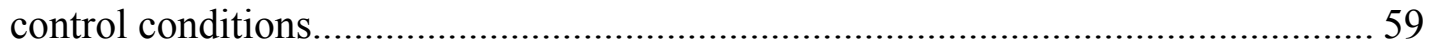
3.3.4. Analysis of time series from Rhode Island: Does larval release coincide with

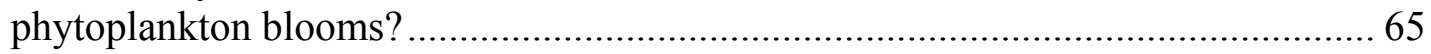

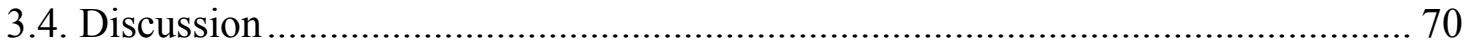


Chapter 4: Reproductive ecology and larval biology of the land crab Gecarcinus quadratus on the Pacific coast of Panama

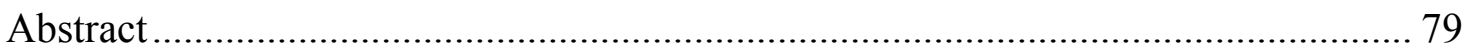

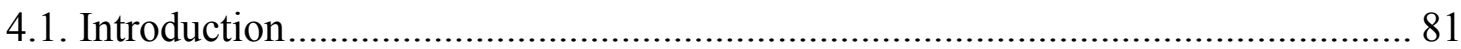

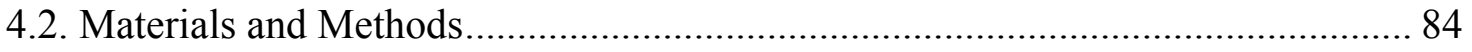

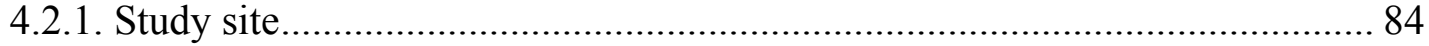

4.2.2. Investigations of adult migrations and egg release behavior ........................ 85

4.2.3. General morphology and development rate of Gecarcinus quadratus larvae 88

4.2.4. Nearshore abundance of zoeas and megalopae in relation to rain, tidal phase,

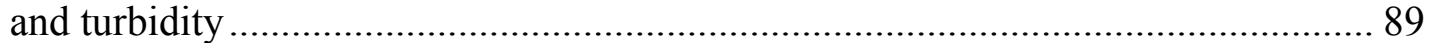

4.2.5. Zoea abundance in relation to the internal tide and internal waves............... 92

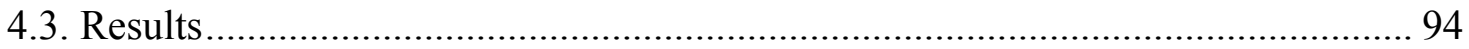

4.3.1. Investigations of adult migrations and egg release behavior........................ 94

4.3.2. General morphology and development rate of Gecarcinus quadratus larvae 96

4.3.3. Nearshore abundance of zoeas and megalopae in relation to rain, tidal phase,

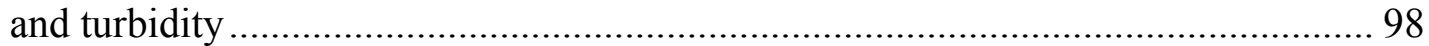
does not seem to be related to turbidity levels (results not shown)..................... 103

4.3.4. Zoea abundance in relation to the internal tide and internal waves .............. 103

4.4.1. Timing of egg release in Gecarcinus quadratus and morphology and development rate of the larvae.......................................................................... 108

4.4.2. Potential for accumulation and transport of zoeas by internal tidal bores .... 118

4.5. Summary and conclusions ..................................................................... 119

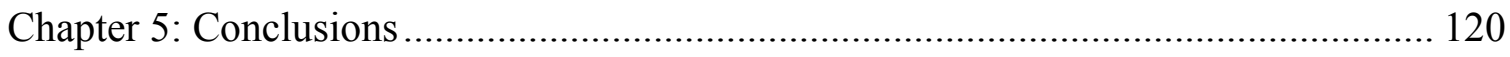

5.1. The importance of temporal scale in observations of marine invertebrate reproduction

5.2. Synchronous reproduction in crustaceans: predator swamping or predator avoidance?

5.3. Potential impacts of climate change on the timing of reproduction ................... 124

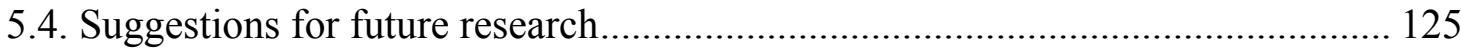

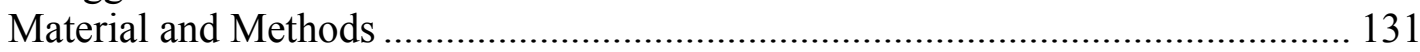

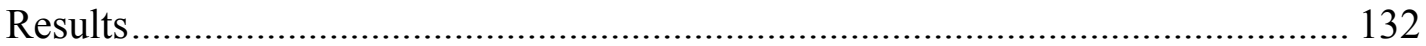

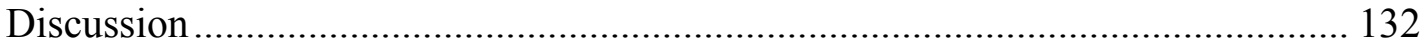

Appendix 1: Filtering process for data from Little Harbor.........................................127

Appendix 2: Observation of needlefish (Strongylura scapularis) spawning coinciding with the egg release of crabs (Gecarcinus quaddratus).

Bibliography 


\section{Chapter 1 Introduction}

\subsection{Background and motivation}

One of the main goals of Ecology is to characterize the assemblage of species present in an environment and to understand how and why it changes. Even in the oceans, which are all interconnected, there are still markedly different species assemblages found throughout, and these assemblages are not static - they are constantly fluctuating, shifting, and changing. Since the early days of Marine Ecology, scientists have been interested in the diversity of species in the ocean. Hutchinson (1961) famously posed The Paradox of the Plankton: how is it possible, he asked, "for a number of species to coexist in a relatively isotropic or unstructured environment all competing for the same sorts of materials?" The answer seems to be that the environment is not at as isotropic or unstructured as it might appear, neither in time nor space (Hutchinson 1961; Richerson et al. 1970).

The abundance and species composition of zooplankton at a given place are known to vary temporally on multiple scales, and this variation can be affected by both physical and biological processes. Two examples of physical processes that influence zooplankton variability on the scale of years to decades are the North Atlantic Oscillation (NAO) and the El Niño Southern Oscillation (ENSO). Changes in the relative abundance of the copepods Calanus finmarchicus and Calanus helgolandicus in the North Sea are strongly tied to the NAO. In years of positive NAO index values, C. finmarchicus abundance decreases, while C. helgolandicus abundance increases (Fromentin and 
Planque 1996; Ottersen et al. 2001). ENSO influences zooplankton communities off the western coast of North America. Zooplankton biomass in the California Current has been observed to decrease during El Niño years, and different functional groups of zooplankton become dominant (McGowan et al. 1998). On the scale of months, zooplankton can be advected or displaced by features such as eddies and Gulf Stream rings (Haury et al. 1978). The progression of seasons can change the depth and strength of thermoclines and upwelling events, the extent of mixing, and the formation of surface water masses (Haury et al. 1978), all of which can affect temperature, salinity, oxygen concentration, food availability, and other parameters that impact planktonic organisms.

Diel vertical migration (DVM) is an example of a biological process that affects zooplankton variability, leading to fluctuations in abundance and species composition with depth and time of day. The most common DVM pattern is for zooplankton to reside in deep waters during the day and ascend toward the surface at night (e.g. Chushing 1951; Hutchinson 1967; Lampert 1989; Ashjian et al. 1998). But some species, for example copepods in the genus Pseudocalanus, perform the vertical migration in reverse (Ohman et al. 1983). Descriptions of DVM and mechanistic understandings of it have allowed marine ecologists to model planktonic ecosystems and design sampling protocols to test hypotheses appropriately.

Synchronous reproduction is another biological process that can drastically alter zooplankton communities. The large flux of propagules into the water column over a short period of time can change the relative abundance of organisms. For example, when the barnacle Semibalanus balanoides releases larvae in Narragansett Bay (Rhode Island, USA), the larvae can account for up to $15 \%$ of the total zooplankton population in 
January and February (Lang and Ackenhusen-Johns 1981). Meroplankton - individuals that reside in the plankton temporarily - can change the food web structure or the dynamics of competition for resources. On the Great Barrier Reef, the massive, synchronous release of coral propagules provides an important source of lipids for fish, and this may enhance the quality and survivorship of fish offspring (Pratchett et al. 2001). Most marine invertebrates, even those that reside on the seafloor, produce planktonic larvae. Many of these organisms also produce larvae seasonally or in shorter, synchronous bursts. Therefore, to understand the processes that govern changes in a zooplankton community, it is important to understand the factors that influence the introduction of meroplankton into the water column.

By understanding the cues that lead to synchronous larval release, it may be possible to make predictions about the ways in which zooplankton communities change over time. Furthermore, some of the cues used for reproduction may be altered by climate change. It is important to characterize the temporal and spatial patterns of synchronous larval release now to have baseline information that will help us detect changes in the future.

\subsection{Objectives and Thesis Structure}

In this thesis, I examine the environmental factors that trigger synchronous reproduction in crustaceans. I focused on two species: the acorn barnacle, Semibalanus balanoides, on the northeast coast of the United States; and a land crab, Gecarcinus quadratus, on the Pacific coast of Panama. I chose these organisms because there is some 
uncertainty about the cues that trigger their reproduction. Larval abundance of the acorn barnacle has been observed to correlate roughly with winter-spring phytoplankton blooms, but some laboratory observations have suggested that phytoplankton abundance alone may not fully explain the timing of reproduction. Similarly, the tropical land crab has been observed making mass migrations to the ocean to breed, but the migration triggers have not been explored quantitatively.

Besides identifying the cues used for synchronous reproduction, I also explored the ecological significance of the timing of release. This was done by characterizing the physical and biological environment to which newly-hatched larvae were exposed, and examining the larval behavior and morphology for clues about sources of mortality that larvae may be avoiding. I then proposed hypotheses about the ways in which the timing of release could maximize larval survival in these two species.

The larvae of Gecarcinus quadratus have not been described in the literature, so a study was conducted to determine the basic larval morphology and estimate the development rate in the plankton. This information could be useful to anyone conducting zooplankton studies in the Eastern Tropical Pacific, since it will aid in the identification of species in samples collected from that area. Furthermore, it will aid future studies of factors affecting the recruitment and population biology of this ecologically important species.

This thesis is composed of three principal chapters. Chapter 2 describes observations acquired in the winter of 2007 to determine which environmental factors might be important in triggering larval release in Semibalanus balanoides. The high frequency of observations (every two hours for two weeks) is unusual in studies of 
marine ecology, especially those focusing on wintertime processes. Larval abundance was strongly related to winter storms, and larvae were more abundant near the surface than near the benthos. This lead to the hypothesis that the barnacles had released their larvae during storms because that is when water turbidity was highest. If predation was an important source of larval mortality, then releasing larvae during turbid conditions might be advantageous because potential predators would be swamped by additional particles. Furthermore, swimming toward the surface might help larvae avoid benthic predators.

Chapter 3 describes field and laboratory tests of the hypotheses proposed in Chapter 2. Turbidity, chlorophyll- $a$, and barnacle larval release were measured at three sites along the northeastern United States: Woods Hole, MA, Narragansett, RI, and New Castle, NH. Examining patterns at multiple sites allowed replicate observations within a single winter. The prevailing hypothesis that phytoplankton blooms trigger larval release was also tested by examining a three-year time series of phytoplankton and zooplankton data from Rhode Island. The abundances of phytoplankton (both individual species and total cell counts) before a larval release event were compared to the abundances after. In addition to the field observations, laboratory studies that exposed gravid adult barnacles to high concentrations of phytoplankton or inert synthetic beads were conducted, and the larval release response was measured. Furthermore, the assumption that turbid conditions would lower predation rates on newly-released larvae was tested.

Chapter 4 relates the studies of the reproductive ecology and larval biology of the land crab Gecarcinus quadratus. Adult migrations were related to precipitation events, but rain was not the only cue for egg release. High-frequency observations, determined 
that the time of day and stage of the tidal cycle also play an important role. A first description of the morphology and development rate of larvae for this species was provided and it was compared to that of other crab species. Hypotheses regarding the sources of larval mortality resulted from this research. In addition, a needlefish spawning event at the coast coincided with a crab spawning event. The development of the needlefish larvae and their timing of reproduction likely coincide with that of the crabs.

Chapter 5 summarizes the major findings of the studies in this thesis. The importance of high-frequency observations in determining the cues of larval release for marine invertebrates is highlighted. The cues for synchronous larval release in these two species are compared. This chapter also discusses the question of whether synchronous release occurs because individuals simply respond to the same environmental conditions that increase survival of their larvae, or whether synchronous reproduction itself improves survival in a density-dependent manner. Finally, the potential effects of climate change on the timing of reproduction are considered. 


\title{
Chapter 2
}

\section{High-frequency observations of early-stage larval abundance: Do storms trigger synchronous larval release in Semibalanus balanoides?}

\begin{abstract}
Synchronous release of planktonic larvae occurs when it confers a survival advantage to offspring and/or adults. Knowledge of environmental conditions at the time of release and the larval behavior soon after release can help identify factors that shape synchronicity. The acorn barnacle, Semibalanus balanoides, is thought to release larvae in response to phytoplankton blooms so that larvae will have plentiful food, but there is evidence that does not support this hypothesis. High-frequency sampling was conducted in Little Harbor, Massachusetts, USA to determine whether early-stage larval abundance was related to several environmental variables, and to determine vertical distributions of the larvae. Larval concentrations peaked at 2.52 and 1.02 individuals $\mathrm{L}^{-1}$ during two storms, and larvae were more abundant near the surface than near the bottom. High turbidity and strong currents associated with storms could protect newly-released larvae by swamping predators with additional particles and by quickly transporting larvae away from the site of release. Swimming toward the surface could also help larvae avoid benthic predators. Future studies should test the hypothesis that barnacles and other invertebrates release larvae during storms to protect offspring from predation.
\end{abstract}




\subsection{Introduction}

Synchronous reproduction is common among marine invertebrates. It is favored when the optimal conditions for survival of gametes, embryos, larvae and/or adults occur within a narrow time frame (Morgan and Christy 1995), or when it increases the probability of fertilization (Harrison et al. 1984). For example, green sea urchins (Strongylocentrotus droebachiensis) and blue mussels (Mytilus edulis) time their spawning to coincide with phytoplankton blooms so that their larvae have plentiful food available (Starr et al. 1990), and many species of corals in the Great Barrier Reef spawn synchronously to satiate predators and maximize fertilization success (Harrison et al. 1984). Thus, different factors can lead to selection for synchronous reproduction in different taxa. It is important to identify the cues involved in synchrony to better understand how changes in the marine environment might affect the reproduction of marine invertebrates.

The acorn barnacle, Semibalanus $(=$ Balanus) balanoides, is among the coastal marine invertebrates that reproduce synchronously. S. balanoides inhabit rocky intertidal zones in the Arctic and temperate regions of the northern hemisphere. Fertilization in these hermaphroditic animals occurs once per year, sometime in the late fall or early winter, depending on latitude and other factors (Moore 1935; Crisp 1959a, b). After fertilization, the embryos develop within the body of the adult for approximately one month, but they are not released immediately after development is complete; the adult continues to brood the embryos for weeks to months until environmental cues trigger the 
synchronous release of their planktonic larvae, known as nauplii (Moore 1935; Barnes 1962; Crisp 1964).

Field and laboratory studies have identified high food concentration as the environmental cue that triggers larval release in S. balanoides. Barnes $(1956,1957,1962)$ reviewed multiple years of field data from several locations in the North Atlantic and showed that nauplii concentration generally increased when diatom blooms occurred. Early laboratory studies (Crisp 1956; Barnes 1957) found larval release in response to feeding, though the food types and food concentrations used were not reported. Crisp and Spencer (1958) subjected gravid adults to many different treatments and treatment combinations: raw plankton, Artemia larvae, barnacle nauplii, Phaeodactylum spp. culture, stirred water, still water, and several temperature regimes, with varying exposure times. They concluded that many kinds of food can trigger larval release, as long as they are given in high concentrations. Starr et al. (1991) tested the effect of (1) various concentrations of the diatom Skeletonema costatum, (2) the diatom Phaeodactylum tricornutum, and (3) larvae of the brine shrimp Artemia salina on the rate of larval release in adult barnacles. They found that all three food types triggered release. All of these studies and observations support the hypothesis that high food concentration triggers release, perhaps because it is a sign that a phytoplankton bloom is underway, and it would be beneficial for nauplii to be released into such a high-food environment.

However, some data do not support the hypothesis. First, field studies show that larval release is often, but not always, synchronized with phytoplankton blooms. In his review of nine years of data from Millport, Scotland, Barnes (1962) found two years (1950 and 1960) when nauplius release occurred in the absence of a diatom bloom. 
Second, barnacles in the laboratory release larvae in response to food, but the response is substantial only when the food is given in extremely high concentrations, higher than those found in typical blooms (Starr et al. 1991). Third, barnacles do not seem to be able to recognize phytoplankton chemically: when exposed to phytoplankton culture filtrates in the laboratory, adults do not respond (Starr et al. 1991). Fourth, release can be triggered by exposure to high concentrations of brine shrimp larvae, which is not a typical food item for adult barnacles or their nauplii (Starr et al. 1991). In summary, there are indications that the timing of larval release is often correlated with phytoplankton blooms, but the blooms themselves may not be the trigger for larval release. Instead, $S$. balanoides may be using an unidentified cue for larval release.

A limitation of the field studies (e.g. Barnes 1956, 1957, 1962) performed so far is that the sampling resolution was on the order of days, and this may not be sufficiently high to determine the environmental characteristics at the exact moment of release. Environmental conditions can change on the scale of hours or minutes, and once they are liberated, the larvae could be transported away from the site of release within hours. Studies conducted at fine temporal scales are rare (but see Macho et al. 2005) because they are logistically difficult, but they can provide valuable insight into phenomena such as synchronous larval release.

In addition to the environmental conditions at the time of release, larval behavior can provide clues about the factors that are most important in shaping synchronous release behavior. For example, larvae that swim to deep waters during the day may be avoiding visual predators, and this might explain why adults release larvae synchronously at nighttime (Morgan and Christy 1996). The final (cyprid) stage of S. balanoides tends 
to be found near the middle of the water column (Bertness et al. 1996). Distribution and behavior during the early naupliar stages, however, has received less attention. Earlystage nauplii in the laboratory are attracted to light, presumably so that they will swim toward the surface to escape the benthic environment and its associated planktotrophic predators (Singarajah et al. 1967, Macho et al. 2005). Some studies (e.g. Bousfield 1955) have stated that newly-released nauplii occur near the surface, but there seem to be no published studies that quantified vertical distributions. If nauplii indeed swim toward the surface to escape planktotrophic predators, then we would expect synchronous larval release to occur under environmental conditions that would facilitate this escape.

This study investigated whether larval release is related to environmental variables that have received less attention in the published literature. These variables include water temperature and salinity, tidal height, lunar phase, air temperature, wind speed, precipitation, and atmospheric pressure. To obtain high-resolution measurements, we sampled larvae on the scale of hours and environmental variables on the scale of minutes. The vertical distribution of early-stage nauplii was also quantified to determine whether their concentrations are higher near the surface than near the benthos.

\subsection{Materials and Methods}

\subsubsection{Study Site}

This study was conducted in Little Harbor, located in the town of Woods Hole, MA, USA $\left(41^{\circ} 31.249^{\prime} \mathrm{N}, 70^{\circ} 39.952^{\prime} \mathrm{W}\right)$. Little Harbor is an embayment that is 
oriented with its long axis in the North-South direction (Fig. 2.1). The mouth is located along the southern end. The bay is $0.63 \mathrm{~km}$ long. Its width is approximately $200 \mathrm{~m}$ along the northernmost half, and $300 \mathrm{~m}$ along the southernmost half. The shores of the bay are lined with rocks, boulders, a few concrete piers, and numerous smaller wooden docks. Adult $S$. balanoides are attached to these surfaces all around the bay. Other barnacles are also found in this area. Chthamalus fragilis can be found just above $S$. balanoides in the intertidal zone. Balanus crenatus, B. eburneus, and C. stellatus have also been reported near Woods Hole (Fish 1925). The bottom of the bay is mainly sand. Most of the bay is shallow, with an average depth of approximately $2-3 \mathrm{~m}$. However, the center has a $60 \mathrm{~m}$ wide dredged channel that is approximately $4 \mathrm{~m}$ deep. The mean tidal range is $0.43 \mathrm{~m}$ (NOAA 2010a).

\subsubsection{Timing of larval release in relation to environmental variables}

Previous research (Pineda et al. 2004) showed that $S$. balanoides in the Woods Hole area release their larvae in late December or early January. Therefore, highfrequency larval sampling was conducted from December 27, 2006 to January 10, 2007. Plankton samples were taken every two hours from the northernmost pier in Little Harbor. Out of 167 possible samples during this time period, 141 were obtained. Sampling was impossible during 26 instances due to equipment failure, severe weather, or shortage of volunteer helpers.

Plankton samples were obtained with an Ebara submersible sewage semi-vortex

impeller pump, which had strong suction and a flow rate of approximately $200 \mathrm{~L} \min ^{-1}$. 


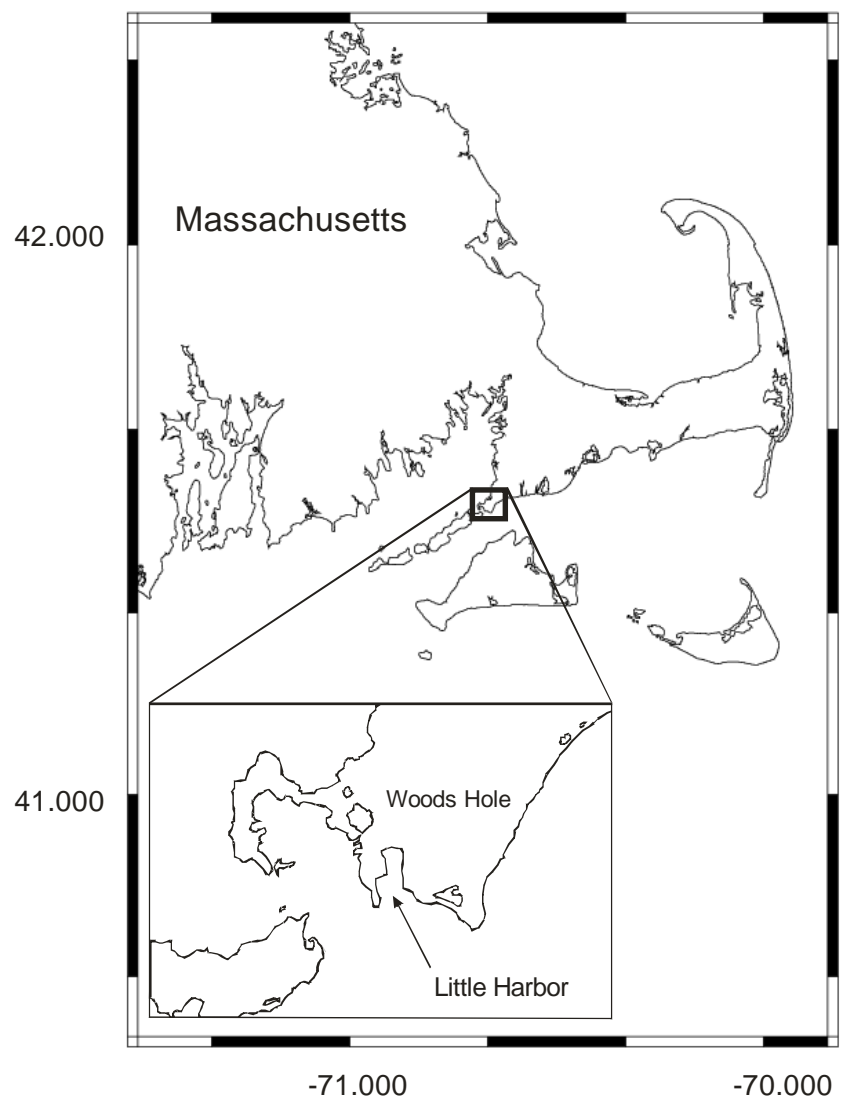

Fig. 2.1 The study site was Little Harbor, an embayment in the northeastern coast of the United States. 
The actual volume pumped for each sample was measured with a flow meter (Great Plains Industries, model TM200). Because water does not flow through the pump impeller, crustacean larvae are not damaged during sampling. The pump hung from a pier piling about $1 \mathrm{~m}$ above the bottom. The total water depth was approximately $2.5 \mathrm{~m}$ at high tide. When possible, at least $1000 \mathrm{~L}$ of water were pumped and filtered through a $100 \mu \mathrm{m}$ mesh. On a few occasions, large quantities of suspended sediments after a storm made it difficult to filter that much water, so smaller samples were taken.

Most samples were preserved in $95 \%$ ethanol immediately after filtering. When immediate preservation was not possible, samples were stored in a cooler with ice packs for less than 12 hours, and then preserved in ethanol. Stage I and II S. balanoides nauplii were identified according to Crisp (1962). It can be difficult to identify stage I and II nauplii to species, but the differences in the reproductive season of local barnacles provided certainty that the nauplii in the samples belonged to $S$. balanoides. The reproductive season of Chthamalus fragilis is July-August (Fish 1925; Lang and Ackenhusen-Johns 1981). Balanus crenatus nauplii are found from June until the middle of July (Fish 1925). B. eburneus and Chthamalus stellatus nauplii have been observed in August (Fish 1925).

The concentration of stage I and II nauplii in each sample was calculated. Only the first two naupliar stages were counted because $S$. balanoides transition from stage I to stage II within minutes to hours of being released (Barnes and Barnes 1958), and from stage II to stage III in approximately 3 days (Harms 1984). Focusing on the first two stages increased the probability that the larvae in the samples had been released very recently at the study site and had not been advected from elsewhere. 
While taking plankton samples, a YSI probe was used to determine water temperature and salinity. Additionally, weather data were downloaded from the Weather Underground website (www.wunderground.com) for the weather station KMAOAKBL1, which is located at $6 \mathrm{~m}$ elevation in Oak Bluffs, MA (41 $\left.21^{\circ} 14^{\prime \prime} \mathrm{N}, 70^{\circ} 34^{\prime} 43^{\prime \prime} \mathrm{W}\right)$. The weather station is $10.5 \mathrm{~km}$ away from the study site. This record is the most complete out of all the weather stations in the area, and the data are nearly indistinguishable from the available records of other stations that are closer to the site (data not shown). Tidal height data were obtained from the dock at the Woods Hole Oceanographic Institution with a Paroscientific pressure gauge. The measurements are relative to mean sea level.

\subsubsection{Statistical analysis}

Initial assessment of the field sampling data suggested a strong relationship between larval abundance and winter storms, which can be identified by periods of low atmospheric pressure, high wind speeds, increased precipitation rate, and sometimes lower salinity. However, since those three environmental variables are related, the focus here is on the relationship between nauplius abundance and atmospheric pressure. A Superposed Epoch Analysis (SEA) was used to determine whether the relationship was significant. SEA is a tool for analyzing time-series data. It is analogous to a $t$-test in the sense that it can be used to compare two means, but it is a non-parametric test (Prager and Hoenig 1989). SEA was developed by Chree (1912) for the analysis of geophysical data (Singh and Badruddin 2006). Since then, it has been applied to observed physicalbiological relationships such as sea level and recruitment success of chub mackerel 
(Prager and Hoenig 1989); wind direction or water stratification and settlement of barnacle larvae (Ladah et al. 2005); and hydroclimatic variability and abundance of salps (Licandro et al. 2006).

SEA compares the average nauplius concentration during "key events" to the average concentration during "background periods" and determines whether the differences are statistically significant. A "key event" is defined here as a time period in which the atmospheric pressure was at least one standard deviation below the mean "winter" atmospheric pressure. "Winter" is defined here as the period between December 1, 2006 and February 6, 2007, since this is when the atmospheric pressure data were available. "Background periods" are the times in which a key event is not taking place.

Mean nauplius concentrations were calculated for the key events and for the background periods, and then they were compared by using the $W$-statistic (defined below). The null distribution of the $W$-statistic was determined with a Monte Carlo randomization. Then, a $p$-value was calculated to determine whether the null hypothesis could be rejected. The null hypothesis here is that for this dataset, there is no relationship between atmospheric pressure and larval abundance. Since the key events were defined after the data had been examined, and since only one year of data is available for one location, the results of the SEA analysis cannot be used to test the general hypothesis that larval abundance is related to atmospheric pressure. However, the results of the SEA analysis can be used to formulate the general hypothesis, which can then be tested with future datasets and experiments.

Three key events were identified: between 17:15 on January 1 and 07:16 on January 2; between 5:31 on January 6 and 21:16 on January 6; and between $06: 30$ on 
January 8 and 01:01 on January 10. Only the first two key events were used for this analysis because the third event was too close to the end of the time series. The background periods were the time step before and the time step after each key event. Each of the background periods was the same length as the key event that it flanked. As an example, key event \#1 was 841 minutes long, so it was compared to the 841 minutelong periods before and after it. The mean nauplius concentrations for each of these time periods was placed in a matrix (Table 2.1) so that the number of rows equaled the number of key events (two), and the number of columns equaled the number of time periods analyzed for each key event (three - one before the key event, the event itself, and the one after it).

The $W$-statistic compares the mean nauplius concentration during key events to concentrations during the background periods that flank them (Prager and Hoenig 1989). It is defined as

$$
W=\frac{\bar{d} N_{B}^{1 / 2}}{S_{W}}
$$

$N_{B}$ is the total number of background periods that will be used in the calculations. In this case, it equals 4 , since there is one background period before and after each of the 2 key events. $\bar{d}$ is the mean of all the paired differences between key event $i$ and each of its corresponding background periods:

$$
\bar{d}=\frac{1}{N_{B}} \sum_{i=1}^{N_{E}} \sum_{j=1}^{n_{i}}\left(E_{i}-B_{i j}\right) .
$$

$N_{E}$ is the number of key events. $n_{i}$ is the number of background periods available for the key event $i . E_{i}$ is the average nauplius concentration for the key event $i . B_{i j}$ is the average 


\begin{tabular}{|c|c|c|c|}
\hline \multirow{2}{*}{ Key event } & \multicolumn{3}{|c|}{ Average nauplius concentration (number $\mathrm{L}^{-1}$ ) } \\
\cline { 2 - 4 } & $i=-1$ & $i=0$ & $i=1$ \\
\hline$\# 1$ & 0.050 & 0.736 & 0.197 \\
\hline$\# 2$ & 0.074 & 0.217 & 0.051 \\
\hline
\end{tabular}

Table 2.1 Matrix for the superposed epoch analysis of average nauplius concentration in relation to atmospheric pressure. Key events $(i=0)$ are time periods in which the atmospheric pressure was less than one standard deviation below the mean. Background periods $(i=-1$ and 1$)$ are the time periods before and after the key event. 
nauplius concentration for the background event $j$ corresponding to key event $i$. The measure of dispersion, $S_{W}$, is calculated according to the formula

$$
S_{W}=\left[\frac{1}{N_{B}-1} \sum_{i=1}^{N_{E}} \sum_{j=1}^{n_{i}}\left(E_{i}-B_{i j}-\bar{d}\right)^{1 / 2}\right] .
$$

Once the $W$-statistic has been calculated, it is necessary to determine whether its value is sufficiently large to reject the null hypothesis. To do this, the observed $W$-statistic was compared to the distribution of the $W$-statistic under the null hypothesis. The distribution under the null hypothesis can be calculated by using a Monte Carlo simulation. It randomly places the key events (and their flanking background periods) along the time series. The $W$-statistic is then computed, and the simulation is repeated several thousand times.

100,000 iterations of the Monte Carlo simulation were run via a MATLAB program. For each iteration, if a key event and/or one of its background periods fell outside the range of the time series, then that iteration was discarded. The estimated $p$ value of the observed $W$ was then calculated using the formula $(x+1) /(v+1)$, where $x$ is the number of randomized values of $W$ that were greater than the observed $W$, and $v$ is the total number of randomly generated values of $W$.

\subsubsection{Vertical distribution of Barnacle Larvae}

From December 9, 2008 to January 23, 2009, larvae were sampled from the northernmost pier in Little Harbor with two pumps (Pondmaster). These pumps were different from the one used to investigate the timing of larval release - their suction was gentler, so they each sampled a narrow horizontal layer of the water column. One pump 
was placed $0.25 \mathrm{~m}$ above bottom. The other pump was placed $0.25 \mathrm{~m}$ below the surface. The total water depth was approximately $2.5 \mathrm{~m}$ at high tide. 20 samples were taken over the 46-day sampling period. The time of sampling was chosen haphazardly, and included both daytime and nighttime hours. The pumps were designed to sample at a rate of

approximately $16 \mathrm{~L} \mathrm{~min}{ }^{-1}$, but the exact volume of water pumped was measured with flow meters (Great Plains Industries). The mean volume of water per sample at the surface was $39.8 \mathrm{~L}(\mathrm{SD}=18.7, N=17)$, and the mean volume per sample near the bottom was $43.5 \mathrm{~L}(\mathrm{SD}=19.4, N=17)$. Samples were filtered through $100 \mu \mathrm{m}$ mesh. Stage I and II nauplii were counted less than 12 hours after sample collection. The difference in nauplii concentrations near the surface and near the bottom was analyzed by using a paired comparisons $t$-test (Sokal and Rholf 1995). The analysis did not include samples in which surface and bottom larval concentrations were zero.

\subsection{Results}

\subsubsection{Timing of larval release in relation to environmental variables}

Two large peaks in nauplius abundance occurred during the two-week sampling period (Fig. 2.2a). The first peak was at 23:00 on January 1, and the second peak was at 11:00 on January 6. Smaller peaks occurred in between. The two main peaks coincided with two storm events, which were characterized by low atmospheric pressure (Fig. 2.2b), high wind speeds (Fig. 2.2c), precipitation (Fig. 2.2e), and lower salinity (during the first event only, Fig. 2.2f). During storm events, high turbidity was observed (but not 


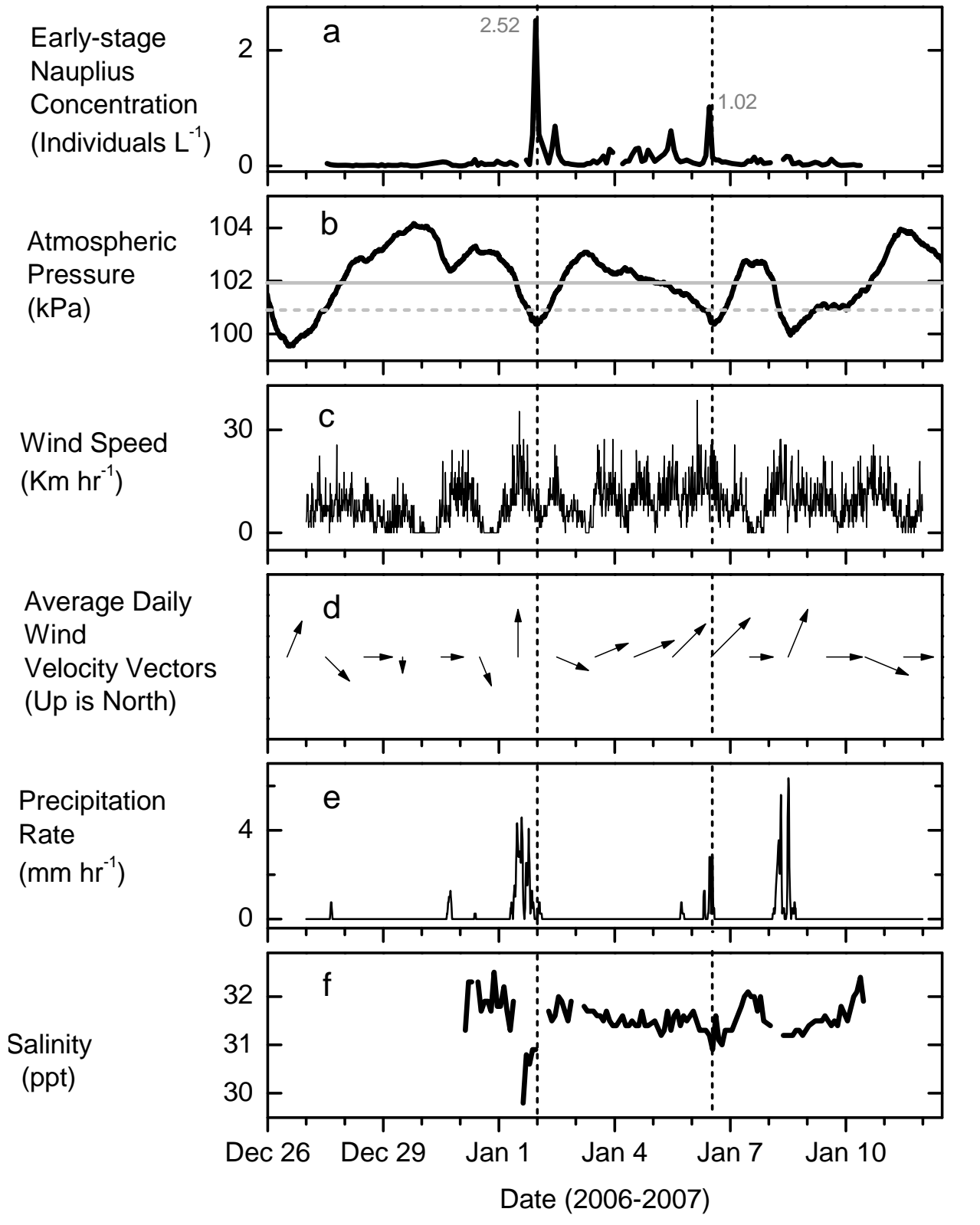

Fig. 2.2 (a) Early-stage nauplius abundance in Little Harbor shows two large peaks and a few smaller ones. Vertical dashed lines have been drawn for ease of comparison. (b) The mean atmospheric pressure between December 1, 2006 and February 6, 2007 is shown by the horizontal grey line. The horizontal dashed line represents one standard deviation below the mean. The two largest peaks in nauplius abundance coincide with two periods of low atmospheric pressure that occurred during stormy weather. The two peaks in larval abundance occurred within 24 hours of high wind speeds (c) that were from the south or had a southerly component (d). (e) Precipitation rates increased with the arrival of the storms. (f) A sharp drop in salinity was associated with the first storm, but not the second. 
measured) in the water. The two large peaks in larval abundance also occurred within 24 hours of strong winds that were from the south or had a southerly component (Fig. 2.2c, 2.2d). Almost all average daily wind velocities had a westerly component, which is typical for this location at this time of year (NOAA 2010b).

Larval release occurred around the time of the full moon (Fig. 2.3a). Although the peaks in larval abundance coincide with periods of high water level, they did not occur at the same phase of the tide (Fig. 2.3b). The first peak happens during an ebbing tide, and the second peak happens during a high tide. Larval concentrations did not appear to be related to air temperature (Fib. 2.3c) or water temperature (Fig. 2.3d).

The mean atmospheric pressure for the winter was $101.930 \mathrm{kPa}(\mathrm{SD}=1.016, N=$ 6358), so atmospheric pressures below $100.914 \mathrm{kPa}$ were considered to be "key events" in the SEA analysis. The two largest nauplius abundance peaks coincided with two key events on January 1 and January 6 (Fig. 2.2b). According to the SEA analysis, this relationship was statistically significant. The observed value for the $W$-statistic was 2.824 . Out of 100,000 iterations of the Monte Carlo simulation, 31,379 had to be discarded because a key event and/or one of its background periods fell outside the range of the time series. This left 68,621 usable calculations of the $W$-statistic. Out of these, 2139 were greater than the observed $W$ value of 2.824 . Thus, the $p$-value of the observed $W$ was 0.031 , which is less than the significance level of $p=0.05$. 


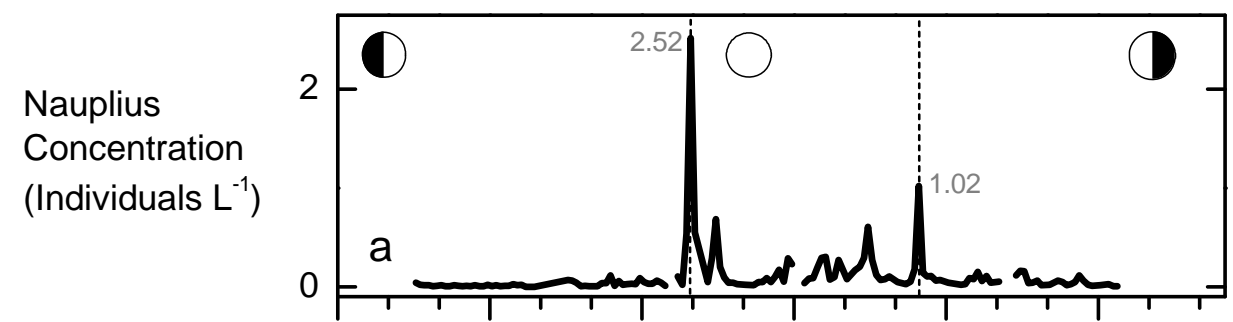

Tide Level

(m)

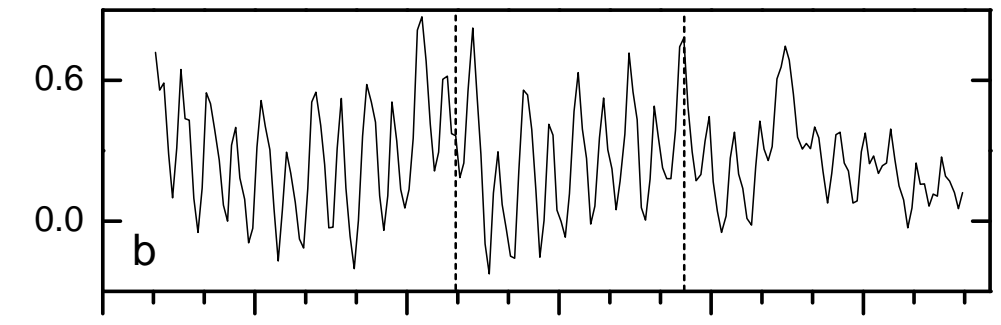

Air

Temperature

$\left({ }^{\circ} \mathrm{C}\right)$

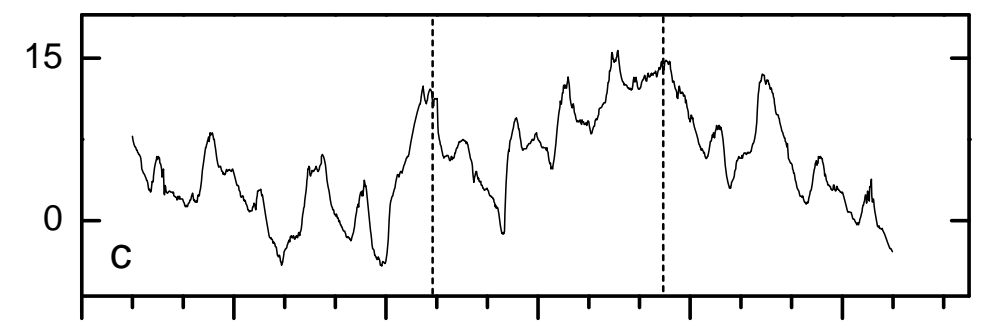

Water

Temperature

$\left({ }^{\circ} \mathrm{C}\right)$

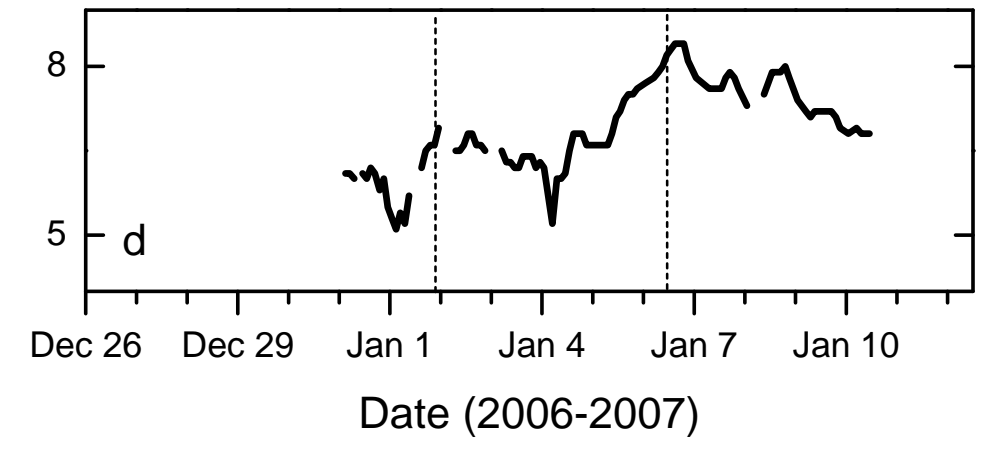

Fig. 2.3 (a) Early-stage nauplius concentration in Little Harbor presented again for comparison with other variables that we investigated. The shaded and un-shaded circles represent the phases of the moon. Larval release occurred near the full moon. (b) The two peaks in larval abundance did not occur during similar tidal phases; the first peak happened during an ebbing tide, and the second peak occurred during a high tide. (c) Air temperatures were high during the peaks in larval abundance, but they were also high during times when peaks were not observed. (d) The peaks in larval abundance do not seem to be related to water temperature 


\subsubsection{Vertical distribution of Barnacle Larvae}

Mean nauplius concentration near the surface was 2.20 nauplii $\mathrm{L}^{-1}(\mathrm{SD}=3.45, N$ = 17) (Fig. 2.4). Mean nauplius concentration near the bottom was 0.31 nauplii $\mathrm{L}^{-1}(\mathrm{SD}=$ $0.67, N=17)$. The difference between the two means was highly significant $(p<0.001)$.

\subsection{Discussion}

Early-stage larval abundance was significantly related to winter storms, which were characterized by low atmospheric pressure, high wind speeds, high precipitation rates, and lower salinity (in one case). Release of larvae or gametes in response to storms has been observed in other marine invertebrates. The polychaete Phragmatopoma lapidosa californica spawns in response to storm damage, and it was suggested that this was to maximize reproductive success when the probability of adult mortality is high (Barry 1989). S. balanoides adults can be crushed or removed from their substrate by stones and driftwood mobilized by energetic waves during storms. Perhaps the barnacles use a strategy analogous to that of $P$. californica, though barnacles are much more resistant to damage because of their calcareous shells. Storms are known to intensify currents and reduce the residence time of water in the surf zone, so larvae released in stormy conditions may have a survival advantage if they are transported away from planktotrophic predators associated with the surf zone (Amend and Shanks 1999; Onitsuka et al. 2007). Winter storms also re-suspend sediments, benthic diatoms and other organic matter near the region of this study (Parmenter et al. 1983), which increases 


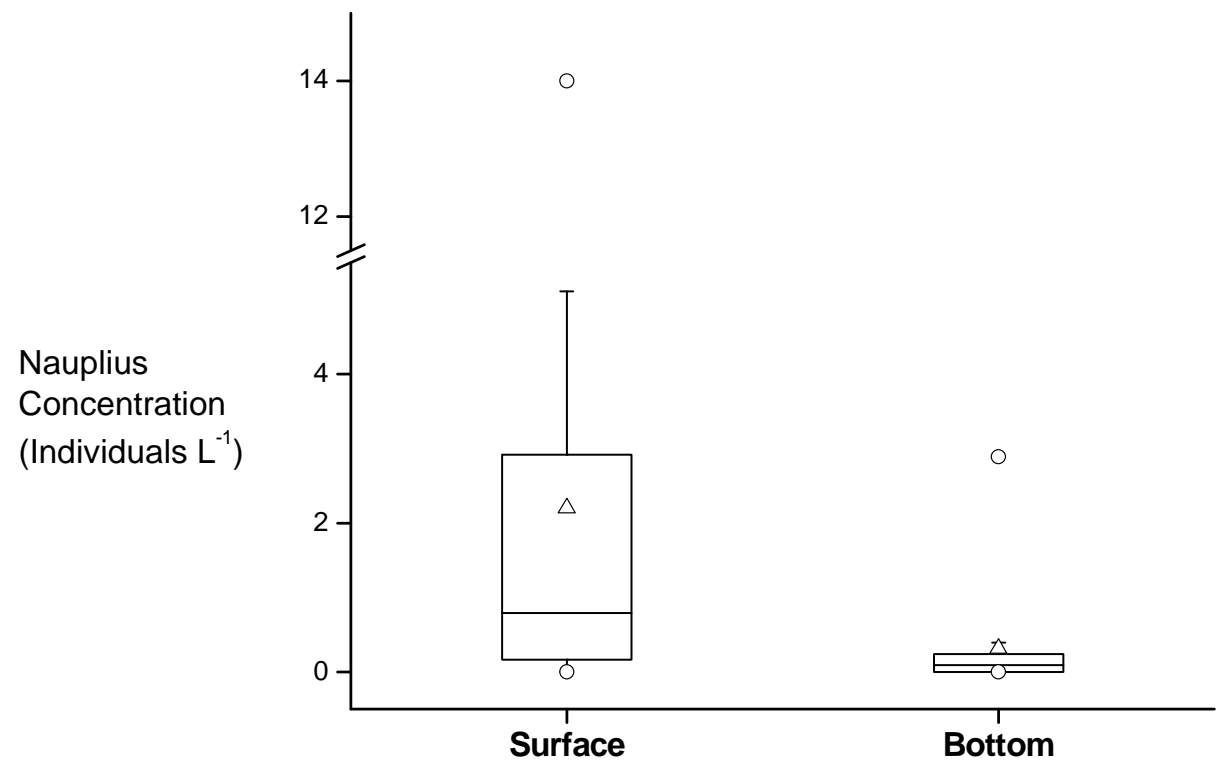

Fig. 2.4 Mean nauplius concentration (indicated by triangles) was significantly greater near the surface than near the bottom in December 2008 - January 2009. The horizontal lines of the boxes depict the $25^{\text {th }}$ percentile, the median, and the $75^{\text {th }}$ percentile. The whiskers represent the $5^{\text {th }}$ percentile and the $95^{\text {th }}$ percentile. The circles identify the minimum and maximum values. 
water turbidity. Perhaps the re-suspended diatoms trigger larval release, even in the absence of a full-blown phytoplankton bloom. Alternatively, increased turbidity during storms may provide a predation refuge for barnacle larvae, since potential predators would be swamped with high concentrations of additional particles.

The finding that $S$. balanoides nauplii concentrate near the surface is consistent with the idea that predation is the most important danger that larvae face when they first emerge. It has been suggested previously that swimming upward toward light allows the larvae to escape incidental ingestion by adults (Singarajah et al. 1967, Macho et al. 2005). This study confirms that early-stage nauplii in the field are found near the surface, even at night. If they are released at night in turbid conditions, then nauplii must be highly sensitive to light or rely on geotaxis. Crisp and Ritz (1973) calculated that even on overcast, moonless, winter nights, the level of illumination would probably be sufficient for nauplii to respond and swim toward the surface. The data from the present study indicate that nauplius release occurred around the time of the full moon (Fig. 2.3a), and some of the release occurred in the daytime. Perhaps the available light was sufficient to guide nauplii to the surface, even during turbid conditions.

Peaks in larval concentration were short-lived, lasting less than 8 hours. Previous studies of S. balanoides larval release have sampled on a daily (or less frequent) time scale, but the results of the present study show that a higher sampling frequency is required to properly characterize the patterns of larval release in the field. The ephemeral nature of high larval concentrations also suggests that the nauplii were transported away quickly, which is an advantage for larvae that face strong predation pressure near the site of release. It is possible that the peaks in larval abundance were caused by larval patches 
advected from elsewhere. This is unlikely, however, because including only the first two naupliar stages maximizes the likelihood that the larvae in our samples had been in the water column for a short time and thus had been released locally.

Early-stage nauplius abundance seemed related to wind velocity. The highest concentrations of larvae occurred less than 24 hours after periods of strong winds with a southerly component. Little Harbor is oriented in the north-south direction, with the opening of the harbor in the southern end. Thus, it is possible that winds from the south led to retention and accumulation of larvae in the harbor. However, if wind-driven transport was causing the patterns in larval abundance, then the high larval concentration on January 6 would be expected to keep increasing until at least the following day, since the wind had a strong southerly component on the $6^{\text {th }}$ and then died down to a light westerly breeze on the $7^{\text {th }}$ (Fig. 2.2c). Similarly, the strong southerly component of the wind on January $8^{\text {th }}$ would be expected to cause a peak in nauplius concentration on January $9^{\text {th }}$, but no such pattern was observed. This suggests that the peak in abundance occurred not as a result of the accumulation of individuals that were already in the area, but as a result of mass liberation of nauplii at that time.

An alternative explanation for the results in this study is that more larvae were sampled during storms because the water column was well-mixed. Larval concentrations are highest near the surface, yet the semi-vortex impeller pump was 1-1.5 m below the surface. However, the pump had a very strong suction, and if it had not been adequately sampling larvae near the water surface, then the highest concentrations of nauplii would be expected to occur during low tides, when the pump was closer to the surface. This pattern was not observed in the data. Instead, the two highest peaks in nauplius 
concentration occurred during some of the highest tides of the sampling period (Fig. 2.3b). Furthermore, even though high-wind conditions lasted approximately 24 hours during each storm event, the peaks in larval concentrations did not last more than 8 hours (Fig. 2.2a, c).

In conclusion, high-frequency sampling of Semibalanus balanoides early-stage larvae resulted in a pattern of larval release that coincided with the passage of winter storms. The most likely explanation is that the adult barnacles responded to high turbidity levels, since releasing under those conditions could protect their larvae by swamping potential predators. Swimming upward toward the surface could also help larvae to escape benthic predators. Additionally, strong storm-generated currents might sweep larvae away from the surf zone. Perhaps food availability for nauplii leads $S$. balanoides to release larvae near the beginning of spring phytoplankton blooms, but predation on newly-released nauplii fine-tunes the timing of release to coincide with winter storms. Other benthic invertebrates may also employ the same strategy to protect their larvae from planktotrophic predation. Future experimental and observational work should test this hypothesis. 


\section{Chapter 3}

\section{Does turbidity trigger larval release by the intertidal barnacle Semibalanus balanoides? A test of the hypothesis.}

\section{Abstract}

Many marine invertebrates release larvae or gametes synchronously under conditions that maximize their survival probability. The acorn barnacle, Semibalanus balanoides, is thought to release larvae in response to phytoplankton blooms, which provide abundant food for their young. Recent high-frequency observations revealed that early-stage larval abundance in the nearshore was related to winter storms (Gyory and Pineda, submitted). It was hypothesized that the barnacles might be using turbidity, not phytoplankton abundance specifically, as a cue for release. In the present study, field observations and experiments were conducted to study the effect of turbidity and phytoplankton abundance on the larval release response of gravid Semibalanus balanoides adults. Larval release coincided with increased turbidity in all four release events that were observed at three sites along the northeast coast of the United States (Little Harbor, Massachusetts; Narragansett Bay, Rhode Island; and New Castle, New Hampshire). Examination of a three-year time series of weekly phytoplankton and zooplankton samples from Rhode Island found that there was no species of phytoplankton that bloomed consistently prior to larval release. Moreover, larval release was related to total phytoplankton abundance in only one of the three years, and there was no relationship between the changes in the size classes of phytoplankton and the 
timing of larval release. When adult barnacles were exposed to Skeletonema marinoi or inert synthetic beads at concentrations of $10^{7} \mathrm{~L}^{-1}$, the larval release response was stronger than under control conditions, and there was no significant difference in the response to Skeletonema and beads, suggesting that adults were responding to the presence of particles and not to the identity of the particles. Feeding experiments showed that adult predation on newly released larvae is lower in high-turbidity than in low-turbidity conditions. It is suggested here that Semibalanus balanoides times its reproduction to coincide roughly with the onset of winter-spring phytoplankton blooms, but high turbidity might be the cue that fine-tunes the timing of larval release, since turbid waters might provide a predation refuge for the nauplii. 


\subsection{Introduction}

Larvae of marine invertebrates experience high mortality rates in the plankton (Thorson 1950; Young and Chia 1987). Predation is a major cause of mortality (Thorson 1950); others include starvation, physical transport away from suitable settlement habitat, and physiological stresses (Morgan 1995; Rumrill 1990; Vaughn and Allen 2010). To maximize survival of their offspring, marine animals release larvae under conditions that reduce mortality risks (Harrison et al. 1984; Ims 1990; Morgan and Christy 1995). If these conditions occur within a narrow time frame, then individuals in a population may release their larvae synchronously.

Acorn barnacles, Semibalanus balanoides, release larvae synchronously once per year during winter in the northern hemisphere. In some areas, their larvae constitute an important part of the zooplankton community. For example, in Narragansett Bay, Rhode Island, USA, S. balanoides nauplii account for up to $15 \%$ of the total zooplankton population in January and February (Frolander 1955 as cited in Lang and AckenhusenJohns 1981). Thus, knowledge about the cues that trigger larval release would aid in understanding the temporal changes in zooplankton community composition.

The prevailing view has been that phytoplankton blooms trigger larval release in $S$. balanoides, presumably because an abundant phytoplankton supply would reduce larval mortality from starvation (Barnes 1956, 1957; Crisp 1956; Crisp and Spencer 1958; Starr et al. 1991). In coastal temperate areas of the North Atlantic where S. balanoides are found, the timing of the well-known spring phytoplankton bloom is highly variable, and it often begins as early as late winter (Bigelow 1940; Smayda 1998; Cebrián and Valiela 
1999). Field data from multiple years and locations in the North Atlantic indicated that $S$. balanoides larval release often coincided with these winter-spring diatom blooms (Barnes 1956, 1957, 1962). Laboratory studies have also confirmed that an exposure to high concentrations of phytoplankton will often trigger larval release (Crisp 1956; Barnes 1957; Crisp and Spencer 1958). However, the concentrations of food required to trigger release are often higher than what is found in typical blooms, and the barnacles do not seem to be able to recognize phytoplankton chemically (Starr et al. 1991). Additionally, larval release can be triggered by exposure to brine shrimp larvae, which are a type of zooplankton that these barnacles do not normally encounter (Starr et al. 1991). These observations led us to ask whether barnacles could be responding to a cue that is related to phytoplankton blooms, but is not the blooms themselves.

A recent study (Gyory and Pineda, submitted) found that early-stage $S$. balanoides larval abundance was related to winter storm activity in Woods Hole, Massachusetts, USA. It was hypothesized that winter storms increased water turbidity, and this cued the adults to release their larvae. Since barnacles are cemented to the substratum and undergo internal fertilization, they must live in high densities so that they can successfully find, reach, and fertilize their mates. Large swaths of the intertidal zone are covered with barnacles and other filter-feeders. This may constitute a dangerous situation for newly-released nauplii: the weakly-swimming larvae are ejected by their parent into the general vicinity of large numbers of filter-feeders, where it is possible for them to be caught and eaten. Releasing larvae during periods of high turbidity could be a good strategy to combat cannibalism and predation because particles may overwhelm the feeding appendages of adults and impair their filter-feeding abilities temporarily. This 
would give the nauplii an opportunity to escape from the site of release without being eaten. Few studies have examined the extent of adult cannibalism on newly-released nauplii, but there is evidence that it could be important. Crisp and Patel (1960) noted that during their laboratory experiments, nauplii were sometimes consumed by their parents. In the field, Navarrete and Wieters (2000) examined adult Semibalanus cariosus predation on larvae of three barnacle species and found that $16 \%$ of the food items in $S$. cariosus guts were barnacle nauplii.

The present paper describes observations and experiments conducted to test the hypothesis that high turbidity, even in the absence of phytoplankton blooms, could trigger synchronous larval release in Semibalanus balanoides. The following questions were asked: 1) In the field, does larval release coincide with high-chlorophyll and/or highturbidity events? 2) If gravid barnacles are exposed to diatoms, turbidity (inert synthetic particles), or unaltered seawater, will there be a difference in their larval release response? 3) Barnacles may be releasing their larvae in high-turbidity conditions to protect them from cannibalism. Does predation rate by adults on newly-released larvae decrease when barnacles are exposed to high turbidity? Finally, 4) if historical data are examined, is there evidence that larval release coincides with blooms of certain species of phytoplankton, total phytoplankton cell abundance, and/or phytoplankton cell size?

\subsection{Materials and Methods}

\subsubsection{Study sites}


Observations and experiments were conducted at three sites along the northeastern coast of the United States: (1) a dock in Little Harbor, Woods Hole, Massachusetts; (2) the University of Rhode Island pier in Narragansett, Rhode Island; and (3) the University of New Hampshire pier in New Castle, New Hampshire (Fig 3.1). Larval release by $S$. balanoides is known to occur sequentially, in this order, at these three sites (Pineda et al. 2004). These sites were chosen because S. balanoides were plentiful, and because the docks and piers provided a good sampling platform. The sites have the following mean tidal ranges: $0.4 \mathrm{~m}$ in Woods Hole, $1.06 \mathrm{~m}$ in Narragansett, and $2.63 \mathrm{~m}$ in New Castle. Mean tidal range is the difference in height between mean high water and mean low water. At the three sites, adult $S$. balanoides were distributed vertically in the intertidal approximately from high water to low water spring tide levels, which is the usual range for this species (Stubbings 1975).

\subsubsection{Field observations of larval release}

The field observations were conducted between November 21, 2009 and February 25,2010 . At each site, at least 31 adult barnacles $($ mean $=60, \mathrm{SD}=19)$ were sampled randomly daily whenever possible. Sometimes severe weather did not allow sampling. Adults were carefully scraped off rocks or pier pilings and examined tunder a dissecting microscope to determine whether they had embryos in their mantle cavities, and if so, what their developmental stage was. When $S$. balanoides releases larvae, it empties out its mantle cavity completely, usually in 24 hours or less (Barnes 1955). Thus, the state of the adults was binary: either they had or had not released when they were collected. Most 


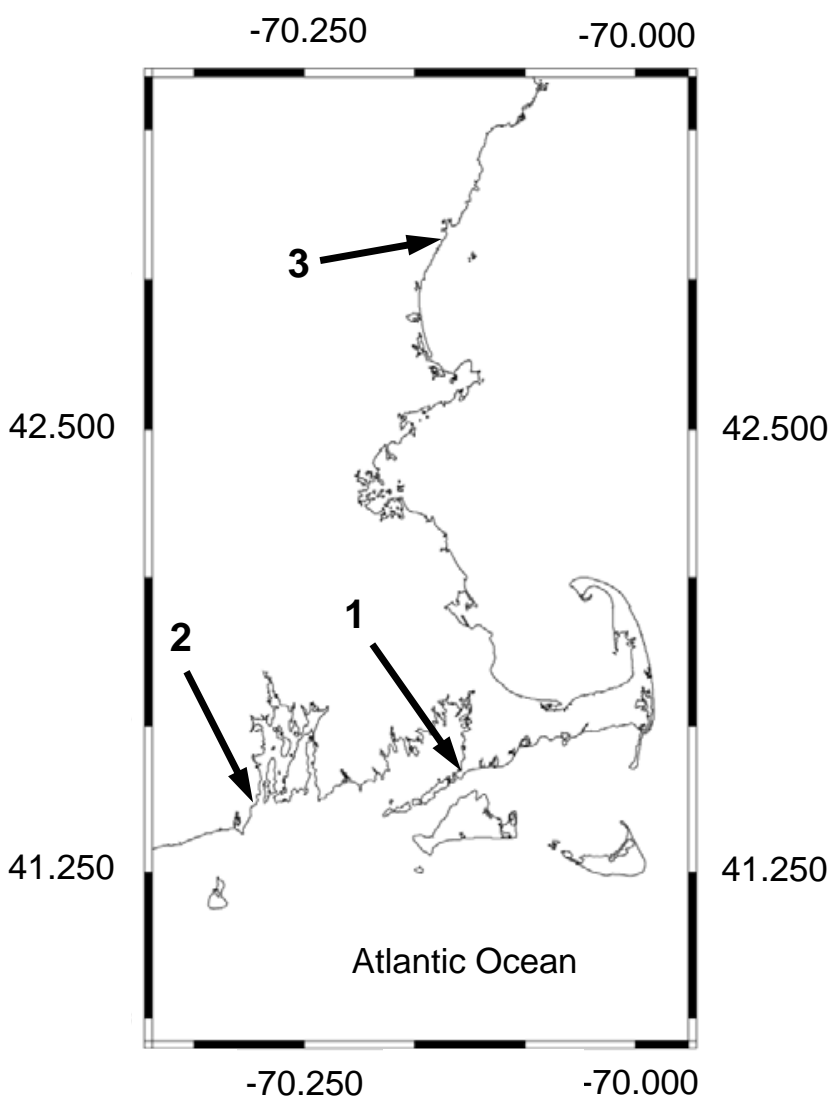

Figure 3.1. Three sites on the northeastern coast of the United States were sampled: 1) Woods Hole, Massachusetts; 2) Narragansett, Rhode Island; and 3) New Castle, New Hampshire. Semibalanus balanoides release larvae sequentially, in this order, at these three sites. 
adults in a population of $S$. balanoides are reproductive, providing there are other adults nearby for fertilization (J. Pineda, pers. obs.). Thus, it was expected that few adults would have empty mantle cavities at the beginning of the sampling period, and that number would rise sharply when there was a larval release event.

At the field sites, water temperature, salinity, turbidity, and chlorophyll fluorescence were measured. A logger (RBR Ltd., model XR-420) was used to record temperature and salinity every five minutes. A dual-wavelength, single-angle sensor fluorometer was used to measure turbidity and in vivo chlorophyll fluorescence simultaneously (WET Labs, model ECO FLNTU). The instrument took a "burst" of measurements (one per second for five seconds) every five minutes. In Massachusetts and Rhode Island, the instruments were strapped to pier pilings approximately $0.5 \mathrm{~m}$ off the bottom. The water depth was approximately $1.5-2 \mathrm{~m}$ during the highest tides. In New Hampshire, it was not possible to strap the instruments to pier pilings, so the instruments were attached to a floating dock instead, where they remained approximately $0.5 \mathrm{~m}$ below the surface at all times. Tide and water level data were obtained from the United States National Oceanic and Atmospheric Administration (station ID numbers: 8447930, 8452660, and 8423898).

In Little Harbor, there were some instrumentation problems. The batteries in the RBR logger failed after a few days, so there is no salinity data for the sampling period. There was a water level/temperature logger (Onset Computer Corporation, $\mathrm{HOBO}{ }^{\circledR}$ logger) attached to the RBR, so it was used to obtain water temperature data. A piece of macroalga wrapped itself around the $E C O$ fluorometer, and every time the blades of the alga swept past the sensors, the readings were unrealistically high. Information about the 
background-level chlorophyll and turbidity was extracted by filtering the data (Appendix 1). Only data from Little Harbor were filtered.

\subsubsection{Experiments - Larval release in response to phytoplankton, turbidity, and control} conditions

Experiments were devised to test whether the larval release response was different when gravid adult barnacles were exposed to control conditions, diatoms, or turbidity. The control treatment was plain, unfiltered seawater. The diatom treatment was seawater with Skeletonema marinoi (obtained from the National Marine Phytoplankton Collection at Bigelow Laboratory for Ocean Sciences) added at $10^{7}$ cells L ${ }^{-1}$. The turbidity treatment was seawater with neutrally-buoyant Dynoseeds ${ }^{\circledR} 40-\mu \mathrm{m}$ polystyrene beads added at $10^{7}$ particles $\mathrm{L}^{-1}$.

Rocks that had S. balanoides attached to them and were small enough to fit inside a one-liter clear plastic jar were gathered from the intertidal zone. One rock was placed inside each jar, and one of the three treatments listed above was added immediately. After the jars were sealed with lids, they were placed inside a plastic cage that floated at the water surface and was tethered to the sampling dock. The floating cage allowed the jars to remain at ambient water temperature and ambient light levels. The slight to moderate wave action around the docks was sufficient to keep the diatoms and particles suspended inside the jars. After 24 hours, the jars were recovered. Their water was filtered through $100 \mu \mathrm{m}$ mesh, and the number of nauplii were counted. Experiments were run twice in 
Rhode Island and twice in New Hampshire. Experiments contained multiple replicates of each treatment (Table 3.1).

The statistical analyses tested the null hypothesis that there is no difference in the larval release response of adults when exposed to particle, Skeletonema, or control treatments, versus the alternative hypothesis that there is a difference among the three treatments in the larval release response. There were two complicating factors: First, not all the adults were gravid at the beginning of the experiments, and it was impossible to determine how many were gravid without sacrificing the animals. Second, the number of nauplii produced by a single adult can be highly variable. These issues were addressed through a statistical model incorporating (1) the number of gravid adults capable of responding to the larval release cue inside each experimental jar, and (2) the number of nauplii that a single adult produces, conditional of it being gravid and capable of responding to the larval release cue. A likelihood ratio test was then used to determine whether the parameter controlling (2) was the same for the three experimental treatments. The details of the analyses are described below, and a summary of the variables involved in the statistical analysis is available for ease of reference (Table 3.2).

To begin with, consider a single jar. Let $m$ be the known number of barnacle adults and let $y$ be the observed number of nauplii in the jar at the end of the experiment. An adult is not necessarily capable of producing nauplii, either because it had released the larvae prior to the start of the experiment, or because it does not respond to the experimental treatment. Let $\pi$ be the unknown probability that an adult is gravid and receptive to the larval release cue being tested. $\pi$ is allowed to be different for each of the four experiments conducted. 


\begin{tabular}{ccccc} 
& $\begin{array}{c}\text { Rhode } \\
\text { Island }\end{array}$ & $\begin{array}{c}\text { Rhode } \\
\text { Island }\end{array}$ & $\begin{array}{c}\text { New } \\
\text { Hampshire }\end{array}$ & $\begin{array}{c}\text { New } \\
\text { Hampshire }\end{array}$ \\
\cline { 2 - 5 } & Jan 11 2010 & Jan 13 2010 & Jan 31 2010 & Feb 02 2010 \\
\cline { 2 - 5 } Skeletonema & 4 & 3 & 5 & 5 \\
Particles & 4 & 3 & 5 & 5 \\
Control & 2 & 1 & 5 & 5
\end{tabular}

Table 3.1. Number of replicates for three treatments (Skeletonema, Particles, and Control) used in four experiments conducted in Rhode Island and New Hampshire. 


\begin{tabular}{|l|l|}
\hline$m$ & number of adult barnacles in a jar \\
\hline$n$ & number of adults that release larvae \\
\hline$\pi$ & unknown probability that an adult is gravid and receptive to a larval release cue \\
\hline$N$ & the unknown number of adults that are gravid and receptive to a larval release cue \\
\hline$x$ & number of nauplii produced by a single adult \\
\hline$\theta$ & unknown shape parameter of the negative binomial distribution \\
\hline$y$ & total number of nauplii inside a jar at the end of an experiment \\
\hline$\Lambda$ & test statistic of the likelihood ratio test \\
\hline
\end{tabular}

Table 3.2. Summary of variables involved in the statistical analysis of experimental data. 
Under the model, the unknown number $N$ of adults capable of producing nauplii has a binomial distribution with probability mass function given by:

$$
p(n)=\left(\begin{array}{c}
m \\
n
\end{array}\right) \pi^{n}(1-\pi)^{m-n}
$$

where $n$ is the number of adults that release larvae.

Conditional on its being gravid and receptive to the larval release cue, it is assumed that the number $x$ of nauplii produced by a single adult follows a geometric distribution with probability mass function:

$$
p(x)=\theta(1-\theta)^{x} \quad x=0,1,2, \ldots
$$

with unknown parameter $\theta(0<\theta<1)$. The geometric distribution is commonly used as a model for count data with a long upper tail. The mean and variance of $x$ are $(1-\theta) / \theta$ and $(1-\theta) / \theta^{2}$, respectively.

The total number $y$ of nauplii observed inside a jar at the end of an experiment represents the sum of a random number $N$ of independent and identically distributed geometric counts. The probability mass function of $y$ is given by:

$$
p(y)=\sum_{n=0}^{m} p(y \mid n) p(n)
$$


where $\mathrm{p}(\mathrm{y} \mid \mathrm{n})$ is the conditional probability mass function of $y$ given $N=n$, which can be shown to be negative binomial with scale parameter $n$ and shape parameter $\theta$. The negative binomial probabilities required for the calculation of (3) were approximated by the method of Best \& Gipps (1974).

The analysis proceeded using the basic model outlined above, allowing $\pi$ to vary among the 4 experiments and with interest centering on testing the null hypothesis $H_{0}$ that the geometric parameter $p$ is the same for the three treatments (control, particles, and Skeletonema) against the alternative hypothesis $H_{l}$ that it is not. The likelihood ratio (LR) test was used. It involved fitting the model under both $H_{0}$ and $H_{1}$. The LR test statistic is given by:

$$
\Lambda=2\left[\log \mathrm{L}_{1}-\log \mathrm{L}_{0}\right]
$$

where $\mathrm{L}_{1}$ is the maximized likelihood value under $H_{l}$ and $\mathrm{L}_{0}$ is the maximized likelihood value under $H_{0}$. Under $H_{0}, \Lambda$ has an approximate chi-squared distribution with degrees of freedom given by the difference in the number of parameters under $H_{1}$ and $H_{0}$. In this case, there are 7 parameters under $H_{l}$ (one geometric parameter for each treatment and one binomial probability for each of the four experiments), and 5 under $H_{0}$ (one common geometric parameter and one binomial probability for each treatment). Thus, there are two degrees of freedom.

The entire analysis was repeated while omitting the outlier from the Skeletonema treatment, as this has undue influence on the results. The LR test was also used to test the 
null hypothesis that the geometric parameter is the same for the particle treatment and the Skeletonema treatment.

Since it was possible that the barnacle adults in the control treatment were preying on the nauplii at a higher rate than in the Skeletonema and particle treatments, the percentage of adults that continued to brood viable larvae at the end of the experiment was also determined. Results were pooled for the Rhode Island and New Hampshire experiments. Replicate jars that had fewer than five percent of adults brooding larvae at the end of the experiment were considered to be replicates with high levels of larval release. The percentage of replicates with high levels of larval release was compared qualitatively among the three treatments.

3.2.4. Experiments - Predation rate of adults on newly released larvae under turbid and normal conditions

In New Hampshire, we conducted an experiment on February 19, 2010 to determine whether predation rates of adults on newly released larvae would differ under turbid versus normal conditions. More than $95 \%$ of the adults in the field had released larvae by the date of the experiment. Rocks (small enough to fit inside 1-L plastic jars) that had $S$. balanoides adults attached to them were collected. The adults on these rocks had presumably released their larvae already, but this could not be verified, since it would have required sacrificing the animals.

The experiment consisted of 5 jars with a control treatment (seawater filtered through $100 \mu \mathrm{m}$ mesh) and 5 jars with an experimental treatment (filtered seawater with 
$40 \mu \mathrm{m}$ Dynoseeds ${ }^{\circledR}$ added at $10^{7}$ particles $\left.\mathrm{L}^{-1}\right)$. Each experimental jar contained a rock with live adult barnacles attached to it. After placing the rocks and treatments in the jar, we added at least 250 live, actively swimming nauplii to each. The exact number of nauplii used in each jar was noted. The nauplii were obtained as follows: adults were scraped off pier pilings along the uppermost limit of the barnacle zone. A few of these adults still had viable embryos inside their mantle cavities. Egg masses were collected from 10 individuals and were placed in seawater (pre-filtered through $100 \mu \mathrm{m}$ mesh). The eggs hatched within minutes, and the nauplii swam to the surface. Using a glass pipette, actively swimming larvae were suctioned out to use in the experiment. After adding the nauplii to the experimental jars, they were sealed with lids, placed in the plastic cages described above, and hung off the pier so that the jars were submerged in ambient seawater.

The experiment began at 14:00 and ended at 20:00. The afternoon was sunny with clear skies. At the end of the experiment, the water from each jar was filtered through 100 $\mu \mathrm{m}$ mesh, and the number of remaining nauplii were counted. Data analysis consisted of calculating the percentage of nauplii that survived in each jar without being consumed, and performing an ANOVA to compare the percentages among the three treatments.

3.2.5. Analysis of time series from Rhode Island: Does larval release coincide with phytoplankton blooms?

The Graduate School of Oceanography at the University of Rhode Island has sampled local phytoplankton and zooplankton once per week for more than a decade, and 
they have made those data publicly available on their website (University of Rhode Island Graduate School of Oceanography 2010). Phytoplankton have been enumerated and identified to the lowest possible taxonomic level, and barnacle nauplii have been counted (but not identified to the species level). A study by Lang and Ackenhusen-Johns (1981) found that in Narragansett Bay, nauplii from three species of barnacles can be found in January. Balanus improvisus is restricted to the Pettaquamscutt River, though, and the numbers of Balanus crenatus nauplii are much smaller than Semibalanus balanoides, which is the most abundant intertidal metazoan in the northeastern United States. Nauplius abundances in October, November, and December were near zero (Fig 3.2). Thus, it was assumed that the first large pulse in barnacle nauplius abundance in January could be attributed to the synchronized larval release of $S$. balanoides. The timing in peaks of nauplius abundance was compared to the timing of blooms of particular groups or species of phytoplankton. Data for both barnacle nauplii and phytoplankton abundance are available from early 2001 to late 2004, so these are the years that were chosen for the analysis.

Both phytoplankton and zooplankton samples were collected from the lower west passage of Narragansett Bay $\left(41^{\circ} 34.2^{\prime} \mathrm{N}, 71^{\circ} 23.4^{\prime} \mathrm{W}\right)$. The details for sample collection are described on the URI webpage as follows: for phytoplankton, water samples were taken from the surface and bottom. Equal volumes of surface and bottom samples were combined for counting under a compound microscope with a SedgewickRafter counting chamber. The organisms were counted live and unconcentrated. For zooplankton, vertical net tows were taken from $5 \mathrm{~m}$ to the surface with a 0.25 -m diameter, $64-\mu \mathrm{m}$ mesh net. The total volume filtered was $0.25 \mathrm{~m}^{3}$. Samples were preserved 


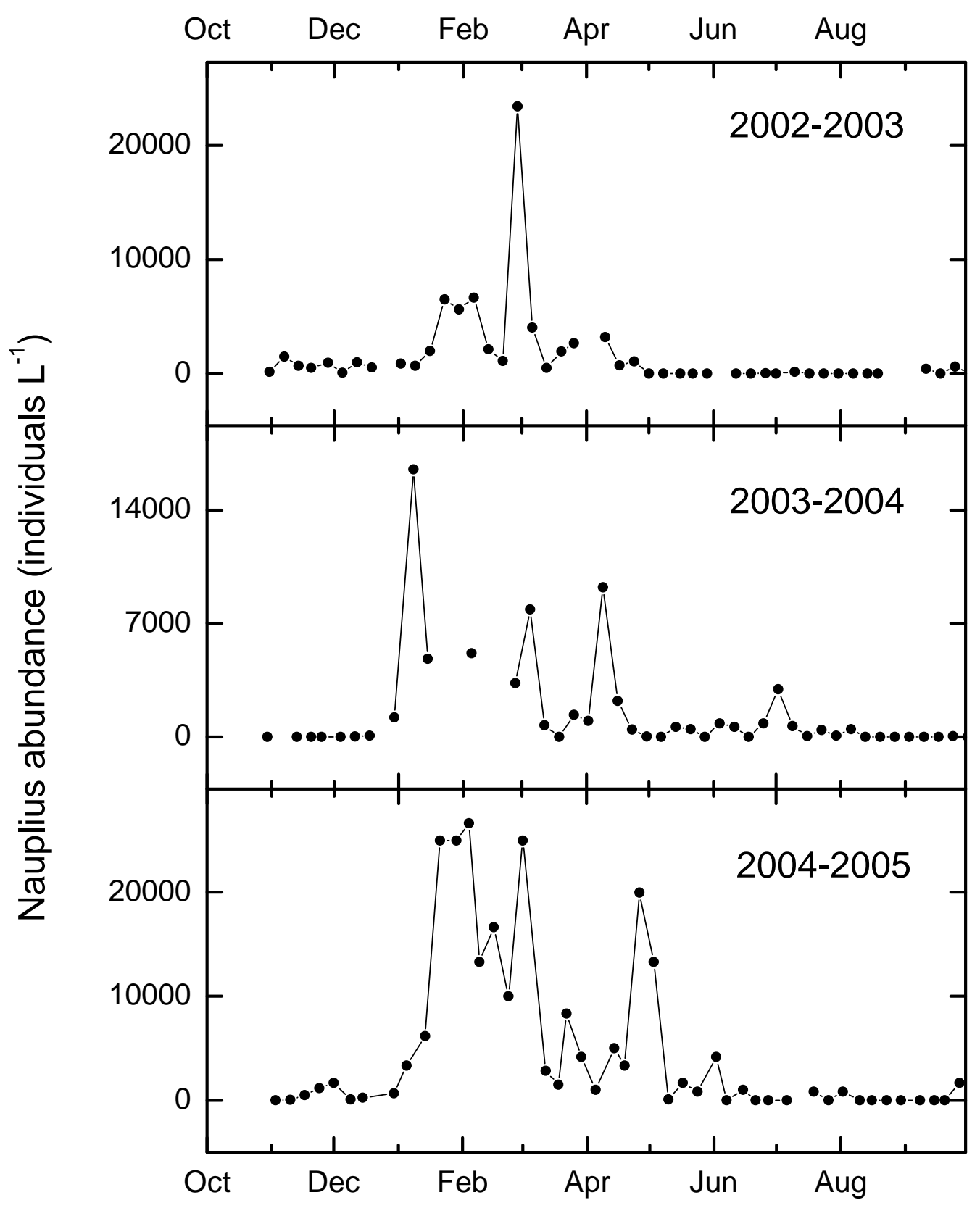

Figure 3.2. Weekly barnacle nauplius abundance in Narragansett Bay from 2002-2005. Nauplii were not identified to the species level. 
immediately in $4 \%$ buffered formalin-seawater solution. Subsamples were taken with a wide bore pipette, and zooplankton were identified and counted under a dissecting microscope. The subsample volume was such that at least 200 organisms were counted (University of Rhode Island Graduate School of Oceanography 2010).

In the present study, phytoplankton concentration on the week of larval release (week 0) was compared to the phytoplankton concentration during an earlier, four-week period (weeks -2 through -5). Separately, phytoplankton concentrations in week -1 were also compared to the phytoplankton concentration on weeks -2 through -5 , since there could have been a lag between a phytoplankton bloom and the detection of a larval release event. In other words, it is possible that a phytoplankton bloom could have happened on week -1 , and even if the larval release event had followed one or two days later, the peak in nauplius abundance would not have been detected until a sample was taken the following week. For the phytoplankton abundance comparisons, a $t$-test was used to compare a single value (from week 0 or week -1) to the mean phytoplankton concentration of weeks -2 to -5 (Sokal and Rholf 2001). An alpha level of 0.05 was used. If the phytoplankton concentration in either week 0 or week -1 was significantly greater than the mean phytoplankton concentration of weeks -2 through -5 , then the larval release event was considered to be related to the phytoplankton bloom event.

The possibility that the barnacles were not responding to changes in species composition in the plankton, but to changes in the size of the cells that made up the phytoplankton assemblage was considered. A test was conducted to determine whether larval release coincides with a change in the proportion of phytoplankton in three size classes (nanoplankton [2-20 $\mu \mathrm{m}]$, microplankton [20-200 $\mu \mathrm{m}]$, and mesoplankton [200 
$\mu \mathrm{m}-20 \mathrm{~mm}])$. For every phytoplankton species that was present from week 0 to week -5 , the number of cells was obtained from the survey data, and the typical cell size was found using two taxonomic guides (Tomas 1997, Horner 2002). In these guides, the size of the cells was always reported as a range. As an example, Chaetoceros compressus is 7-40 $\mu \mathrm{m}$. The midpoint between the minimum and maximum size (for C. compressus it was $23.5 \mu \mathrm{m}$ ) was used in this analysis. he number of cells in each of the three size classes was tallied, and the change in the percentage of phytoplankton in each size class was examined.

\subsection{Results}

\subsubsection{Field observations of larval release}

In Little Harbor, Massachusetts, two major larval release events can be seen in the adult barnacle survey data: one between December 12 and December 14, and another between December 18 and December 20 (Fig 3.3). On December $8^{\text {th }}$, the increase in the percent of empty adults suggests that there was a larval release event, but this is unlikely because the next three samples had a lower percentage of empty adults. Since adults reproduce only once per year, it is not possible that the barnacles released larvae and then became gravid again a few days later. The sample from December $8^{\text {th }}$ is more likely to be an anomaly, especially since its standard error is relatively high, so it was not classified as a larval release event. Similarly, the decrease in the percentage of empty adults on December $17^{\text {th }}$ and $22^{\text {nd }}$ is likely due to sampling error. 


\section{Little Harbor, Massachusetts}

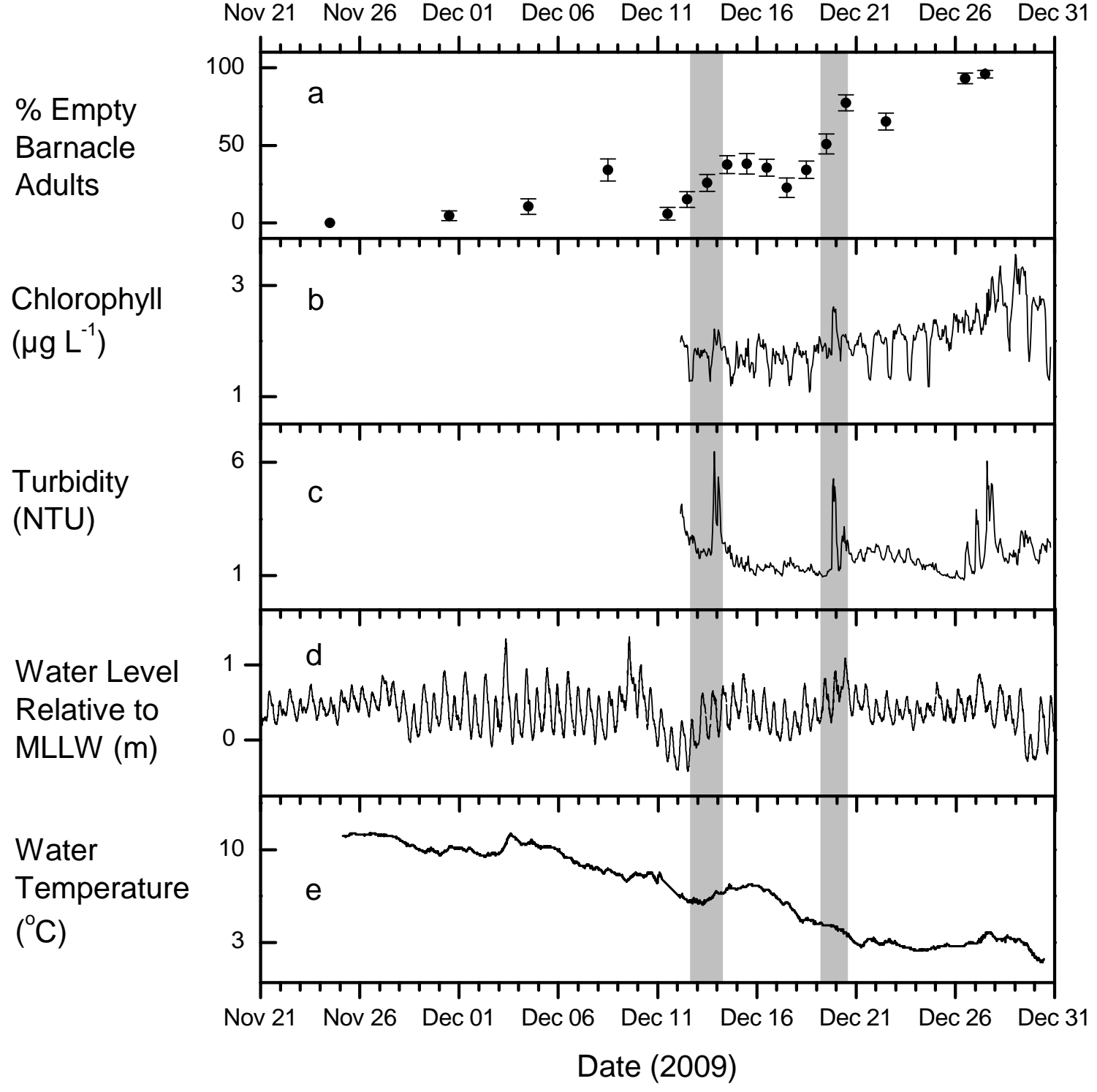

Figure 3.3. (a) Surveys of empty Semibalanus balanoides adults, shown with standard error bars, suggest that there were two major larval release events in Little Harbor. These are indicated by grey vertical bars. (b) Chlorophyll concentration. (c) Turbidity. (d) Water level relative to mean lower low water. (e) Water temperature. 
Chlorophyll measurements show fluctuations between approximately 0.6 and 3 $\mu \mathrm{g} \mathrm{\textrm {L } ^ { - 1 }}$ in Little Harbor (Fig 3.3). A short-lived, modest increase in chlorophyll concentration was observed during the second larval release event, but not during the first. Throughout most of the time series, there are decreases in chlorophyll values during the middle of the day. Turbidity ranged from approximately 0.8 to 6.5 Nephelometric Turbidity Units (NTU). NTUs measure the amount of light scattering that particles produce. A high-turbidity event was ending when the instrument was placed in the water, and another event followed it the next day. These two events coincided with the first larval release event. A second high-turbidity event coincided with the second larval release event. Water level relative to mean lower low water fluctuated between -0.1 and $1.4 \mathrm{~m}$. Water temperature declined steadily from $11^{\circ}$ to $1.5^{\circ} \mathrm{C}$.

The sampling period in Narragansett, Rhode Island, was shorter than in Massachusetts, lasting only seven days (Fig 3.4). A major larval release event occurred between January 11 and January 13. During this period, there was one high-chlorophyll event and two high-turbidity events. Chlorophyll data show the same slight mid-day decrease that was observed in Little Harbor. Water level fluctuated between -0.5 and 1.7 m. Salinity and water temperature fluctuated with a semi-diurnal period, so they were probably tidally influenced. Salinity ranged from 30.4 to $31.8 \mathrm{ppt}$. Water temperature ranged from $1.4^{\circ}$ to $3.9^{\circ} \mathrm{C}$.

In New Castle, New Hampshire, a larval release event was identified between February 12 and February 14 (Fig 3.5). Chlorophyll values were generally low. Three chlorophyll pulses can be seen on January 26, February 2, and February 20, but these are likely to be artificial because of their large magnitude and short duration. The mid-day 


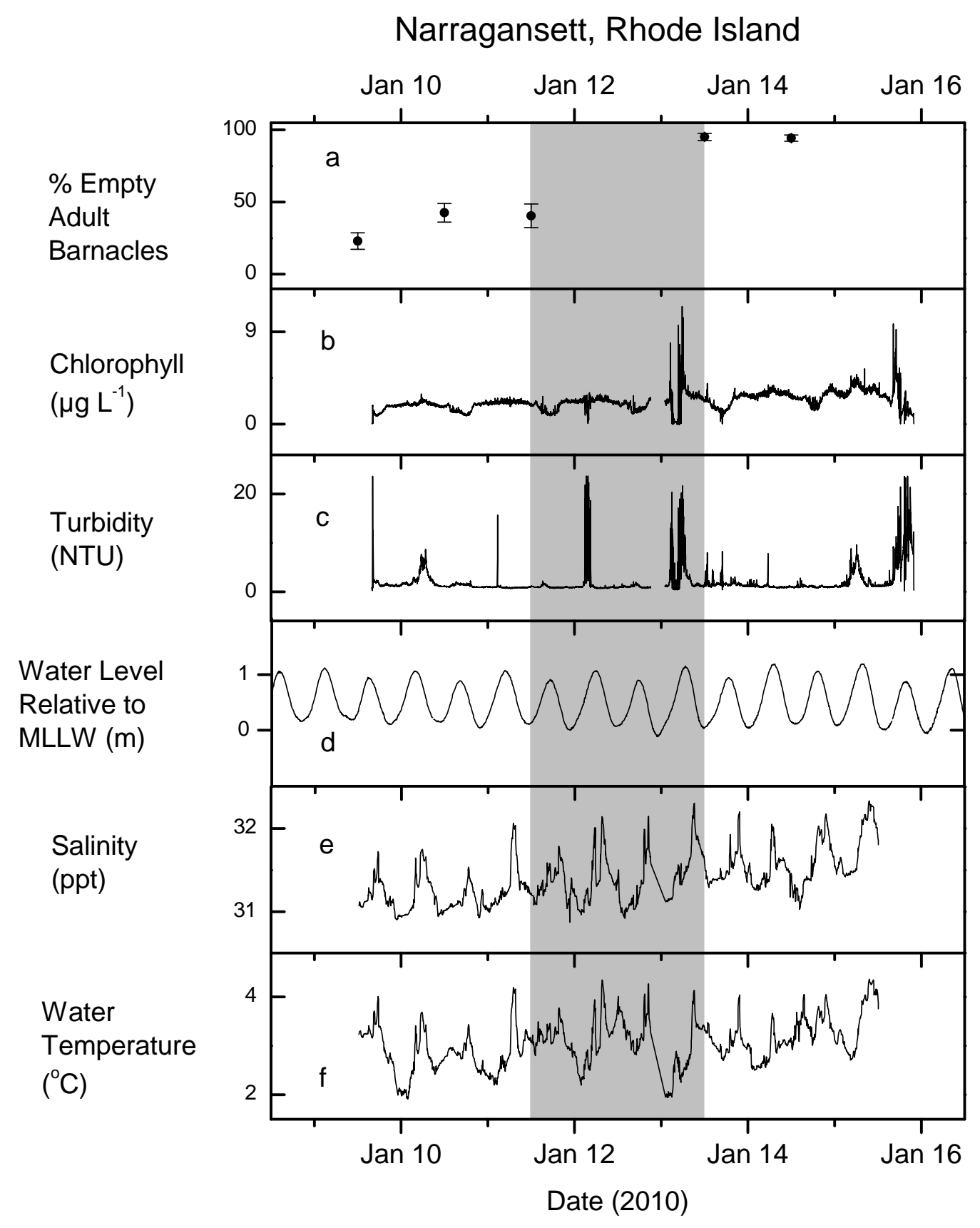

Figure 3.4. (a) Surveys of empty Semibalanus balanoides adults, shown with standard error bars. A major larval release event occurred between January 11 and January 13. (b) Chlorophyll. (c) Turbidity. The missing values in chlorophyll and turbidity correspond to a short period when the water level was so low that the instruments were exposed to air. (d) Water level relative to mean lower low water. (e) Salinity. (f) Water temperature. 


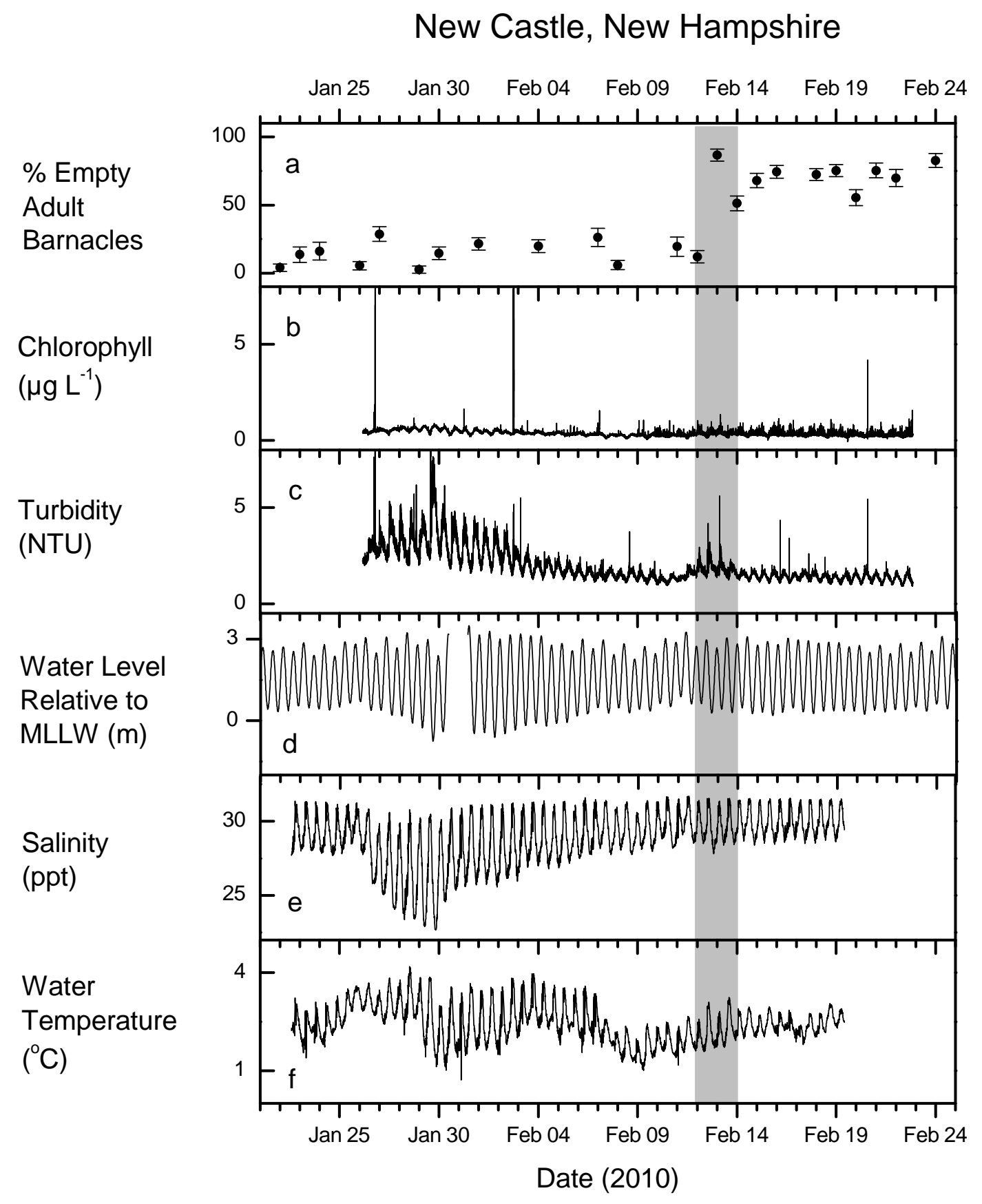

Figure 3.5. (a) Surveys of empty Semibalanus balanoides adults, shown with standard error bars. A major larval release event occurred between February 12 and February 14. (b) Chlorophyll. (c) Turbidity. (d) Water level relative to mean lower low water. (e) Salinity. (f) Water temperature. 
chlorophyll decreases that were observed in Little Harbor and Narragansett Bay are also evident here. Turbidity was generally high near the beginning of the sampling period and then decreased, although there was an increase at high tide during the larval release period. Turbidity values also showed semi-diurnal fluctuations related to the tides, as did salinity and water temperature. Water level fluctuated between -0.7 and $3.5 \mathrm{~m}$. Salinity ranged from 22.7 to $31.7 \mathrm{ppt}$. Water temperature ranged from $0.7^{\circ}$ to $4.2^{\circ} \mathrm{C}$.

\subsubsection{Experiments - Larval release in response to phytoplankton, turbidity, and control} conditions

In the four experiments conducted, the highest number of released nauplii were in the particle and Skeletonema treatments (Fig 3.6, 3.7). Moreover, when the four experiments are pooled together and plotted in rank order, the shape of the distributions is different (Fig 3.8). There was uncertainty in the number of adults that were gravid at the beginning of the experiment and in the number of nauplii that a gravid adult produced, so the results were analyzed with a statistical model that incorporated these uncertainties.

The null hypothesis that the larval release response is the same when adults are exposed to Skeletonema, particles, and control conditions was rejected ( $p<<0.001)$, even when the outlier in the Skeletonema treatment was removed $(p<<0.001)$. Using the likelihood ratio test, the null hypothesis that the larval release response was the same between the Skeletonema and particle treatments $(p \approx 1)$ could not be rejected. The analyses thus showed that the larval release response is similar for the Skeletonema and 
Experiment \# 1 - Rhode Island - January 112010

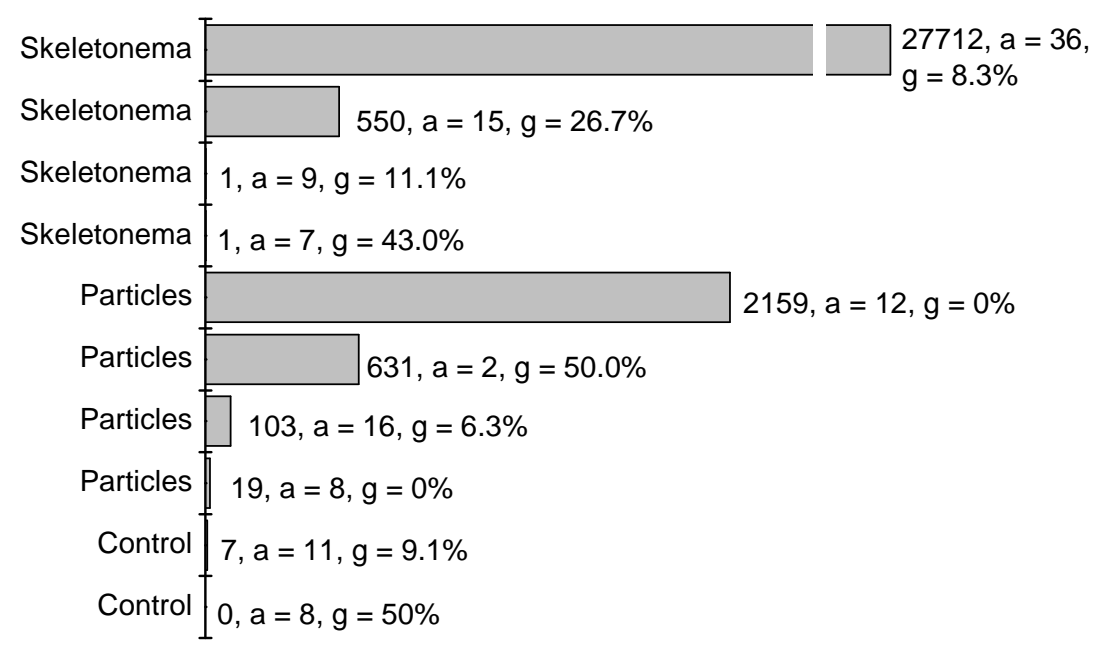

Experiment \# 2 - Rhode Island - January 132010

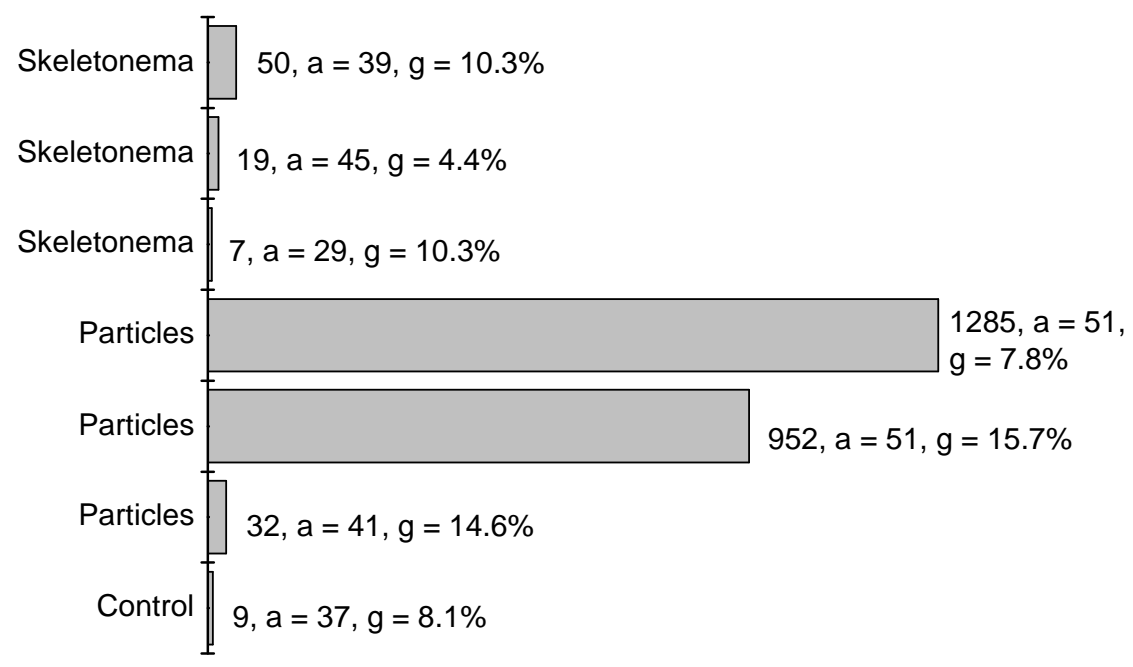

Figure 3.6. Number of nauplii found at the end of experiments in Rhode Island in which Semibalanus balanoides adults were exposed to one of three treatments: the diatom Skeletonema marinoi, inert synthetic particles, or control (plain seawater). $a$ refers to the number of adult barnacles present in a replicate, and $g$ is the percentage that were still gravid at the end of the experiment. 
Experiment \# 3 - New Hampshire - January 312010

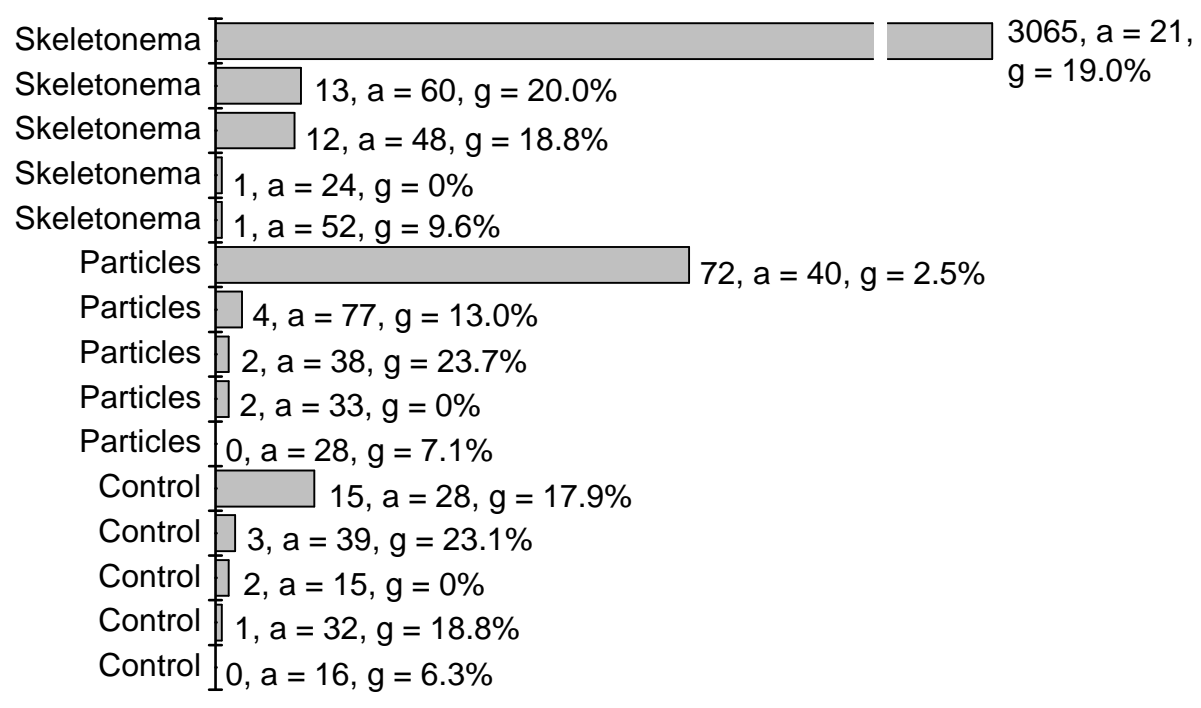

\section{Experiment \# 4 - New Hampshire - February 022010}

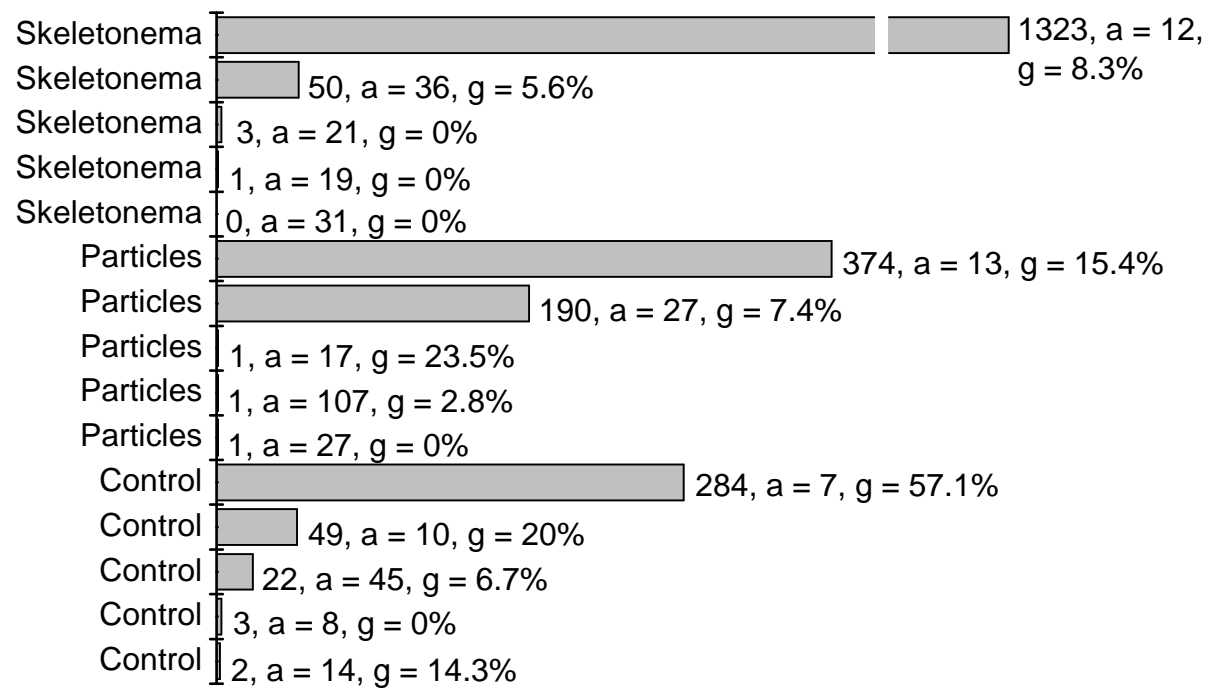

Figure 3.7. As in Rhode Island, adult $S$. balanoides were exposed to Skeletonema, particle, and control treatments. $a$ refers to the number of adult barnacles present in a replicate, and $g$ is the percentage that were still gravid at the end of the experiment. 


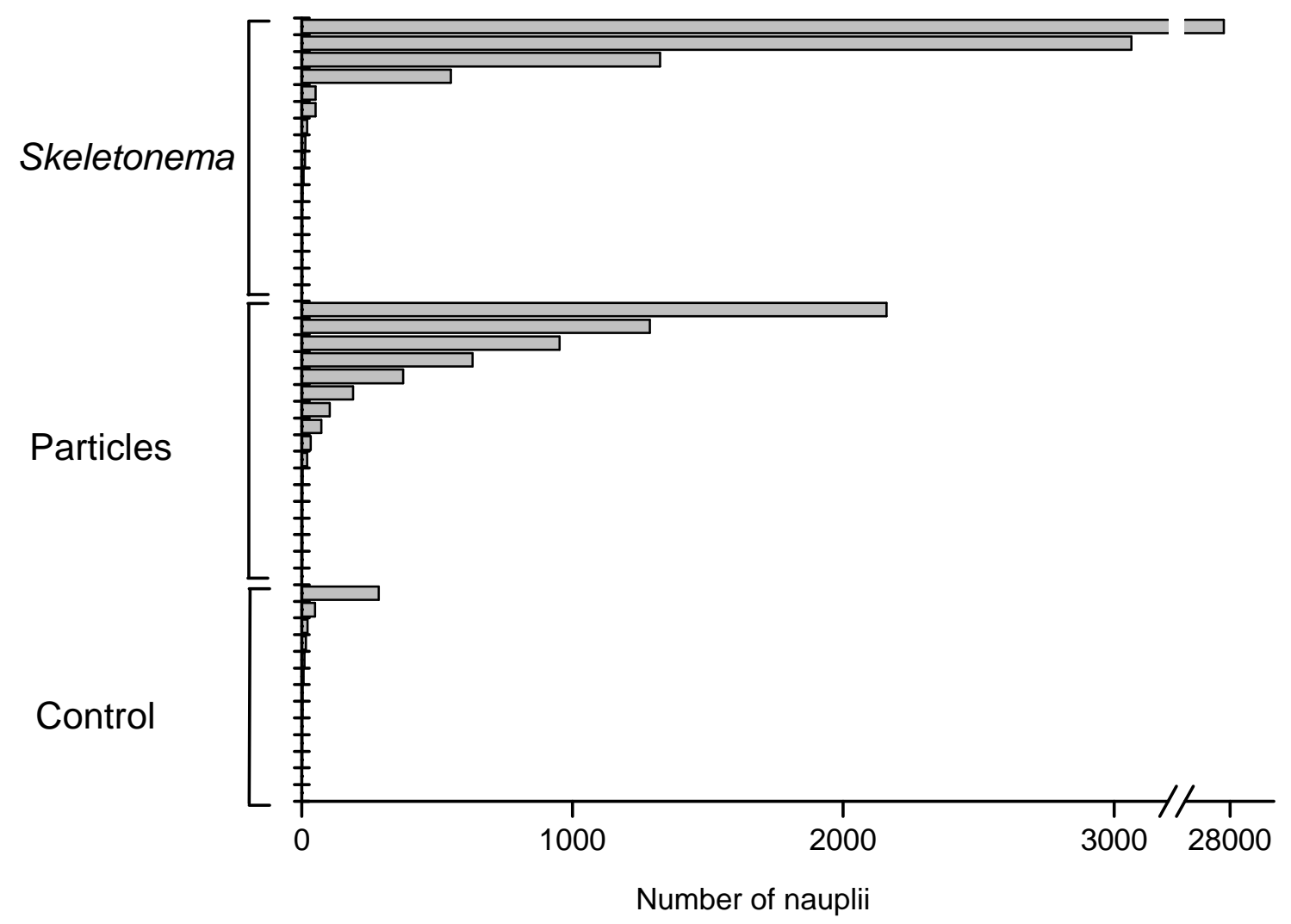

Figure 3.8. Pooled results of the Rhode Island and New Hampshire experiments in rank order, showing the number of nauplii at the end of experiments in which adult barnacles were exposed to Skeletonema marinoi, particles, or control treatment. Each bar represents one replicate for a treatment. 
particle treatments, and it is significantly higher than the response under the control treatment.

The estimates of $\pi$ under $H_{0}$ were $0.310,0.032,0.030$, and 0.041 for each of the four experiments. Thus, the estimated probability that an adult produced nauplii was $31 \%$, $3.2 \%, 3 \%$, and $4.1 \%$ respectively for each experiment. The estimates of $\pi$ under $H_{l}$ were $0.240,0.045,0.030$, and 0.047 . After removing the outlier for the Skeletonema treatment, the estimates of $\pi$ under $H_{l}$ were $0.18,0.05,0.03$, and 0.05 .

The estimate of $\theta$ under $H_{0}$ was 0.0018 . The estimates of $\theta$ under $H_{1}$ were 0.038 , 0.005, and 0.001 for the control, particle, and Skeletonema treatments, respectively. After removing the Skeletonema outlier, the estimate of $\theta$ under $H_{0}$ was 0.006 , and the estimates of $\theta$ under $H_{1}$ were $0.042,0.0049$, and 0.0051 . Thus, the estimated mean number of nauplii for a gravid adult was 165.67 under $H_{0}$ and 22.81, 203.08, and 195.08 under $H_{l}$ for control, particle, and Skeletonema treatments.

In addition to examining the number of nauplii in the experimental jars at the end of the experiments, the percentage of adults that continued to brood viable larvae was also determined (Fig 3.9). Replicate jars that had fewer than five percent of adults brooding larvae at the end of the experiment were considered to be replicates with high levels of larval release. Twenty-seven percent of replicates for the control treatment had high levels of larval release. In contrast, forty-six percent and fifty-four percent of particle and Skeletonema replicates, respectively, had high levels of larval release. 


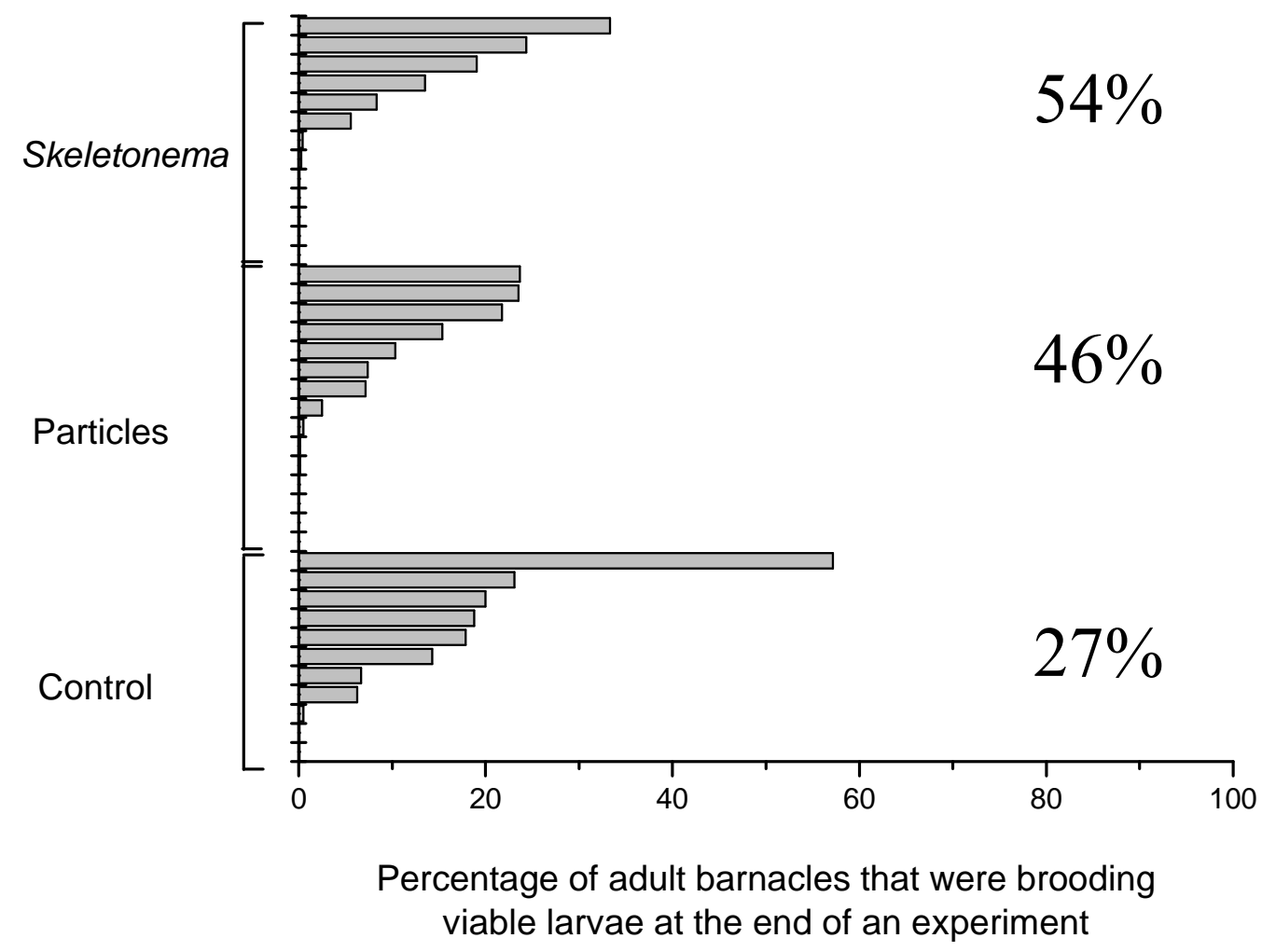

Figure 3.9. Pooled results of the Rhode Island and New Hampshire experiments in rank order, showing the percentage of adult barnacles within each replicate jar that had not released larvae by the end of the experiment. Replicate jars that had fewer than five percent of adults brooding larvae at the end of the experiment were considered to be replicates with high levels of larval release. Twenty-seven percent of replicates for the control treatment had high levels of larval release. In contrast, forty-six percent and fiftyfour percent of particle and Skeletonema replicates, respectively, had high levels of larval release. 


\subsubsection{Experiments - Predation rate of adults on newly released larvae under turbid and}

normal conditions

Adult barnacle predation rates on nauplii were lower in high turbidity conditions than in control conditions (ANOVA, $\mathrm{p}=0.015$, Fig 3.10). The mean percentage remaining in the particle treatments (85.4) was greater than in the control treatments (65.7), implying more nauplius consumption in the control treatments. The mean number of adult barnacles used in the particle treatments (16.6) was not statistically different from the mean number of adult barnacles in the control treatments (17.6) (ANOVA, $p=$ $0.874)$.

3.3.4. Analysis of time series from Rhode Island: Does larval release coincide with phytoplankton blooms?

Out of 120 phytoplankton species or groups that are enumerated in the weekly phytoplankton samples in Rhode Island, none show a consistent relationship with nauplii abundance. Some groups showed a positive relationship in particular years. In the winter of 2001-2002, it was centric diatoms, Chaetoceros spp., and pennate diatoms (Fig 3.11); in 2002-2003, it was Chaetoceros compressus and Thalassiosira nordenskioeldii (Fig 3.12); and in 2003-2004 it was Asterionellopsis glacialis, Thalassionema nitzschoides, Thalassiosira nordenskioeldii, Thalassiosira rotula, and the total phytoplankton cell abundance (Fig 3.13). These non-consistent relationships could have occurred due to chance, since so many phytoplankton groups were examined. Nauplius release was 
Percentage of Nauplii Remaining in the Experimental Jar after Being Exposed to Adult Barnacles for 6 Hours

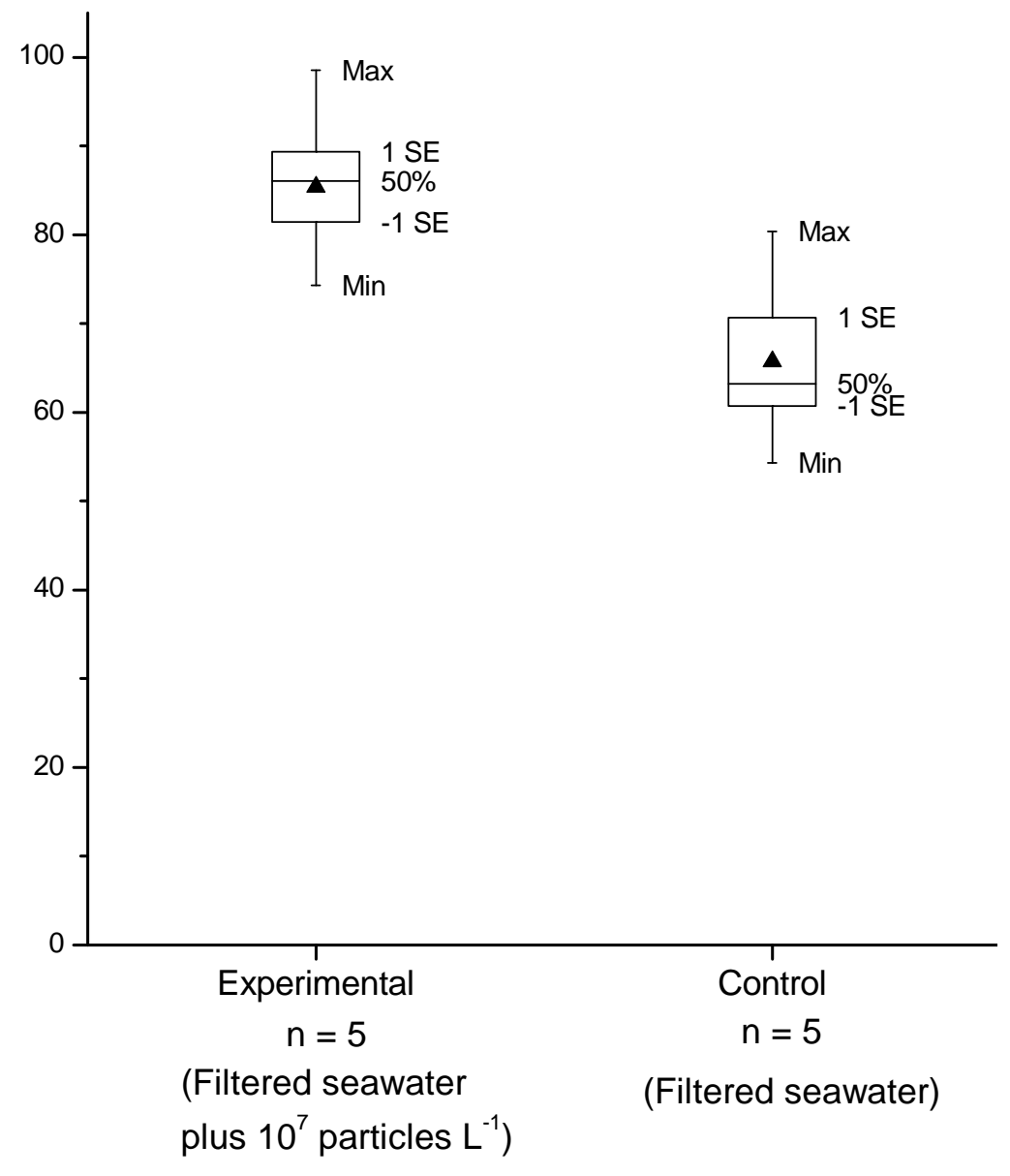

Figure 3.10. Adult barnacle predation rates on nauplii were lower in high turbidity conditions than in control conditions (ANOVA, $p=0.015$ ). The triangles represent the means, the boxes represent the median and the standard error of the mean, and the whiskers represent the minimum and maximum values. 


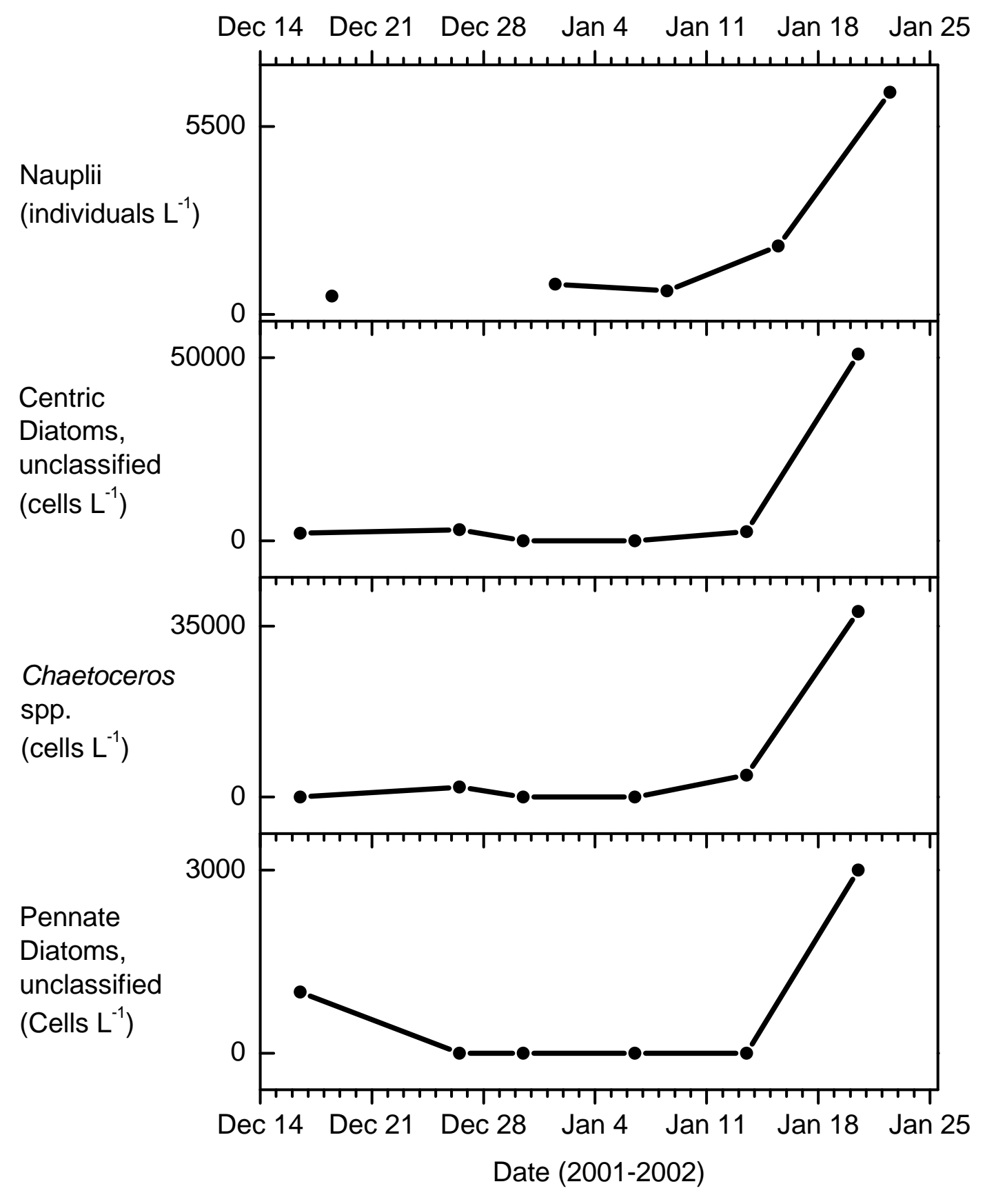

Figure 3.11. In December 2001 - January 2002, the increase in S. balanoides nauplius abundance coincided with increases in the concentration of centric diatoms, Chaetoceros spp., and pennate diatoms. 


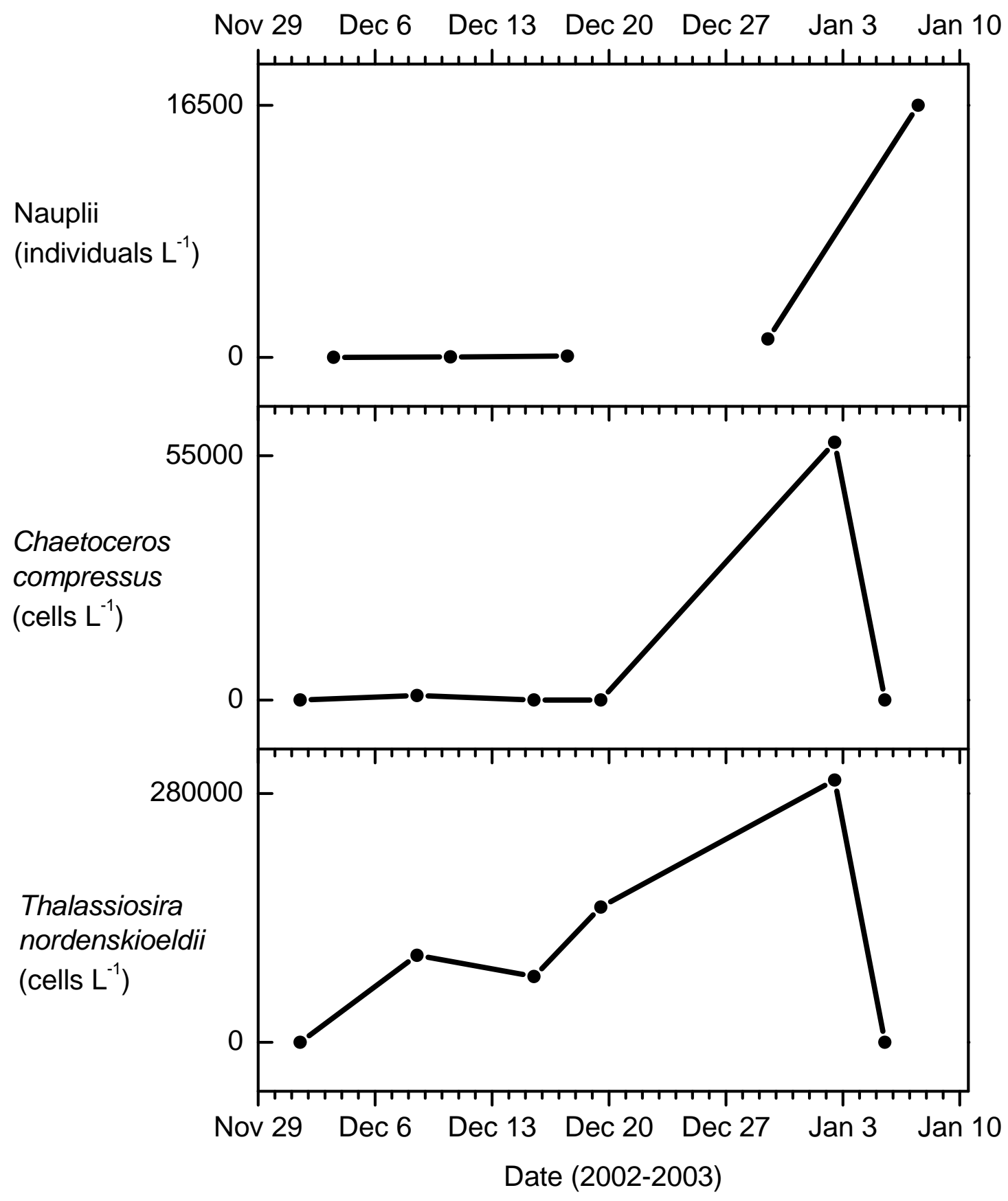

Figure 3.12. In December 2002 - January 2003, the increase in S. balanoides nauplius abundance coincided with increases in the concentration of Chaetoceros compressus and Thalassiosira nordensioeldii. 


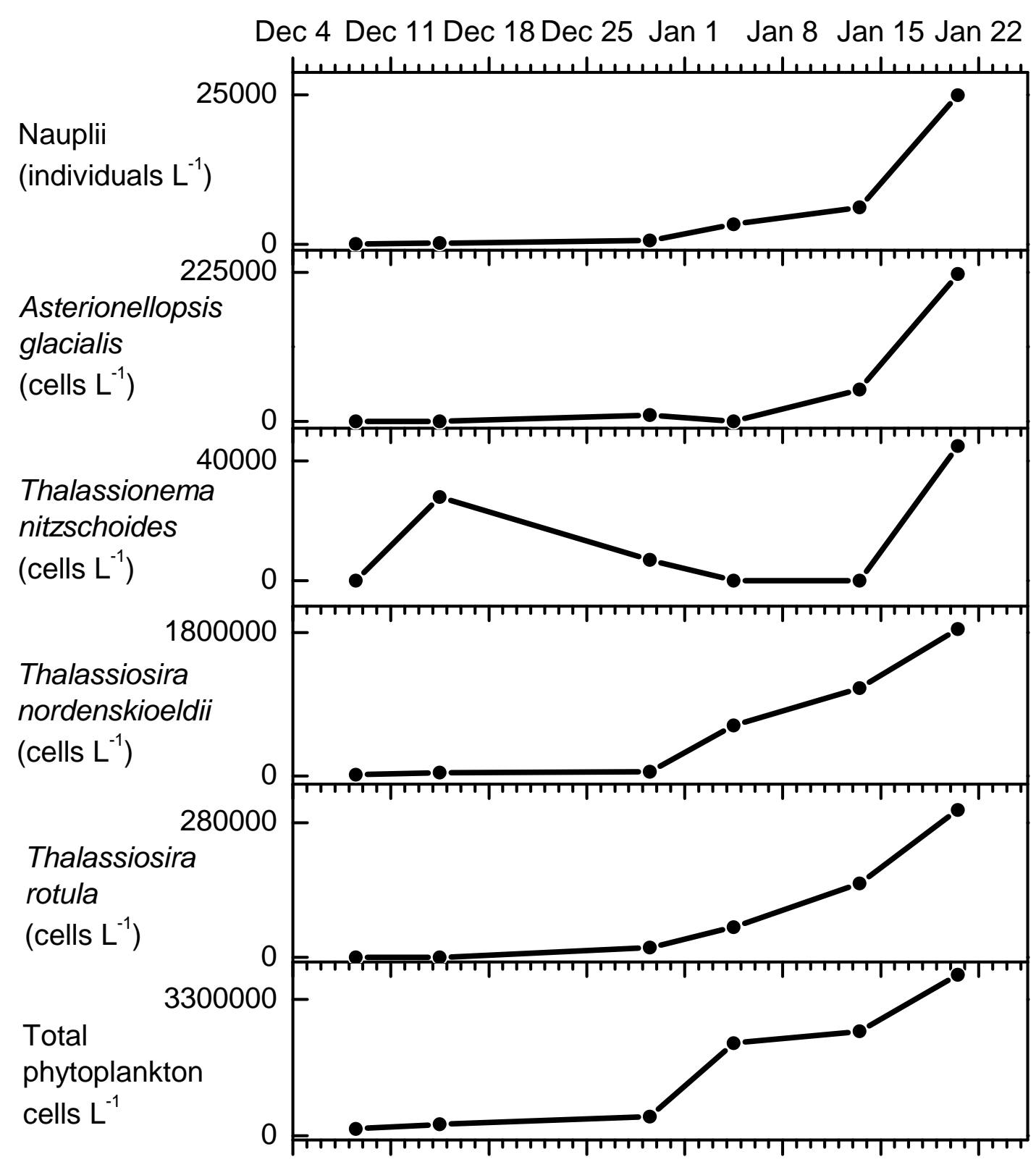

Dec 4 Dec 11 Dec 18 Dec 25 Jan 1 Jan 8 Jan 15 Jan 22

Date (2003-2004)

Figure 3.13. In December 2003 - January 2004, the increase in $S$. balanoides nauplius abundance coincided with increases in the concentration of Asterionellopsis glacialis, Thalassionema nitzschoides, Thalassiosira nordenskioeldii, Thalassiosira rotula, and the total phytoplankton cell abundance. 
related to the total phytoplankton cell abundance in only one of the years examined.

The patterns in phytoplankton size distributions were also different in all three years examined (Fig 3.14). In the winter of 2001-2002, weeks -2 to -5 had a high percentage of nanoplankton (86\%) and a low percentage of microplankton $(11 \%)$ and mesoplankton (3\%). On week -1 there was a dramatic change, with nanoplankton decreasing to $31 \%$, microplankton increasing to $64 \%$, and mesoplankton remaining low at $5 \%$. On week 0 (the week of barnacle larval release), the proportions changed again to $46 \%$ nanoplankton, 23\% micrcoplankton, and 31\% mesoplankton. The patterns in the winter of 2002-2003 were completely different to those in the previous winter. In all of the weeks examined in 2002-2003, there was a high percentage of nanoplankton (67$78 \%$ ), an intermediate percentage of microplankton (22-32\%), and almost no mesoplankton $(\sim 0 \%)$. The patterns changed again in the winter of 2003-2004. In weeks 2 to -5 there were approximately equal proportions of nanoplankton $(53 \%)$ and microplankton (46\%), and a low proportion of mesoplankton (1\%). In week -1 there was a slight decrease in nanoplankton (to $43 \%$ ) with an increase in microplankton (to $57 \%$ ), and $0 \%$ mesoplankton. Finally, on the week of larval release, nanoplankton decreased further (to $37 \%$ ), microplankton increased (to $63 \%$ ), and mesoplankton remained at $0 \%$.

\subsection{Discussion}

The field observations and experiments in this studywere designed to test two hypotheses: that (1) high turbidity or (2) high phytoplankton concentrations trigger larval release in the barnacle Semibalanus balanoides. The two hypotheses are not independent, 

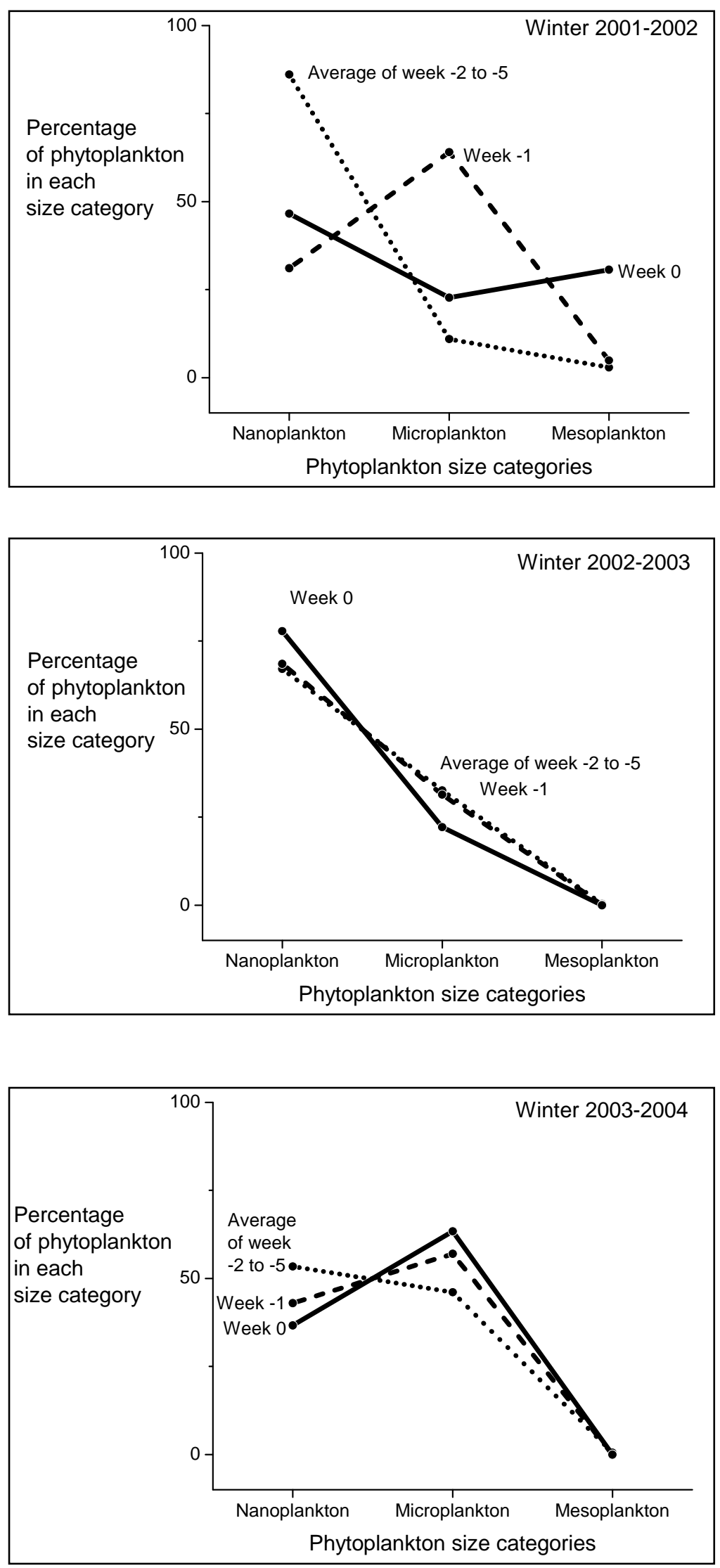

Figure 3.14. Changes in phytoplankton size classes throughout the winters of 2001-2002

(a), 2002-2003 (b), and 2003-2004 (c).

Nanoplankton are 2-20 $\mu \mathrm{m}$, microplankton are 20-200 $\mu \mathrm{m}$, and mesoplankton are $200 \mu \mathrm{m}-2 \mathrm{~mm}$. "Week 0" is the week of nauplius release, "week -1 " is the week prior to nauplius release, and "week -2 to -5 " are the four weeks prior to week -1 . 
since phytoplankton blooms are also one source of turbidity, but these results suggest that larval release in the field and in the laboratory could be triggered by high-turbidity events in the absence of phytoplankton blooms.

In Little Harbor, Massachusetts, the two larval release events coincided with pulses of high turbidity. No such pulses in chlorophyll were evident. Since macroalgal interference with the instrument sensors forced filtering of the data, it is possible that short-lived pulses in chlorophyll went undetected. This is unlikely, though, because short-lived pulses in turbidity could still be detected after filtering, so the same should have been able possible with chlorophyll. In Narragansett, Rhode Island, there were pulses in both turbidity and chlorophyll at the time of larval release, so it is not possible to rule out one of the two factors as a trigger for larval release. In New Castle, New Hampshire, the data show that there was an increase in turbidity at the time of larval release, but there was no increase in chlorophyll.

A question that arises is why the barnacles did not release during the highturbidity events at the beginning of the time series in New Hampshire. A possible explanation is that the barnacle larvae were not yet developmentally ready to be released. Surveys showed that between January 21 and January 26, only 15 to $40 \%$ of barnacle had larvae that were viable when extracted from the mantle cavity and placed in seawater (Fig 3.15). By February 4, approximately $80 \%$ of adults had viable larvae.

To examine the relationship between phytoplankton and barnacle larval release, in vivo chlorophyll fluorescence was used to estimate chlorophyll- $a$ concentrations, but this is known to be an imperfect method. The ratio of fluorescence to chlorophyll- $a$ can 


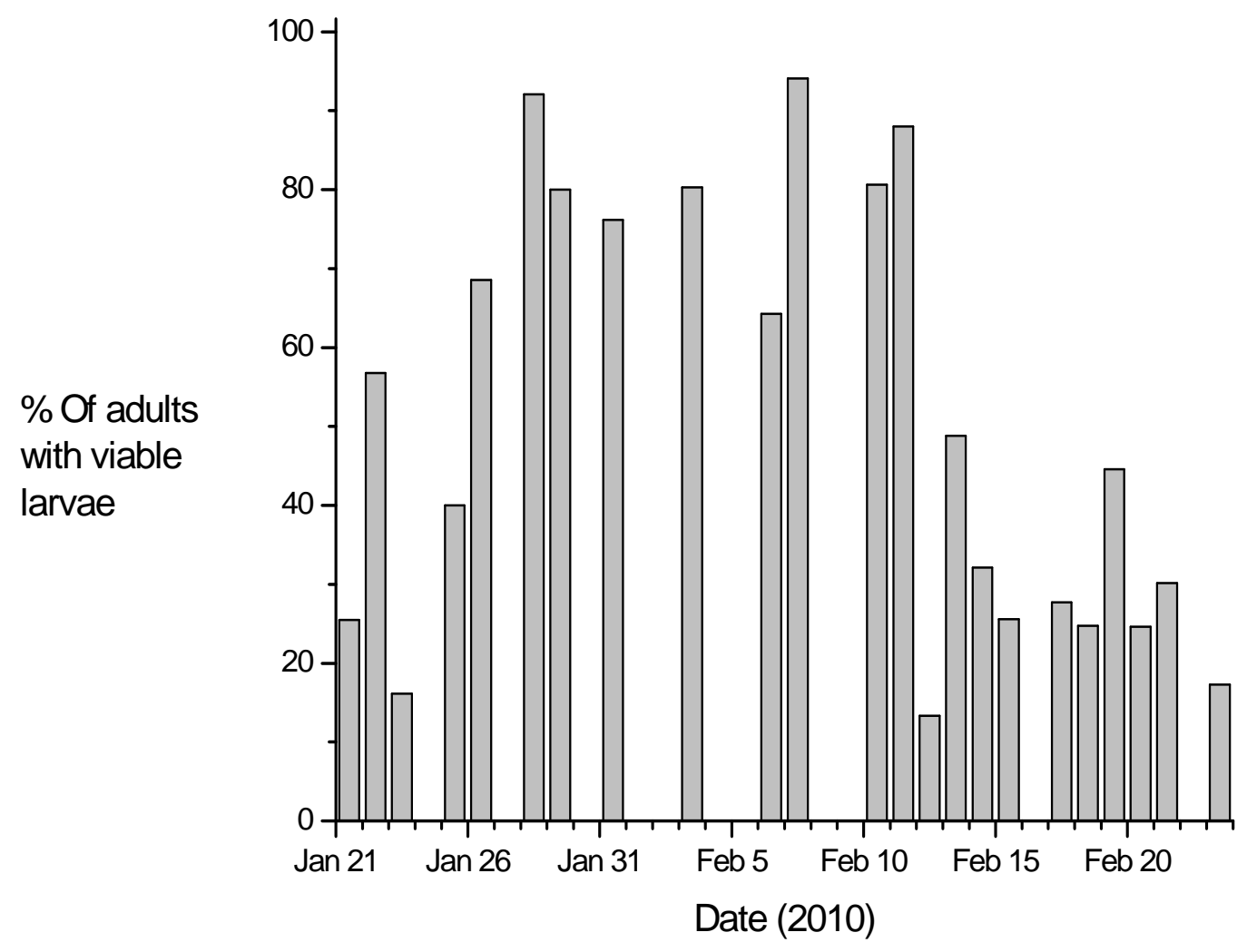

Figure 3.15. Percentage of barnacle adults in the field in New Hampshire that had viable larvae in their mantle cavities throughout the sampling period. 
vary depending on the species composition of the phytoplankton, the health of the cells, and the ambient light conditions (e.g., Loftus and Seliger 1975; Dandonneau and Neveaux 1997). In the present data, decreases in fluorescence can be seen almost daily during the middle of the day. This is likely due to non-photochemical quenching. Nonphotochemical quenching processes serve to protect phytoplankton from photooxidative damage resulting from conditions in which light energy exceeds the capability of the cell to utilize it (Müller et al. 2001). Quenching manifests itself as a reduction in fluorescence during periods of high light intensity. Thus, care must be taken in interpreting the data from the brightest period of the day.

Another approach that was utilized to examine the relationship between phytoplankton and nauplius release was to analyze the weekly time series of phytoplankton and nauplius abundance from 2001 to 2004 in Rhode Island. The prevailing view among barnacle biologists has been that an increase in phytoplankton abundance triggers larval release (Barnes 1956, 1957; Crisp 1956; Crisp and Spencer 1958). Out of the 180 phytoplankton species or groups that the University of Rhode Island has identified, only eight showed a significant increase in abundance coinciding with the onset of larval release in Semibalanus balanoides. None of these species bloomed consistently on all three years at the time of larval release, and due to the high number of comparisons, the significant relationships we found could be due to chance. Moreover, nauplius release coincided with total phytoplankton cell concentration on only one of the years examined. Thus, larval release appears to be unrelated to (1) blooms of any particular phytoplankton species and (2) total concentrations of phytoplankton cells in the water column at weekly scales. A limitation of the data used here is that the 
sampling frequency may have been too coarse to detect a correlation. Future studies should sample at a higher frequency to obtain higher resolution of fluctuating abundances.

No consistent pattern was found for the change in phytoplankton cell size in the weeks leading up to barnacle larval release. However, since cell size data were not available, it had to be estimated using size ranges reported in the literature. Some species of phytoplankton had size ranges that overlapped the nanoplankton and microplankton categories. It is possible that the patterns could be different if the cells are classified as belonging to one category or the other. It would be useful for future studies to obtain data on the actual size of the phytoplankton cells, along with data on whether the cells formed chains, as some species are known to do. Finally, the three size classes that were chosen are somewhat arbitrary. It is possible that barnacles are responding to changes in size categories that are different from the ones considered here. A study by Stone (1989) examined the rate of development, survival, and size at stage IV for $S$. balanoides nauplii reared on various algal diets in the laboratory. She found that the larvae fared best on a diet of larger algae such as Skeletonema costatum, Thalassiosira weisflogii, and Rhodomonas spp. than on a diet of smaller algae such as Chaetoceros calcitrans and Isochrysis galbana. All of these algae are in the nanoplankton size category, so it is unlikely that barnacle adults time their larval release to coincide with blooms in smaller algae, since these are not likely to be sufficiently nutritious for the nauplii.

The findings in the present study regarding interannual variability in phytoplankton community structure in Narragansett Bay agree with results that other workers have obtained in this area. The classic description of spring phytoplankton blooms in the North Atlantic states that phytoplankton are light-limited, and once water 
column stratification begins in the spring, a relatively predictable and stable pattern of phytoplankton blooms begins (Smayda 1998). Shallow coastal areas may not always follow this pattern, though. Bigelow et al. (1940) showed that the spring bloom can begin as early as late winter. Subsequent work has discovered that the timing and duration of blooms can depend on different factors and combinations of factors, including irradiance and cloudiness (Hitchcock and Smayda 1977; Townsend et al. 1994), nutrient limitation (Pratt 1965), and temperature-dependent zooplankton grazing rates (Martin 1965, 1970; Keller et al. 2001; Oviatt et al. 2002). In a review of data from 1959 to 1978, Smayda (1998) found that the time of inception of the winter-spring bloom in Narragansett Bay varied greatly. It occurred 4 times in November, 6 times in December, 6 times in January, and 4 times in February. Such high interannual variability might make it difficult for barnacles to time their reproduction to coincide precisely with a bloom. Instead, it is proposed here that Semibalanus balanoides might be timing its reproduction so that it coincides roughly with the onset of winter-spring blooms, but adults might be using another cue (turbidity) to fine-tune the timing of release.

The hypothesis that turbidity is the cue for larval release is consistent with previous work showing that $S$. balanoides respond to high concentrations of phytoplankton, since phytoplankton suspended in the water column are one source of turbidity. Furthermore, the hypothesis accounts for instances when larval release does not coincide with phytoplankton blooms. Storms may stir up sediments and particles and trigger larval release in the absence of a bloom (Gyory and Pineda, submitted). The turbidity hypothesis also accounts for results of experiments showing that the larval release response is strongest when adults were fed phytoplankton in concentrations 
greater than those found in typical blooms (Starr et al. 1991). The barnacles in these laboratory studies may not have been responding to the phytoplankton per se, but to the high turbidity caused by high concentrations of phytoplankton cells. This would also explain why the barnacles did not respond to phytoplankton culture filtrates, only to the presence of the cells themselves (Starr et al. 1991). The barnacles in the Starr et al. (1991) experiments also released their larvae when they were exposed to high concentrations of brine shrimp nauplii, which are not a normal food item for them or their larvae in the field. When exposed to high concentrations of particles, whether they were phytoplankton cells or brine shrimp nauplii, the adults may have responded to the increased turbidity caused by these particles.

The experiment results in this paper lend further weight to the turbidity hypothesis, since the larval release response was stronger when adults were exposed to Skeletonema and inert synthetic particles than when they were exposed to control conditions. The response under the Skeletonema treatment was not different from the response under the particle treatment, which suggests that the barnacles are responding to the presence of particles, not to the identity of the particles. Starr et. al. (1991) suggested that turbidity might serve as a sign that a phytoplankton bloom is underway. A different possibility is suggested in the present paper: cannibalism and predation might be an important source of larval mortality, and turbid conditions might provide a temporary refuge for barnacle nauplii. The results of our predation experiments showed that adults consumed fewer larvae in turbid conditions than control conditions, suggesting that mortality of larvae is indeed lower when turbidity is high. Since phytoplankton blooms increase the turbidity of 
the water column, it is likely that larval release will often be correlated with phytoplankton abundance, but this may not always be the case.

In summary, field observations showed that larval release occurred during periods of increased turbidity at all three of our field sites. Pulses in chlorophyll coincided with larval release only in one of the two events in Massachusetts, and also during the event in Rhode Island. The 2001-2004 time series data from Rhode Island suggest that larval release was not consistently related to blooms of specific phytoplankton, nor to overall phytoplankton abundance or cell size. In the experiments, the larval release response was highest during exposure to high concentrations of phytoplankton and high concentrations of inert particles, which are both sources of high turbidity. Finally, the feeding experiments show that predation rate by adults on newly released larvae is lower in highturbidity than low-turbidity conditions. Based on these results, it is suggested that Semibalanus balanoides adults release larvae in response to high-turbidity conditions, which can be caused by phytoplankton blooms, sediment re-suspension from storms, or other reasons. The timing of larval release in this species may have evolved to coincide roughly with the onset of winter phytoplankton blooms in order to ensure a plentiful food supply for the larvae, but it may have been fine-tuned further by cannibalism and/or predation pressures. 


\section{Chapter 4}

\section{Reproductive ecology and larval biology of the land crab Gecarcinus quadratus on the Pacific coast of Panama}

\section{Abstract}

Gecarcinus quadratus is a terrestrial crab that influences the soil chemistry and plant community structure of coastal tropical rainforests along the Pacific coast of the Americas (Sherman 2002, 2003, 2006; Lindquist and Carroll 2004). Despite its ecological importance, nothing was known about its larval phase or the processes affecting its recruitment. To address this, a study was conducted on an island off the coast of Panama to investigate the cues for reproduction, the general morphology and development rate of the larvae, and the processes that influence the distribution and survival of the larvae. Females underwent synchronized breeding migrations to the ocean after the first rains of the rainy season, presumably when the risk of mortality from desiccation is lowest. They waited for darkness and an ebbing tide before releasing their eggs into the water. Eggs hatched immediately upon contact with seawater. The first stage zoeas had dark pigmentation, long dorsal and rostral spines, and a pair of lateral spines. In the laboratory, a G. quadratus zoea reached the megalopa stage in 21 days. Hatching in darkness may help zoeas avoid predation from planktivorous diurnal fish, and the zoeal spines may deter predation from planktivorous nocturnal fish. A mass migration of megalopae and juveniles out of the water was observed 30 days after adult 
females released their eggs. Plankton pump samples taken near the island suggest that zoea abundance and distribution may be related to the phase of the internal tide. 


\subsection{Introduction}

In comparison to the relatively well-studied coasts of temperate regions, the coasts of the American tropics are much more mysterious. Many tropical species were described by naturalists and explorers in the $19^{\text {th }}$ century, but there is scarce information about their life histories and their interactions with each other and their environment. This is problematic because humans are rapidly and drastically changing the environment on local and global scales, yet baseline information is missing for many ecosystems, hindering efforts to evaluate the extent of the damage being caused (Dayton and Sala 2001). Wise conservation decisions require knowledge about the natural history of organisms and well-documented observations of their patterns in nature.

Gecarcinus quadratus is a tropical terrestrial crab that was initially described by de Saussure in 1853, but its ecological importance was unknown for more than a century. The crab inhabits coastal tropical rainforests along the Pacific coast of the Americas from Mexico to Peru (Bright and Hogue 1972). It is found on land generally up to $600 \mathrm{~m}$ away from shore in densities as high as 6 individuals $\mathrm{m}^{-2}$ (Sherman 2002). Because of its burrowing and feeding habits, the crab has a substantial influence on the soil chemistry and plant community structure of rainforests. Along most of its range, the crab is subject to two predominant seasons: dry and rainy. To avoid desiccation during the dry season, the crabs dig burrows and spend much of their time there (Sherman 2003). They emerge at night (or in the rainy season, at any time) to remove leaf litter from the rainforest floor and relocate it inside their burrows for consumption (Sherman 2003). The crabs often consume leaf litter only partially, though, and the remainder decomposes inside the 
burrow (Sherman 2003). As a result, burrows have higher concentrations of organic carbon and higher densities of fine plant roots relative to rainforest soil at similar depth (Sherman 2006). The diet of G. quadratus is not limited to leaf litter. The crabs also consume fruits, seeds, and seedlings. Crab predation decreases plant seed abundance (Lindquist and Carroll 2004) and seedling density (Sherman 2002). Despite the ecological importance of G. quadratus, there is no information available about its larval phase or about the processes that might influence the recruitment of new generations into the population.

All species in the Gecarcinidae family of crabs are terrestrial, yet they must migrate to the sea to release eggs that hatch into planktonic marine larvae (Burggren and McMahon 1988). Although each female may produce many thousands of eggs, only a fraction of them eventually metamorphose and crawl back onto land. The processes that influence larval mortality and recruitment success are not well known for land crabs, in particular for Gecarcinus quadratus. What is known is that these crabs undertake mass synchronous breeding migrations. Since breeding occurs over a relatively short period, the processes that affect larval mortality and recruitment success might be somewhat constrained in time and space, perhaps making them straightforward to identify.

Although there is anecdotal evidence that rain triggers mass breeding migrations of G. quadratus to the ocean (Sherman 2002; J. Gyory, pers. obs.), this has not been described quantitatively. Moreover, the morphology of their larvae is unknown. Finding the cue for synchronous reproduction and identifying the larvae would aid in understanding the factors influencing mortality and survival in the planktonic stage of this organism. 
At the midpoint of their range, along the coast of Panama, the complexity of the physical environment could result in many potential mechanisms for accumulating, dispersing, retaining, or transporting G. quadratus larvae. Toward the end of the dry season and the beginning of the rainy season, the water column is highly stratified. In a near-shore water column that is $15 \mathrm{~m}$ deep, it is not uncommon to find that water temperature near the bottom is $18^{\circ} \mathrm{C}$, while water temperature near the surface is $30^{\circ} \mathrm{C}$ (J. Gyory, pers. obs.). In such a highly stratified water column, the direction of horizontal flows can differ between layers, and the vertical position of larvae would determine the direction of transport.

The depth of the thermocline is not static, however. It often changes quickly and drastically with the passage of internal waves, which form at the interface of two layers with different densities. Internal waves and their associated surface convergence zones can result in the accumulation and shoreward transport of zooplankton (e.g., Shanks 1983; Pineda 1991; Leichter et al. 1998; Pineda 1999). Temperature records from this region of Panama also suggest the presence of internal tidal waves and the fronts that can be associated with them (Dana 1975; D’Croz and Robertson 1997; Pineda et al. 2009). The internal tide is an internal wave that has tidal frequency (Roberts 1975). When the internal tide approaches shallow waters, it can become nonlinear, break, and advance shoreward as an internal tidal bore (Pineda 1994). The higher-density (and generally colder) water rushing up the sloping bottom can push the lower-density (generally warmer) water offshore. Gravity eventually pulls the dense water back down the slope, and the warm water returns to shore. As it does this, a front can form at the water surface between the cold and warm-water masses. Warm-water fronts have potential for 
accumulating and transporting neustonic larvae. The Pacific coast of Panama also has semi-diurnal surface tides with amplitudes of up to $6 \mathrm{~m}$ (D'Croz and Robertson 1997), and the associated strong tidal currents may affect larval dispersal. The degree to which G. quadratus larvae are retained near or transported away from their site of release could affect the degree of connectivity among different populations and the survival and successful recruitment to the terrestrial adult stage.

If $G$. quadratus reproduction is triggered by the first rains of the rainy season, then the synchronous reproduction of so many adults would result in a large pulse of biomass into the coastal ocean. It is plausible that such a sudden and massive influx of crab larvae would impact the structure of local food webs. It is also plausible that other organisms could time their reproduction to coincide with that of the crabs so that their offspring could benefit from the abundant food supply in the form of crab larvae.

In this study, several questions regarding the reproductive ecology and larval biology of Gecarcinus quadratus were investigated: (1) Is rain the trigger for mass breeding migrations of adults to the ocean? (2) Are there multiple migrations, and if so, are they of the same magnitude? (3) When does egg release occur with respect to the day/night and tidal cycle? (4) What is the general morphology of Gecarcinus quadratus larvae? (5) How long is the planktonic phase? And finally, (6) what processes might be influencing survival and distribution of the larvae?

\subsection{Materials and Methods}

\subsubsection{Study site}


This study was carried out in 2007, 2008 and 2009 at the Liquid Jungle Lab (Fig 4.1), a field station located on the island of Canales de Tierra in the Gulf of Chiriquí, off the Pacific coast of Panama $\left(7^{\circ} 44.85^{\prime} \mathrm{N}, 81^{\circ} 34.63^{\prime} \mathrm{W}\right)$. The island, a nature preserve where anthropogenic impacts are minimized as much as possible, is approximately 2.5 $\mathrm{km}$ long, $1.5 \mathrm{~km}$ wide, and $300 \mathrm{~m}$ away from the mainland. A fiber-optic cabled observatory known as PLUTO (Panama LJL Underwater Tropical Observatory) measures temperature, salinity, pressure, water velocity, chlorophyll, turbidity, oxygen, and light intensity in approximately $18 \mathrm{~m}$ of water off the southern coast of the island. There are considerable elevation changes throughout Canales de Tierra. The highest point is $100 \mathrm{~m}$ above sea level. Most of the island has steep rocky surfaces along the shore, but some embayments have cobble beaches with gentle slopes. The maximum tidal range is approximately $4.5 \mathrm{~m}$ (PLUTO 2010). There are two predominant seasons: the dry season, which typically runs from January through March, and the rainy season, which runs from May through November. December and April tend to be months of transition between the two seasons.

\subsubsection{Investigations of adult migrations and egg release behavior}

In March-April 2009, a transect study was conducted to determine whether adult migrations are related to rain. The transect path was a road that connects two sets of laboratory buildings on the island. It is $1 \mathrm{~km}$ long and approximately $3 \mathrm{~m}$ wide. It starts at 


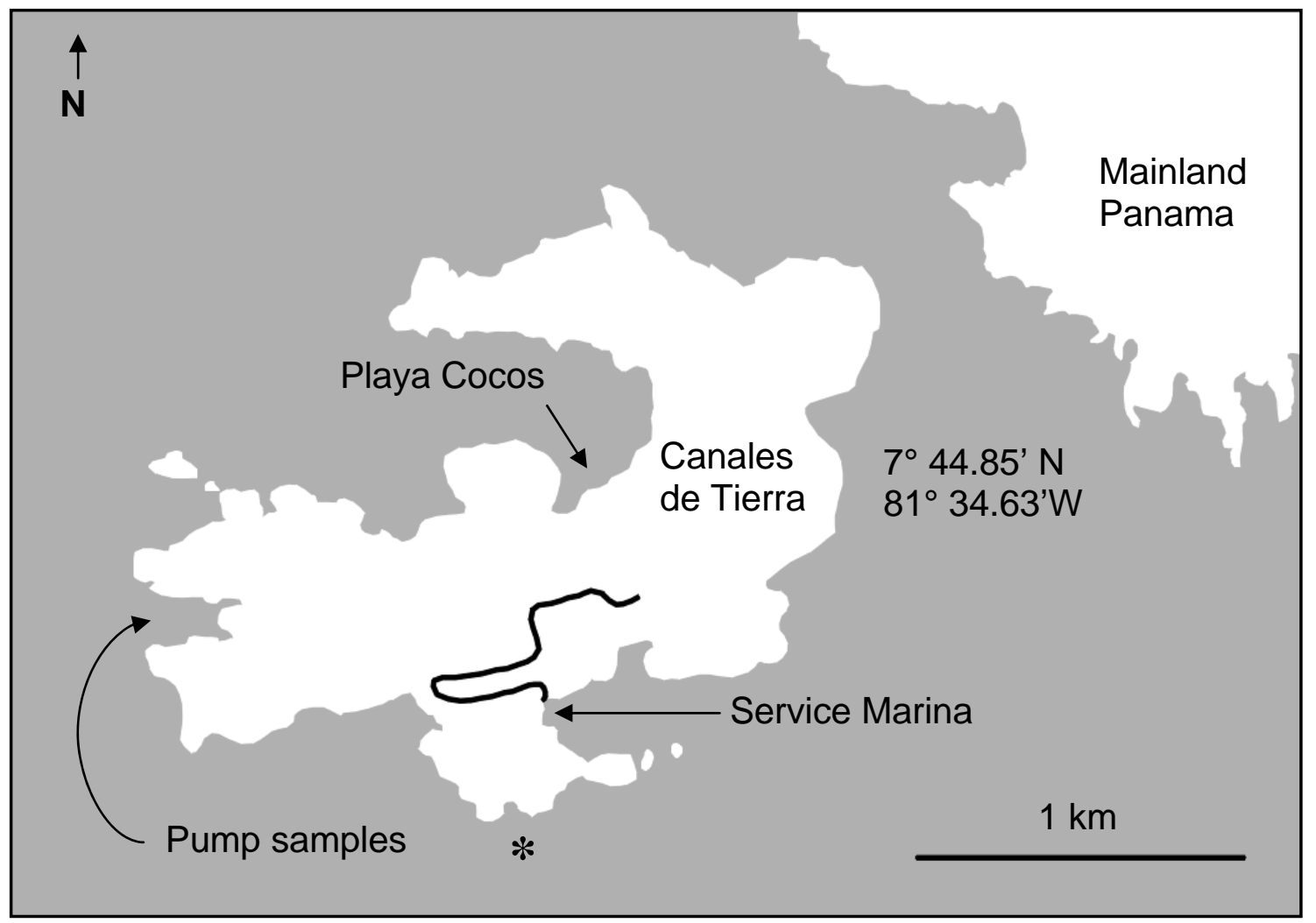

Figure 4.1. Location of the study. The black line on the island traces the path of the transect in the crab migration study. Two cobble beaches, Playa Cocos and Service Marina, were the sites of additional observations. The location of the PLUTO underwater observatory is indicated with the "*". Plankton samples were taken with pumps at the entrance of a small embayment on the western side of the island. 
an elevation of $\sim 50 \mathrm{~m}$ above sea level in the center of the island and runs down to the Service Marina on the southern end of the island (Fig 4.1). Along most of its length, it is bounded by earthen walls ranging in height from a few centimeters to $\sim 5 \mathrm{~m}$. The shorter walls are a result of terrain leveling during road construction, and the taller walls are naturally-occurring, very steep hillsides. The walls prevented crabs from escaping too quickly to be counted. Crabs often dug their burrows into the faces of the walls and were capable of climbing the walls easily to move between the road and the rainforest floor beyond. A transect run involved driving in a small vehicle and counting all the crabs that were on the road. The first run was on April 1. Then, from April 8 to April 29, they were performed daily between approximately 16:00 and 18:00.

Rainfall data came from two sources: one was a weather transmitter (Vaisala, model WXT510) installed on Canales de Tierra; the other was a weather station on the island of Coiba, $25 \mathrm{~km}$ away from the study site. The Coiba station is operated by the Gerencia de Hidrometeorología (Office of Hydrometeorology) of the Empresa de Transmisión Eléctrica (Electricity Transmission Company) in Panama. Rainfall data from Canales de Tierra were used whenever possible. However, from April 10 through April 14 the weather station malfunctioned, so data from the Coiba station were substituted for those dates.

To investigate whether the crabs released eggs at a specific time of day, 30minute observations were conducted 3 times per day at two beaches (Playa Cocos and Service Marina - Fig 4.1) where crabs had been seen in massive numbers in past years (Gyory, pers. obs.). During the observation periods, female crabs that were entering the water and performing the abdominal fanning behavior that accompanies egg release in 
land crabs (Gifford 1962; Wolcott and Wolcott 1982; Liu and Jeng 2007) were counted. Morning observations occurred between 8:00 and 10:00. Mid-day observations occurred between 12:00 and 14:00. Afternoon observations occurred immediately after the transect runs, between approximately 16:00 and 18:00. On three occasions (March 31, April 1, and April 14), evening observations were conducted between 20:00 and 22:00. Since the crabs are sensitive to light, noise, and movement, the observations were obtained while standing still in one place on the beach and using ambient light to observe their behavior.

The binomial test was used for statistical analysis. A crab emergence event was denoted as the crabs emerging after a period of at least 24 hours in which no crabs were observed. Then, the crab emergence events were counted and compared to the presence or absence of rain in the previous 24 hours. The null hypothesis was that crab emergence was unrelated to rain, so crab emergence would be preceded by rain $50 \%$ of the time. The alternative hypothesis was that rain was present within the 24 hours prior to crab emergence.

\subsubsection{General morphology and development rate of Gecarcinus quadratus larvae}

To determine the general morphology of the larvae and to obtain an estimate of the length of the planktonic phase, G. quadratus larvae were cultured in the laboratory in 2008. On March 19, 2008, it rained on Canales de Tierra. The following evening, large numbers of adults emerged from their burrows and migrated toward the shore. A gravid female was captured and kept in the laboratory overnight. The following day, eggs from her egg mass were removed and placed in a 1-L glass beaker filled with seawater 
obtained from a beach on the island. The seawater was filtered through $100-\mu \mathrm{m}$ mesh and sterilized with ultraviolet light. The water temperature throughout the culturing period was approximately $28^{\circ} \mathrm{C}$, and the salinity was $31-34 \mathrm{ppt}$. In the field, water temperature ranged from approximately $18^{\circ} \mathrm{C}$ near the bottom and approximately $30^{\circ} \mathrm{C}$ near the surface. Thus, the temperature of the cultures was near the upper limit of what the larvae can encounter. The culture beaker was placed near a window but away from direct sunlight. An air pump connected to a diffuser provided a gentle current and aeration. Once the larvae hatched, they were fed brine shrimp nauplii ad libidem. Half of the water volume was changed daily. The larvae were photographed and measured several times throughout the development period.

Field observations in March and April 2008 were also used to estimate the length of the planktonic phase. At the Service Marina beach (Fig 4.1), there were two observers who watched over the island 24 hours per day. The observers notified us when they saw (1) adult crabs approaching the water and (2) megalopae or juvenile crabs emerging from the water. Upon notification of such events, the author traveled to the beach to confirm the observations. It was assumed that the first major migration of megalopae onto land would consist of individuals that had been released locally.

4.2.4. Nearshore abundance of zoeas and megalopae in relation to rain, tidal phase, and turbidity

Investigation of whether adults released their eggs at a specific phase of the tide was difficult because light, noise, and movement triggered an escape response in adults 
and prevented direct observation of egg release. Surveying the beach would have required walking on gravel with a flashlight. The noise and light would have altered the behavior of the adults, so instead, the presence of zoeas was quantified in nearshore waters. G. quadratus eggs are released at night, they hatch immediately when they contact seawater, and the first-stage zoeas are strongly attracted to light (see Results). Thus, light traps were used at night to measure larval abundance near the location of egg release.

Light traps are commonly used in studies of zooplankton ecology, and there are many different designs in the literature (e.g., Meekan et al. 2001). Although light traps may not accurately estimate zooplankton densities, they can be useful in measuring relative larval supply (Meekan et al. 2000). The light traps used were made from 9.5-L air-tight transparent plastic containers (Fig 4.2) that were painted white and had three round openings near the top. When the light source was placed inside, the entire container glowed, but the brightest light came from the openings. The light source was a batteryoperated, waterproof LED tube $\left(\mathrm{Glo}^{-\mathrm{Toob}^{\mathrm{TM}}}\right)$. The light was placed at the bottom of each container so that once the zooplankton went inside they were less likely to exit the trap through the openings at the top. The traps were hung with the openings just below the water surface so that when they were pulled out for recovery there was minimal water loss through the openings. Two boats that were moored in the Service Marina served as the sampling platforms (Fig 4.1). On one boat there were two light traps that were hung from the bow and stern, $6.5 \mathrm{~m}$ apart. A third light trap was hung from a boat that was 27 $\mathrm{m}$ away from the first boat. The boats were approximately 50-75 $\mathrm{m}$ away from the beach where the crabs released their eggs. 


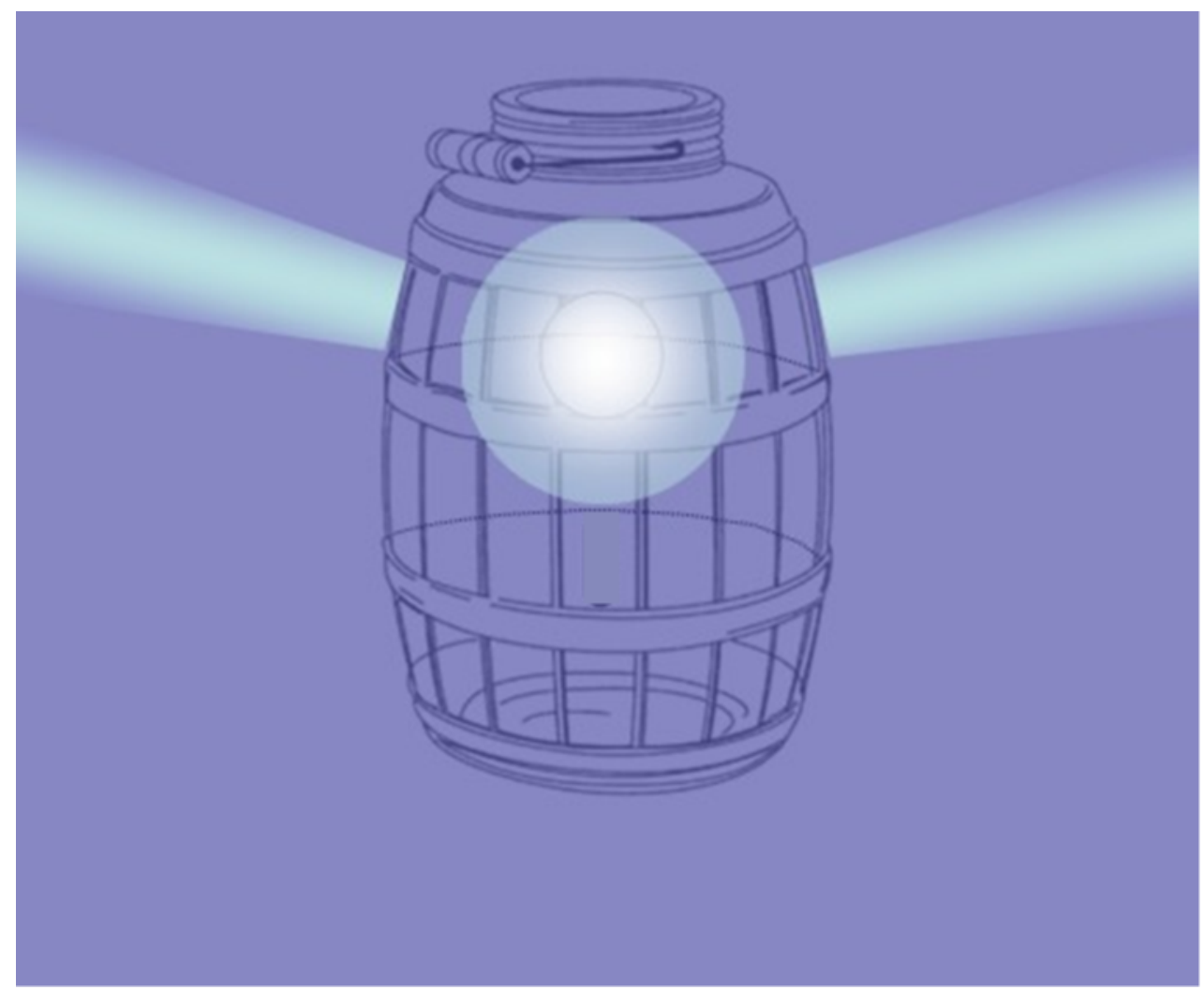

Figure 4.2. Light trap design. Light shines from three holes near the top of a 9.5-L plastic container. Placing the light source near the bottom of the trap decreased the probability that zooplankton would exit through the openings once they were inside. 
Sampling was done nightly from April 5, 2007 until April 26, 2007, with the exception of four nights in which severe weather did not allow it. When sampling, the light traps were emptied hourly from approximately 21:00 until 3:00. The contents were filtered through $100 \mu \mathrm{m}$ mesh and preserved in $4 \%$ formalin buffered with sodium tetraborate decahydrate (Borax). In the laboratory, a dissecting microscope was used to identify and count the zooplankton. All of the samples from one of the light traps were examined, and samples from the other two light traps were sometimes used for comparison with the first to determine the sampling variability.

Tidal height predictions were used because there were no in situ data of observed tide levels for the time period of this study. The source for tide data was the National Oceanographic and Atmospheric Administration tide prediction webpage for Bahia Honda, Veraguas, Panama, which is approximately $5 \mathrm{~km}$ away from Canales de Tierra (NOAA 2009). Also examined were the turbidity levels throughout the time series, since turbidity affects the distance that light can travel underwater, and thus it can alter the effectiveness of a light trap. Turbidity measurements were from a turbidimeter (Model 66000EDSM, YSI Industries) located at $3 \mathrm{~m}$ above bottom on the PLUTO observatory (PLUTO 2010). It measured turbidity in Nephelometric Turbidity Units (NTU) every 4 seconds.

\subsubsection{Zoea abundance in relation to the internal tide and internal waves}

To determine whether G. quadratus zoea abundance is related to the internal tide or to internal wave activity, the temperature structure of the water column was tracked for 
three weeks between April 3, 2009 and May 2, 2009. Additionally, several highfrequency series of plankton samples were obtained near the surface and near the bottom on 16 days between those two dates. In total, 110 samples were collected from each water depth. The concentrations of zoeas during different phases of the internal tide were compared. Also compared were the concentrations of zoeas during the passage of internal waves to periods when there was no internal wave activity.

The sampling station was a slight embayment on the western end of the island $\left(7^{\circ}\right.$ $\left.44.445^{\prime} \mathrm{N}, 81^{\circ} 34.809^{\prime} \mathrm{W}\right)$. This location was chosen because local people reported that slicks on the water surface (often a manifestation of internal wave activity) propagate from west-southwest to east-northeast in this region. Furthermore, the sampling station was relatively protected from the strong northwest-southeast tidal currents. This minimized the risk that the mooring of thermistors being used to monitor the passage of the waves would be swept away by the currents, and it permitted a small boat to be anchored nearby to sample the plankton. The water depth at the lowest spring tide was $20 \mathrm{~m}$.

The thermistor mooring consisted of five temperature recorders (Sea-Bird Electronics, model SBE 39) placed at 3, 5, 7, 11, and 15 meters above bottom. The instruments recorded water temperature every 30 seconds from April 3, 2009 until May 2, 2009. To determine whether strong changes in temperature had a characteristic scale, a power spectral density estimate of the temperature time series from the sensor at $3 \mathrm{~m}$ above bottom was created with Matlab software. The spectrum was created by using the Welch method with a 7-day hanning window and 50\% overlap. The largest peak and its frequency (in cycles day ${ }^{-1}$ ) was identified. 
Zooplankton were sampled at a depth of 1 meter above bottom and 1 meter below surface with two pumps (Pondmaster) that hung from a small anchored boat. The pumps were designed to function at a rate of approximately $16 \mathrm{~L} \mathrm{~min}^{-1}$, but the exact volume of water pumped was measured with flow meters (Great Plains Industries). Water was pumped into PVC filtering canisters with $100 \mu \mathrm{m}$ mesh windows. Approximately every 20 minutes, the filtering canisters were replaced and the full ones emptied into jars that were kept on ice inside a cooler until they could be brought into the laboratory. Sampling typically was done from 09:00 until 12:00. Then, in the afternoon, the organisms from the samples were identified and counted using a dissecting microscope while they were still alive.

\subsection{Results}

\subsubsection{Investigations of adult migrations and egg release behavior}

Large numbers of adult crabs emerged from their burrows after rain events (Fig 4.3). Few or no crabs emerged when there were multiple days without rain. The author arrived on the island on March 31 2009, but according to local people, the crabs had also emerged en masse on March 20 and March 30. Seven events were observed in which crabs emerged after being absent for at least one day (March 20 and 30, April 1, 12-19, 22, 24, and 28). All of the crab emergence events coincided with periods of rain within the previous 24 hours. The binomial probability was 0.0078 , thus leading to the rejection of the null hypothesis that the emergence of crabs is unrelated to rain. 


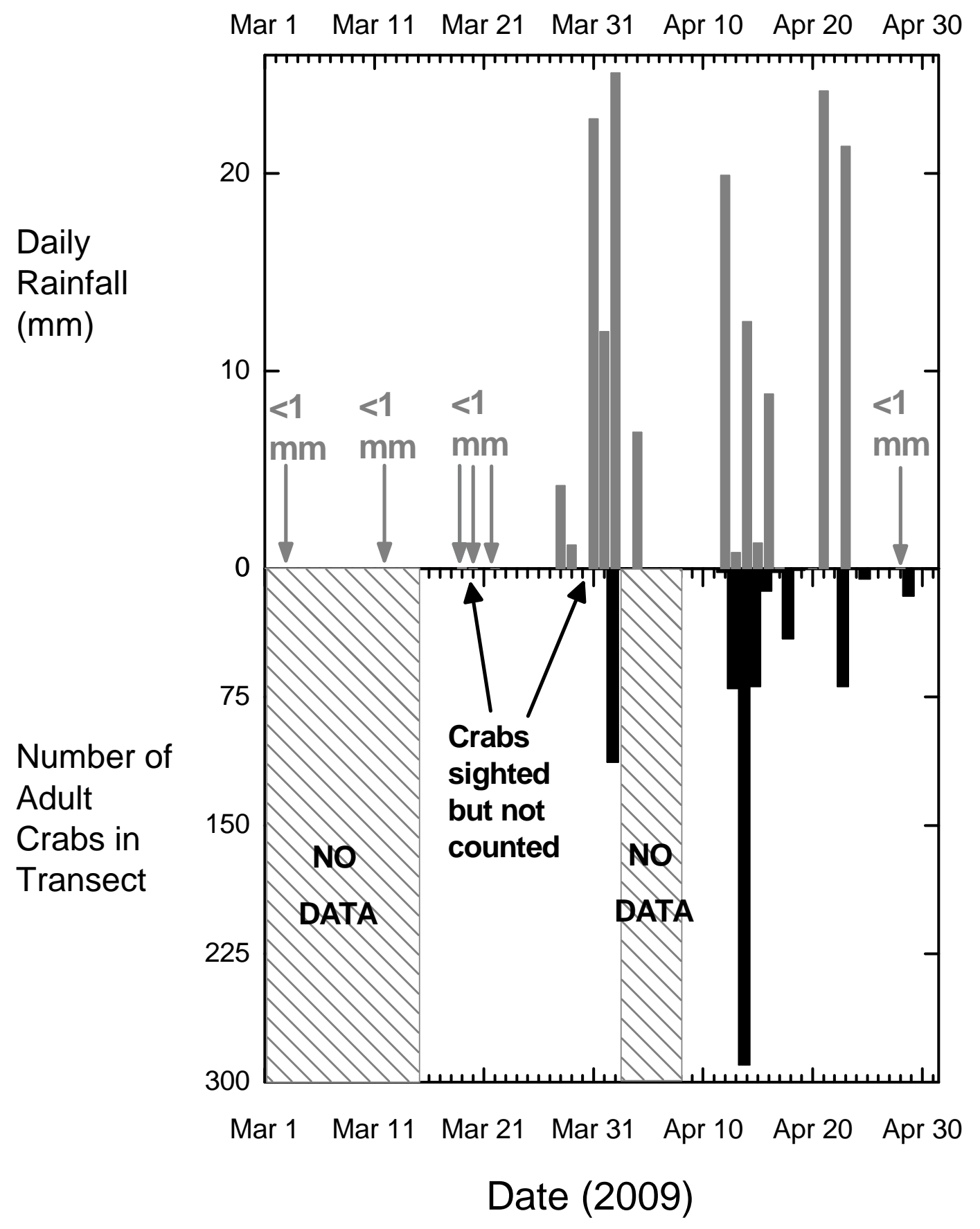

Figure 4.3. Relationship between rainfall (upper panel) and the number of adult Gecarcinus quadratus found outside their burrows (lower panel). Rainfall amounts of less than $1 \mathrm{~mm}$ are indicated with arrows in the top panel of the figure. Local people indicated that crabs had emerged in massive numbers on March 20 and March 30. These events are indicated with arrows in the bottom panel. 
When the crabs emerged from their burrows, many of them headed down to the beaches. Males and females were observed engaging in a behavior known as "dipping". When dipping, adults immerse their legs in tide pools or stand on the shore, where waves wash over them (Hicks 1985; Hicks et al. 1990; Greenaway 1994; Foale 1999). While migrating to the coast, the crabs experience a substantial decrease in the osmolality of their hemolymph. Dipping their bodies in seawater allows the ion concentrations in their hemolymph to recover to normal levels (Greenaway 1994). Although dipping was observed in the daytime, females never released eggs during the morning, mid-day, or afternoon observation periods. However, on all three of the evening observation periods, females were observed performing abdominal fanning leading to egg release.

\subsubsection{General morphology and development rate of Gecarcinus quadratus larvae}

Ripe Gecarcinus quadratus eggs hatched immediately upon contact with seawater. The carapace width of first-stage zoeas was approximately $400 \mu \mathrm{m}$ (not including the lateral spines) (Fig. 4.4). Zoeas had long (relative to body size) dorsal and rostral spines, and also a pair of lateral spines. Spines were capable of re-growth after breaking. The larvae were heavily pigmented with reddish-brown and black coloration. Seventeen days after hatching, carapace width (not including lateral spines) was approximately $2.5 \mathrm{~mm}$. Only a single larva from the cultures survived to the megalopa stage, reaching it on the $21^{\text {st }}$ day after hatching. The megalopa did not survive to the juvenile stage. Measuring the length of zoeal stages would have required rearing the larvae in individual containers and 

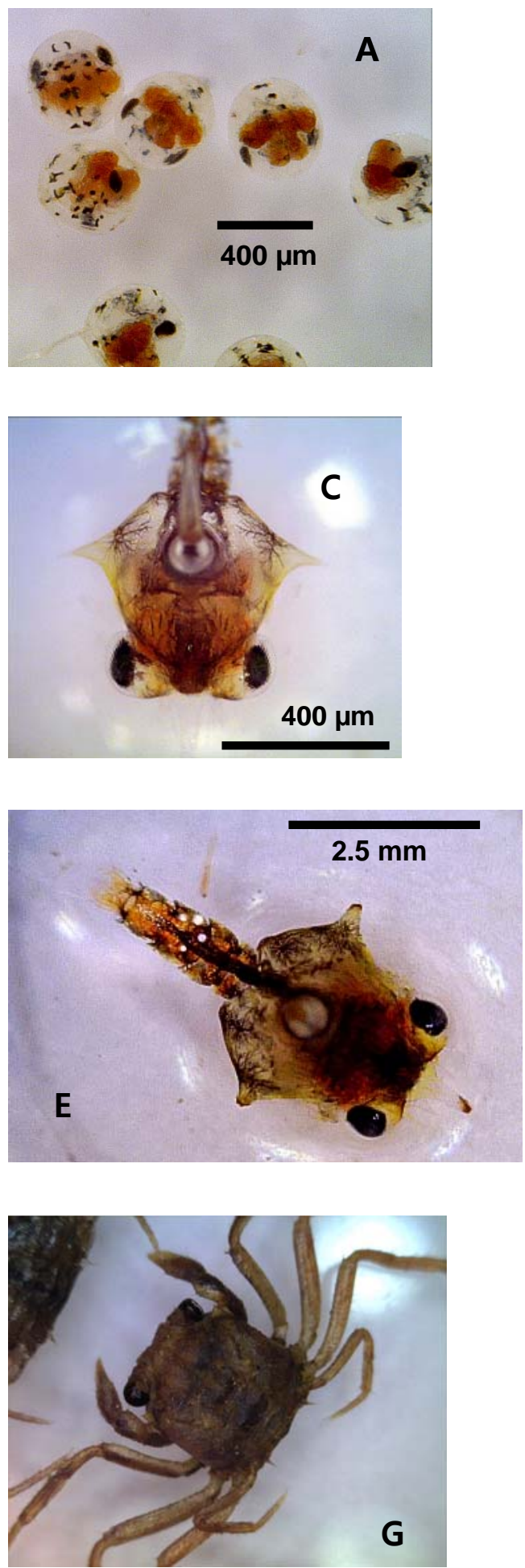
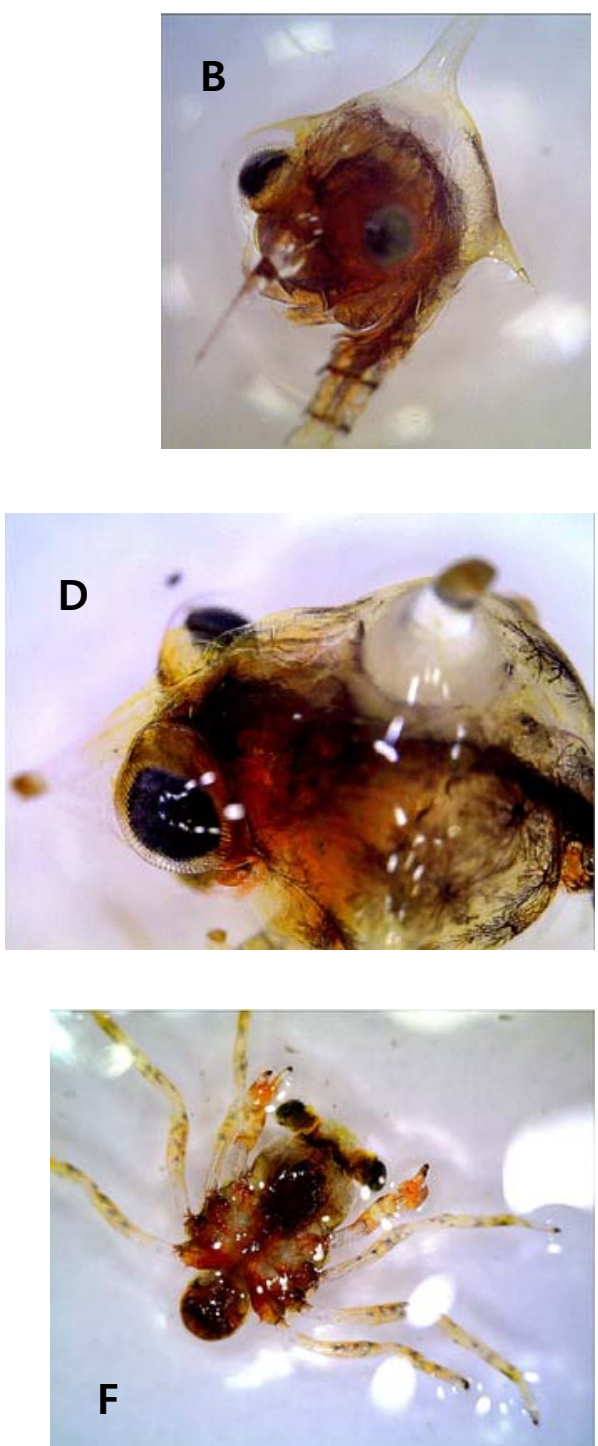

Figure 4.4. Development of Gecarcinus quadratus larvae in the laboratory.(A) Eggs. (B) Zoea, one day after hatching. (C) Zoea, one day after hatching, viewed from above. (D) Zoea, seventeen days after hatching, regrowing a broken dorsal spine. (E) Zoea, seventeen days after hatching, viewed from above. (F) Megalopa, 21 days after hatching. (G) One of many juvenile crabs found alongside megalopae traveling from shore to the rainforest. 
noting when a molt was observed. Since the larvae in this study were batch-cultured, it was not possible to measure the length of individual zoeal stages.

The evening after a rain event on March $4^{\text {th }}, 2008$, adult crabs were observed migrating en masse to the water. Thirty days later, large numbers of megalopae and megalopae-sized juveniles were observed on the shore of the Service Marina beach (Fig. 4.5). The megalopae were identified as G. quadratus.

4.3.3. Nearshore abundance of zoeas and megalopae in relation to rain, tidal phase, and turbidity

Gecarcinus quadratus zoea abundance showed a positive relationship with rainfall amounts (Fig 4.6). Most light trap samples that were taken within 24 hours of a rain event contained a substantial number of crab zoeas. In contrast, during the rainless period from April 16 to April 19, zoea abundance was near zero. Megalopa abundance was much less than zoea abundance (Fig 4.7). While the highest number of zoeas in one sample was 11200 , the highest number of megalopae in one sample was 24. Megalopa abundance did not appear to be related to rainfall amounts, since a small number of them were captured in almost every night of sampling.

Zoea abundance also varied during different phases of the tidal cycle (Fig 4.8). After pooling all the data from the light trap time series, the mean number of zoeas during flood tides (hours 1 through 5) was $177.6(n=36, \mathrm{SD}=422.4)$, and the mean number of zoeas during the ebb tides (hours 7 through 11$)$ was $1451.0(n=35, \mathrm{SD}=$ 2470.9). The difference between the two means was statistically significant (two-sample 


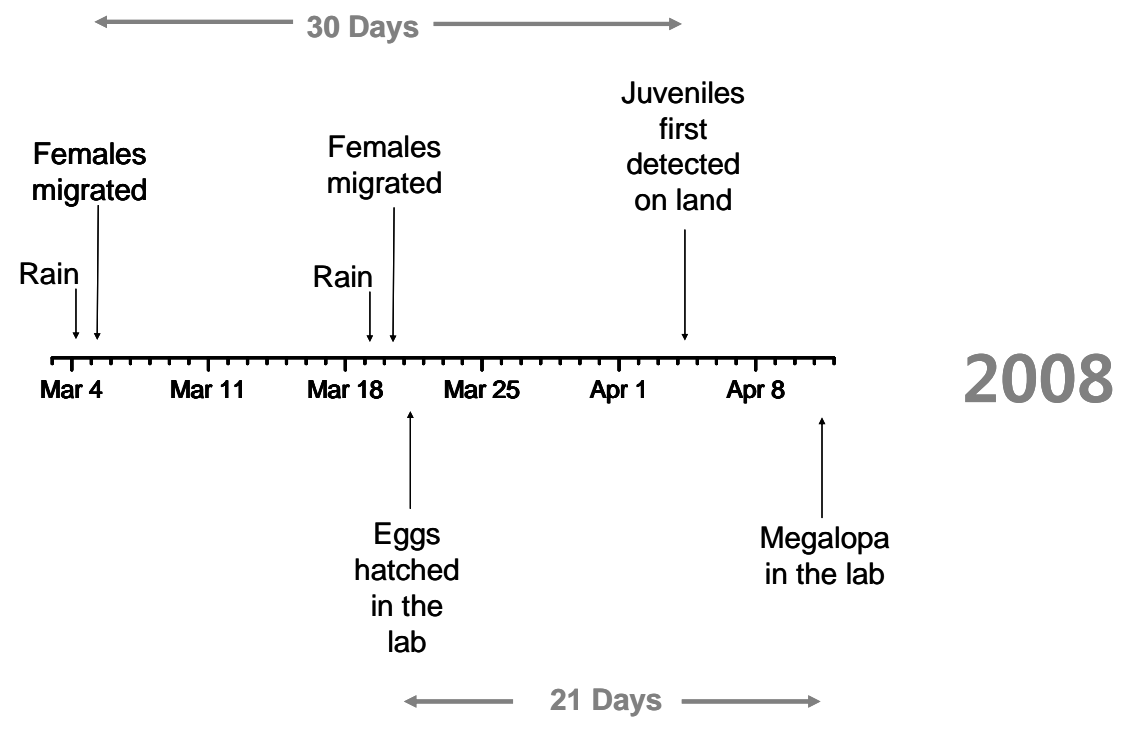

Figure 4.5. Timeline for the development of Gecarcinus quadratus larvae in the field (top) and in the laboratory (bottom). The evening after a rain event on March $4^{\text {th }}$, adult crabs were observed making a mass migration to the water. 30 days later, large numbers of megalopae and megalopae-sized juveniles were observed on the shore of the Service Marina beach. It is no known whether there were release events before the beginning of the observation period. Eggs were collected from females that migrated to the water after the March $19^{\text {th }}$ rain event. The eggs hatched on March $21^{\text {st }}$. A single individual from the cultures made it to the megalopa stage, and it did so on April $11^{\text {th }}, 21$ days later. 


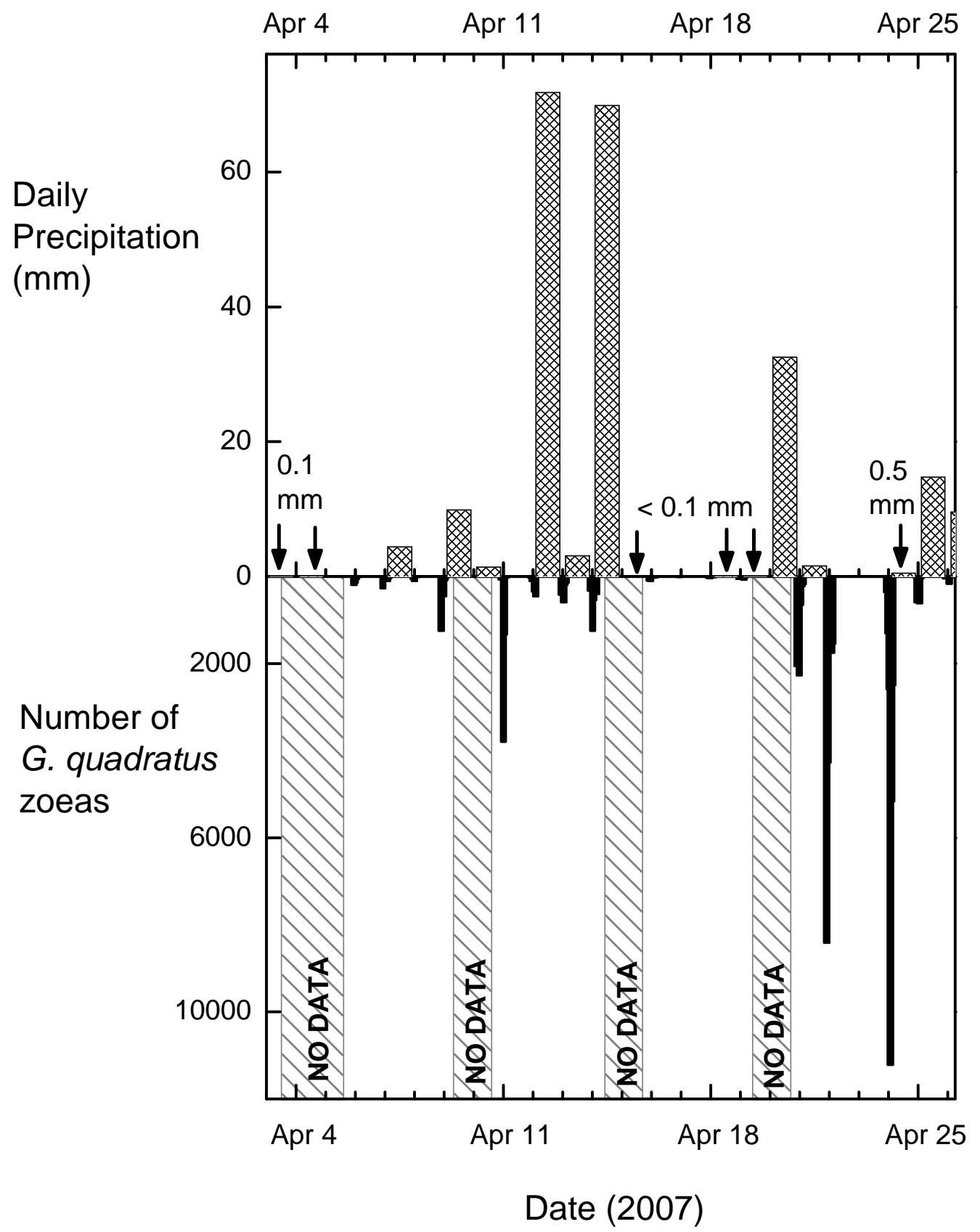

Figure 4.6. Time series of precipitation (top panel) and Gecarcinus quadrauts zoea abundance as measured by nearshore light traps (bottom panel). On April 3 and April 4 it rained approximately $0.1 \mathrm{~mm}$; on April 15, 18, and 19 it rained less than $0.1 \mathrm{~mm}$; and on April 24 it rained $0.5 \mathrm{~mm}$. These rain events are indicated with arrows. Zoea sampling began on April $5^{\text {th }}$, and there were four nights in which sampling was not possible. 


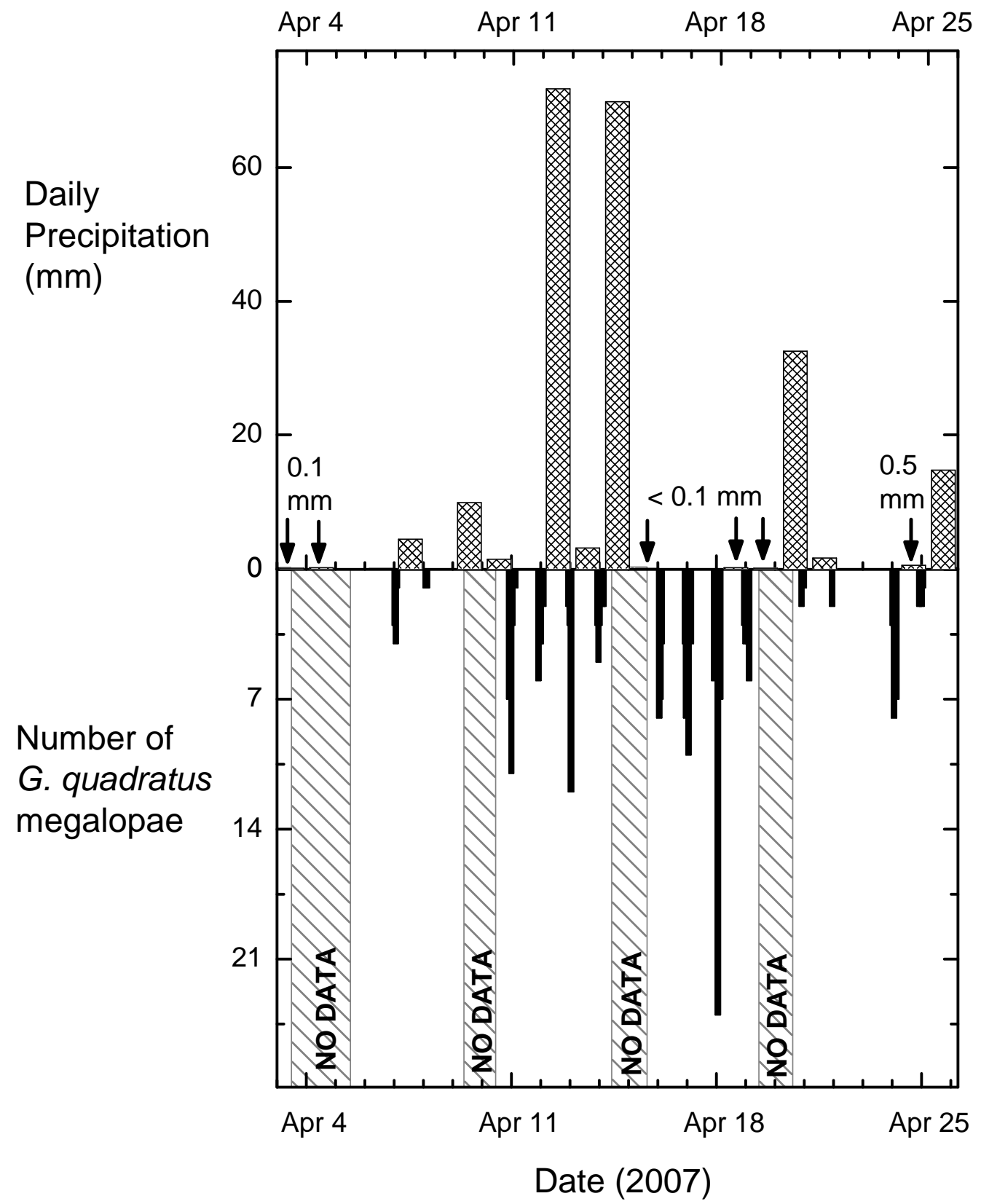

Figure 4.7. Time series of precipitation (top panel) and Gecarcinus quadrauts megalopa abundance as measured by nearshore light traps (bottom panel). On April 3 and April 4 it rained approximately $0.1 \mathrm{~mm}$; on April 15, 18, and 19 it rained less than $0.1 \mathrm{~mm}$; and on April 24 it rained $0.5 \mathrm{~mm}$. These rain events are indicated with arrows. Megalopa sampling began on April $5^{\text {th }}$, and there were four nights in which sampling was not possible. 


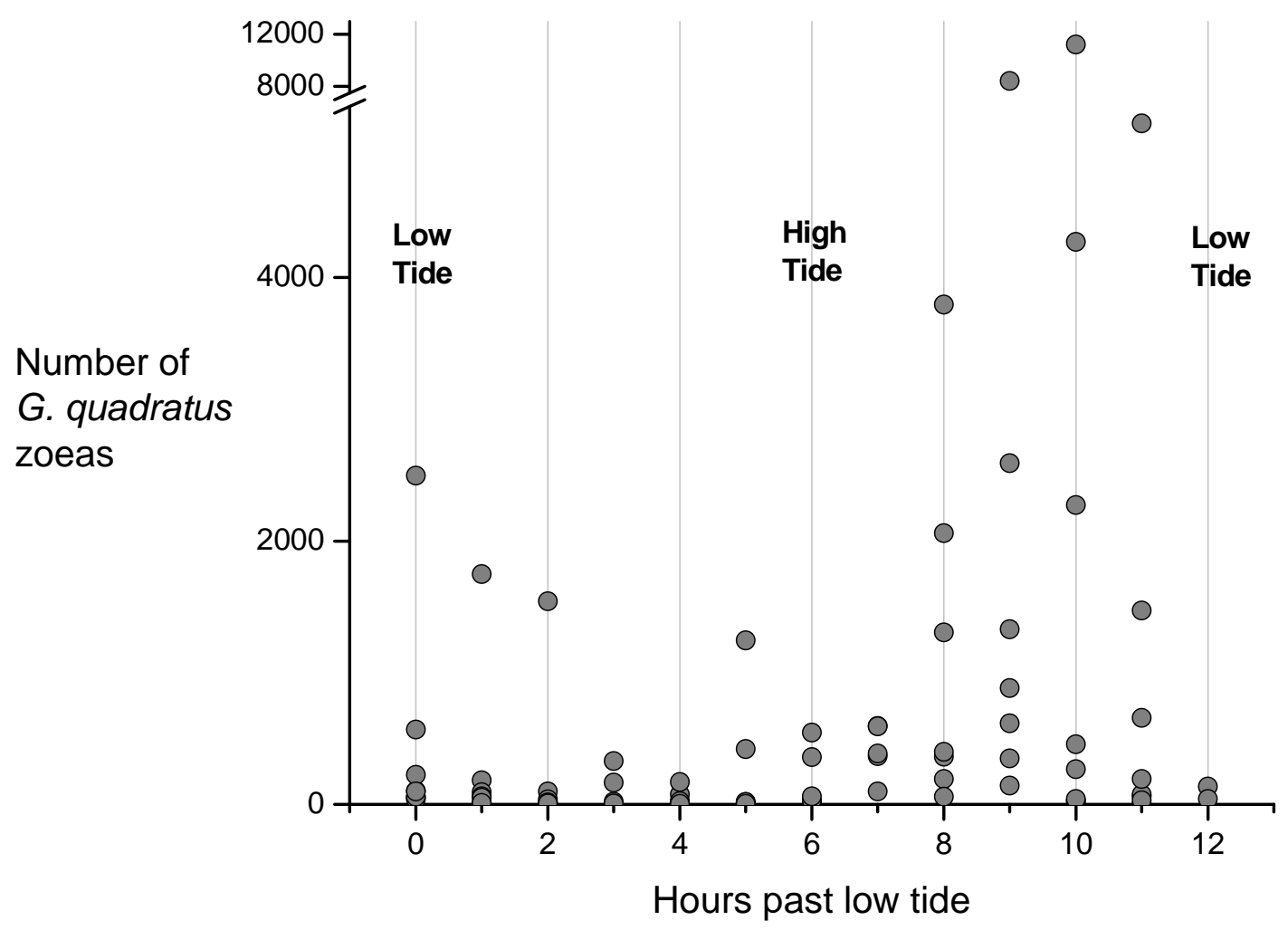

Figure 4.8. Gecarcinus quadratus zoea abundance, as measured by light traps, during different phases of the tidal cycle. The data here are pooled from a three-week time series. The mean number of zoeas during the flood tide (hours 1 through 5) was $177.6(n=36$, $\mathrm{SD}=422.4$ ). The mean number of zoeas during the ebb tide (hours 7 through 11) was $1451.0(n=35, \mathrm{SD}=2470.9)$. The difference between the two means was statistically significant (two-sample $t$-test, $p=0.003$ ). 
$t$-test, $p=0.003)$. G. quadratus megalopa abundance, on the other hand, did not vary during different phases of the tidal cycle (Fig 4.9). The mean number of megalopae during flood tides was $2.9(n=36, \mathrm{SD}=4.7)$, and the mean number of megalopae during ebb tides was $2.3(n=35, \mathrm{SD}=3.0)$. A two-sample $t$-test showed no significant difference between the two means ( $p=0.487$ ).

Overall, turbidity levels were frequently high in this location, but zoea abundance does not seem to be related to turbidity levels (results not shown).

\subsubsection{Zoea abundance in relation to the internal tide and internal waves}

Zoea abundance was generally low in the samples taken by pump. The highest concentration of zoeas in one sample was 2.06 individuals $\mathrm{L}^{-1}$ at the surface and 1.17 individuals $\mathrm{L}^{-1}$ at the bottom. At the time that the highest concentration occurred near the surface, the thermocline was at approximately $12.5 \mathrm{~m}$ depth, and there was no evidence of internal waves of elevation (Fig 4.10). When the highest concentration occurred near the bottom, the thermocline was deep and there was evidence of high-frequency internal waves, but zoea abundance was not high in the observation periods immediately before and after the high-abundance sample (Fig 4.11). The mean volume of water filtered for each sample was $4.82 \mathrm{~L}(\mathrm{SD}=0.43)$ at the surface and $3.40 \mathrm{~L}(\mathrm{SD}=0.28)$ at the bottom.

The power spectral density estimate of the temperature time series had a peak at 12.4 hours, which is the $M_{2}$, or principal lunar semidiurnal, tidal constituent (Fig 4.12). Although the temperature variability had a semidiurnal signal, it did not correspond with the surface tide, suggesting that the pattern observed could be due to the internal tide. 


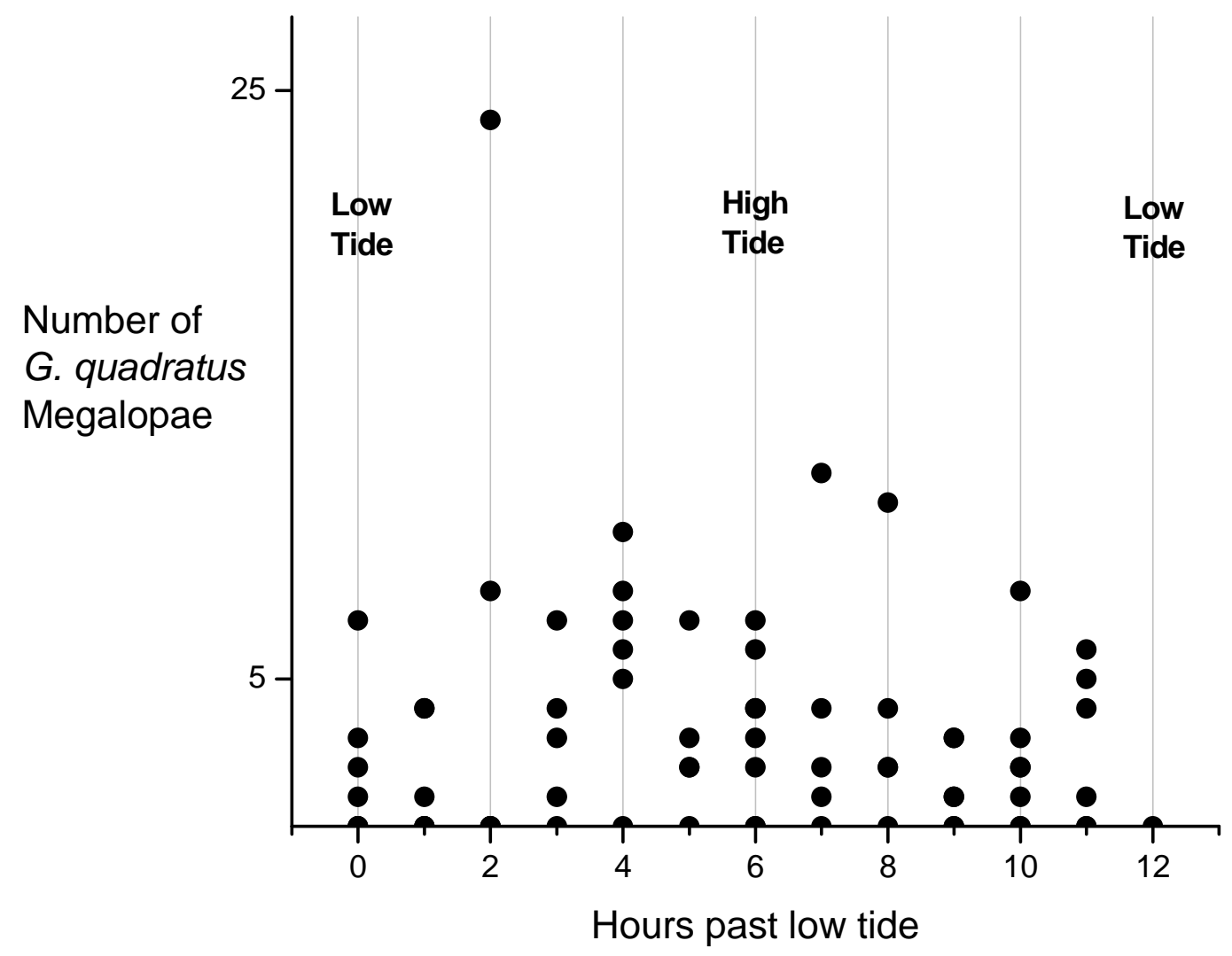

Figure 4.9. Gecarcinus quadratus megalopa abundance, as measured by light traps, during different phases of the tidal cycle. The data here are pooled from a three-week time series. The mean number of megalopae during the flood tide (hours 1 through 5) was $2.9(n=36, \mathrm{SD}=4.7)$. The mean number of megalopae during the ebb tide (hours 7 through 11) was $2.3(n=35, \mathrm{SD}=3.0)$. The difference between the two means was not statistically significant (two-sample $t$-test, $p=0.487$ ). 


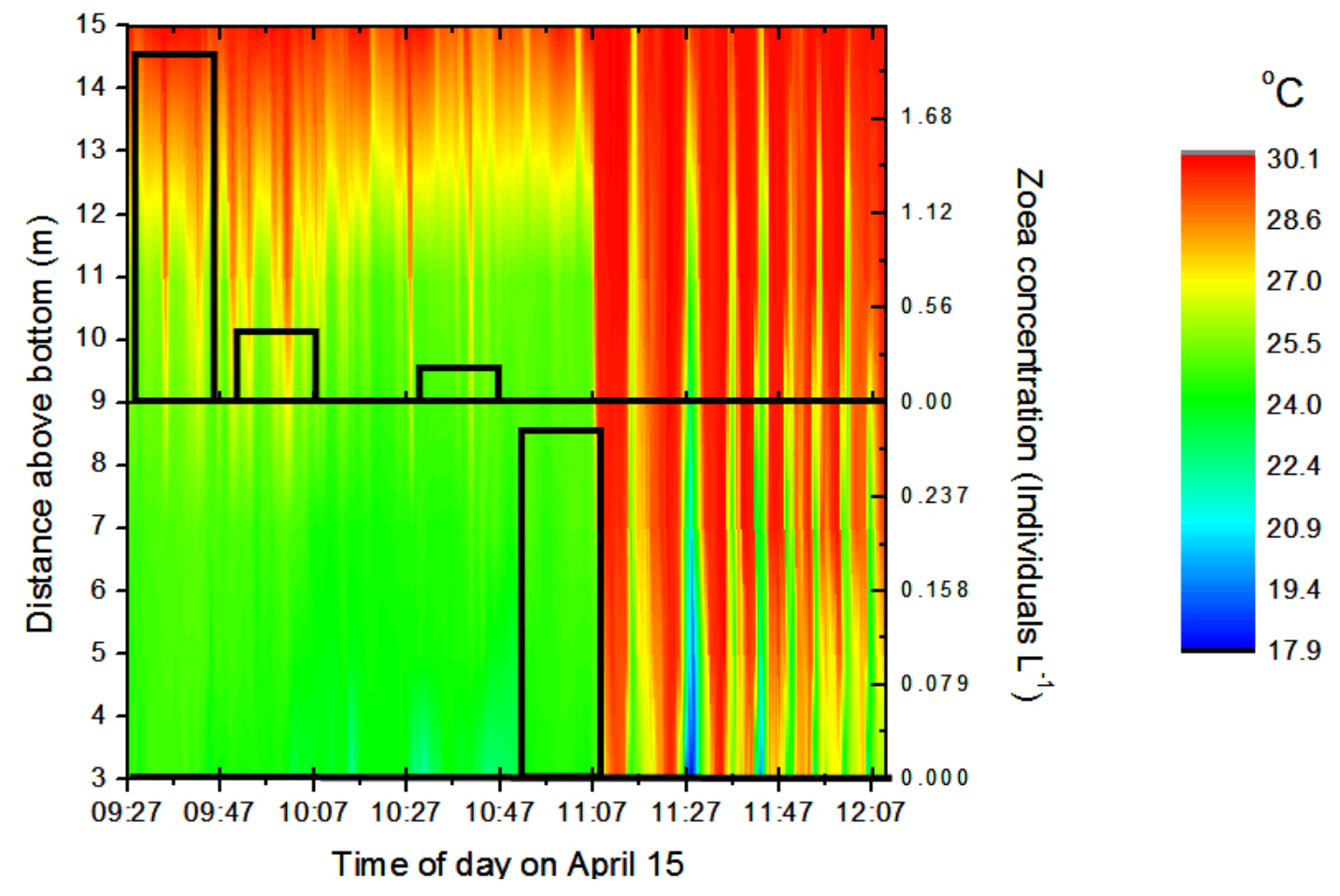

Figure 4.10. Temperature contour plot of the water column during the April 15, 2009 plankton sampling period. The zoea concentration near the surface (top panel) and the zoea concentration near the bottom (bottom panel) are overlaid on the temperature contour plot. The highest near-surface concentration of zoeas occurred between 9:27 and 9:47. 


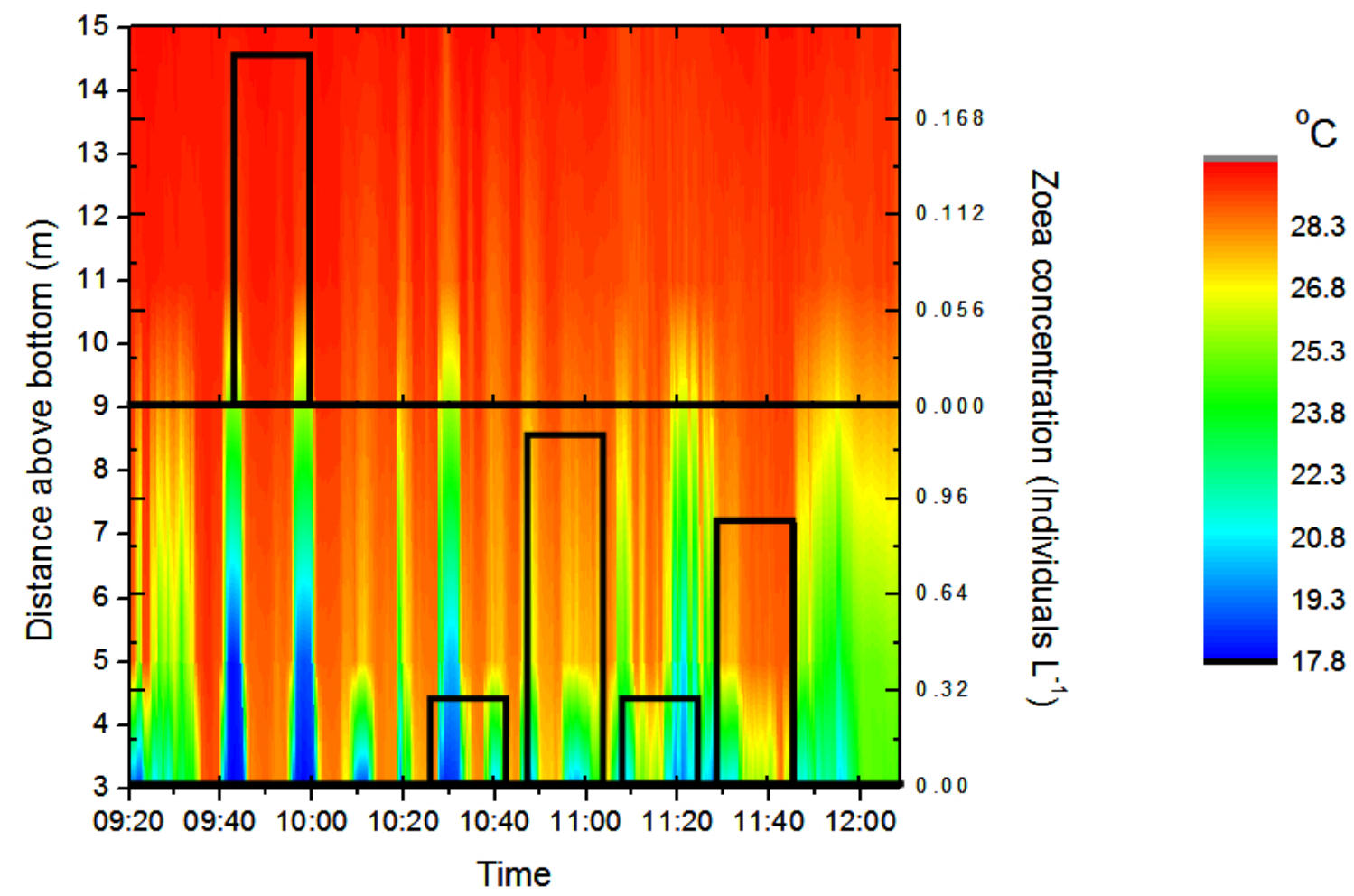

Figure 4.11. Temperature contour plot of the water column during the April 8, 2009 plankton sampling period. The zoea concentration near the surface (top panel) and the zoea concentration near the bottom (bottom panel) are overlaid on the temperature contour plot. The highest near-bottom concentration of zoeas occurred between 10:45 and 11:05. 


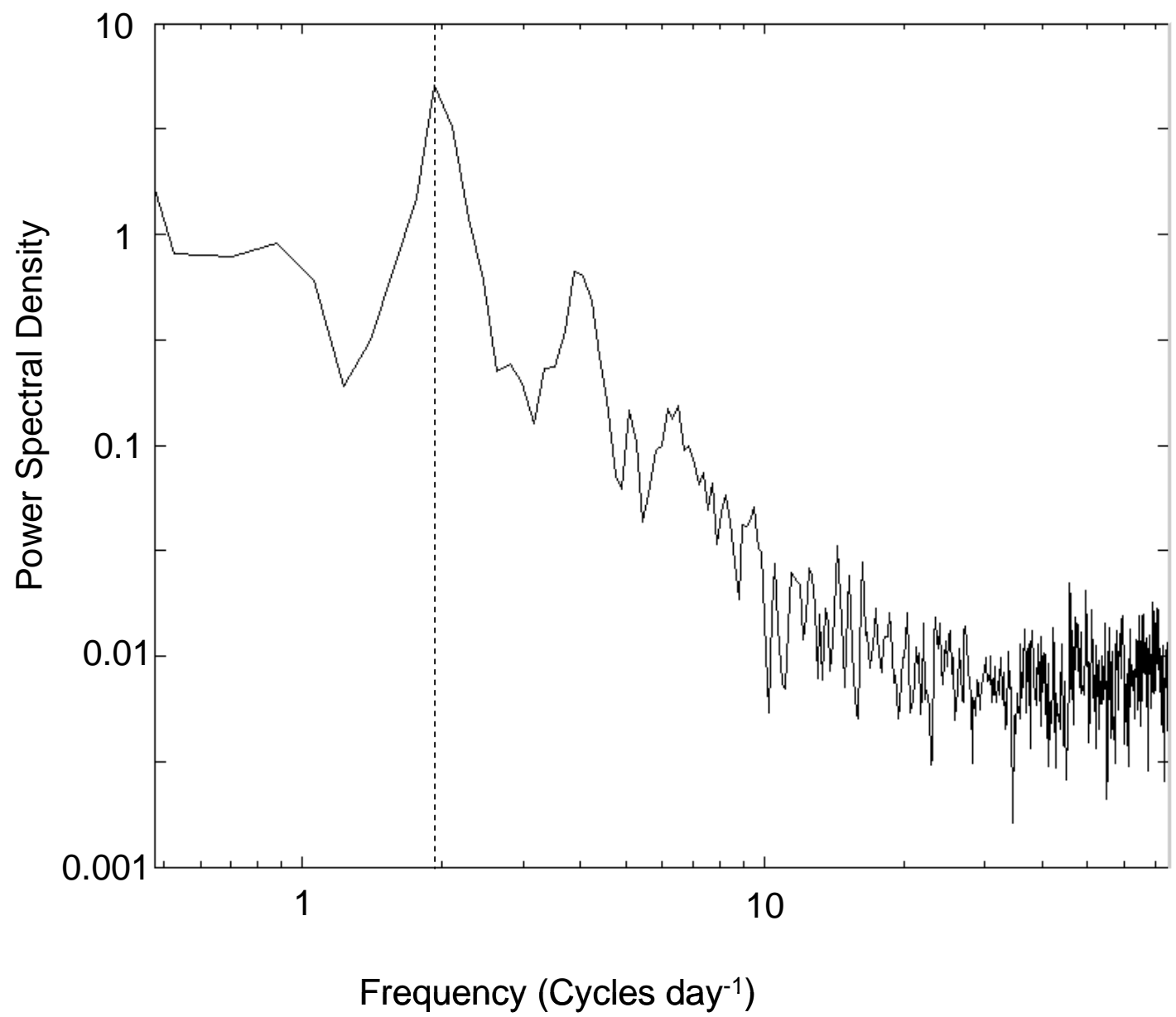

Figure 4.12. Power spectral density estimate of the temperature time series from the sensor at $3 \mathrm{~m}$ above bottom in April 2009. The spectrum was created by using the Welch method with a 7-day hanning window and 50\% overlap. The vertical dashed line indicates the $M_{2}$ frequency. 
Internal tidal bore warm fronts are identified by a sudden increase in bottom temperature by as much as $10.9^{\circ} \mathrm{C}$ in 4 minutes, and these changes often occurred semidiurnally (Fig 4.13). The warm fronts were typically followed by a period of large-range, highfrequency temperature fluctuations (internal waves) (Fig 4.10, 4.11, 4.13), followed by a period of cold water (Fig 4.13).

Zoea abundance appeared to be related to the phase of the internal tide. Near the surface, high zoea abundance was clustered at approximately 5 and 11 hours after a warm front (Fig 4.14). The differences were statistically significant (ANOVA, $p=0.015$ ), but only between the hour 2-4 interval and the hour 10-12 interval (multiple comparisons test of the means). Near the bottom, zoea abundance did not differ with regards to the phase of the internal tide (ANOVA, $p=0.498$ ) (Fig 4.14). Zoea abundance did not appear to be related to the phase of the surface tide (Fig 4.15) nor to the time of day during these morning samples (Fig 4.16).

\subsection{Discussion}

4.4.1. Timing of egg release in Gecarcinus quadratus and morphology and development rate of the larvae

Synchronized reproduction can occur in a population when the optimal environmental conditions for the survival of adults or propagules (or both) occur within a narrow time frame (Giese and Kanatani 1987; Morgan and Christy 1995). Gecarcinus quadratus females on Canales de Tierra synchronized their egg release by utilizing rain, 


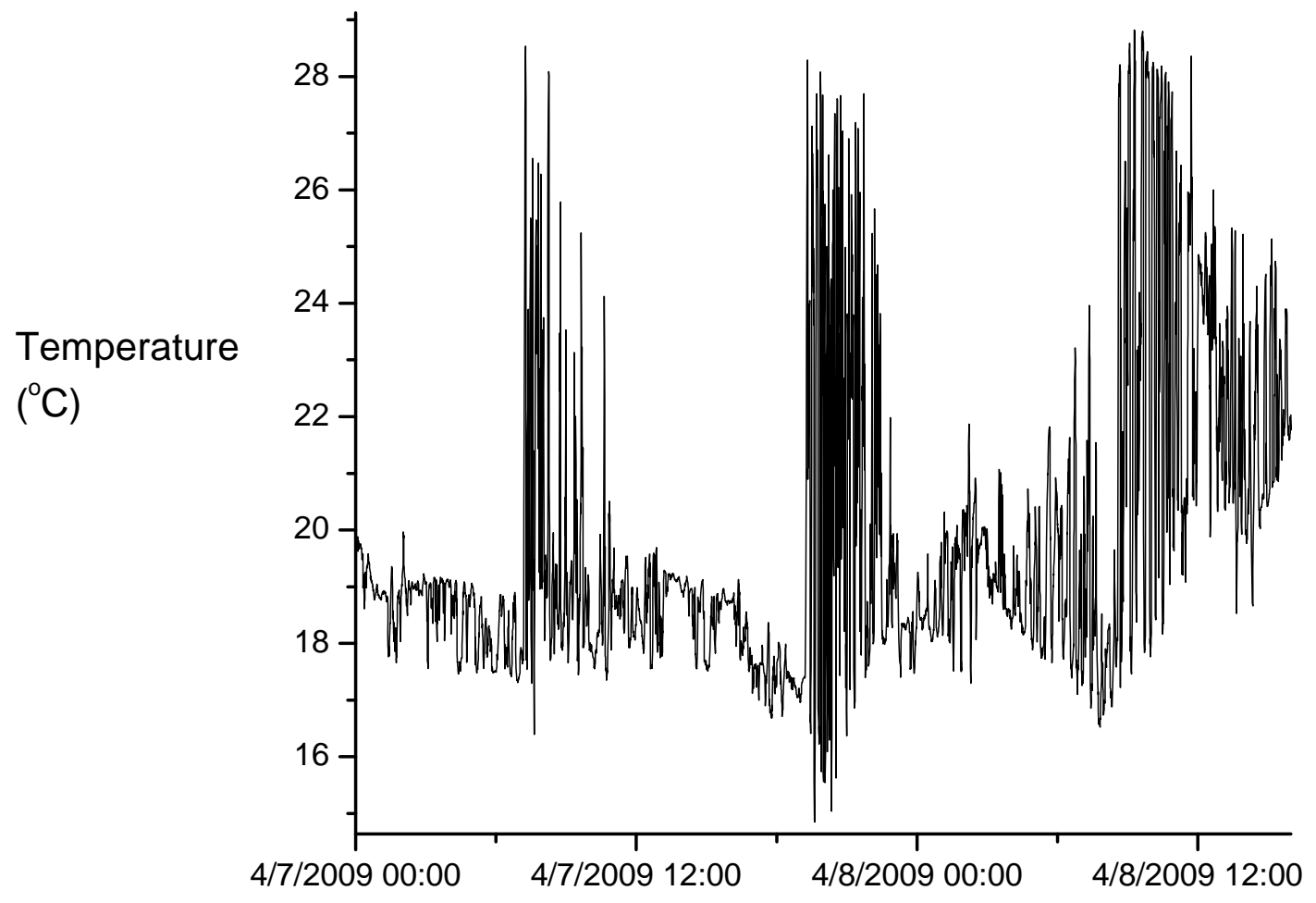

Figure 4.13. Temperature at 3 mab. This portion of the temperature time series showcases three representative examples of the warm fronts, in which water temperature increases approximately $11^{\circ} \mathrm{C}$ on the order of minutes. Warm fronts were typically followed by wide-ranging, high-frequency temperature fluctuations, and then a period of cold temperature. 


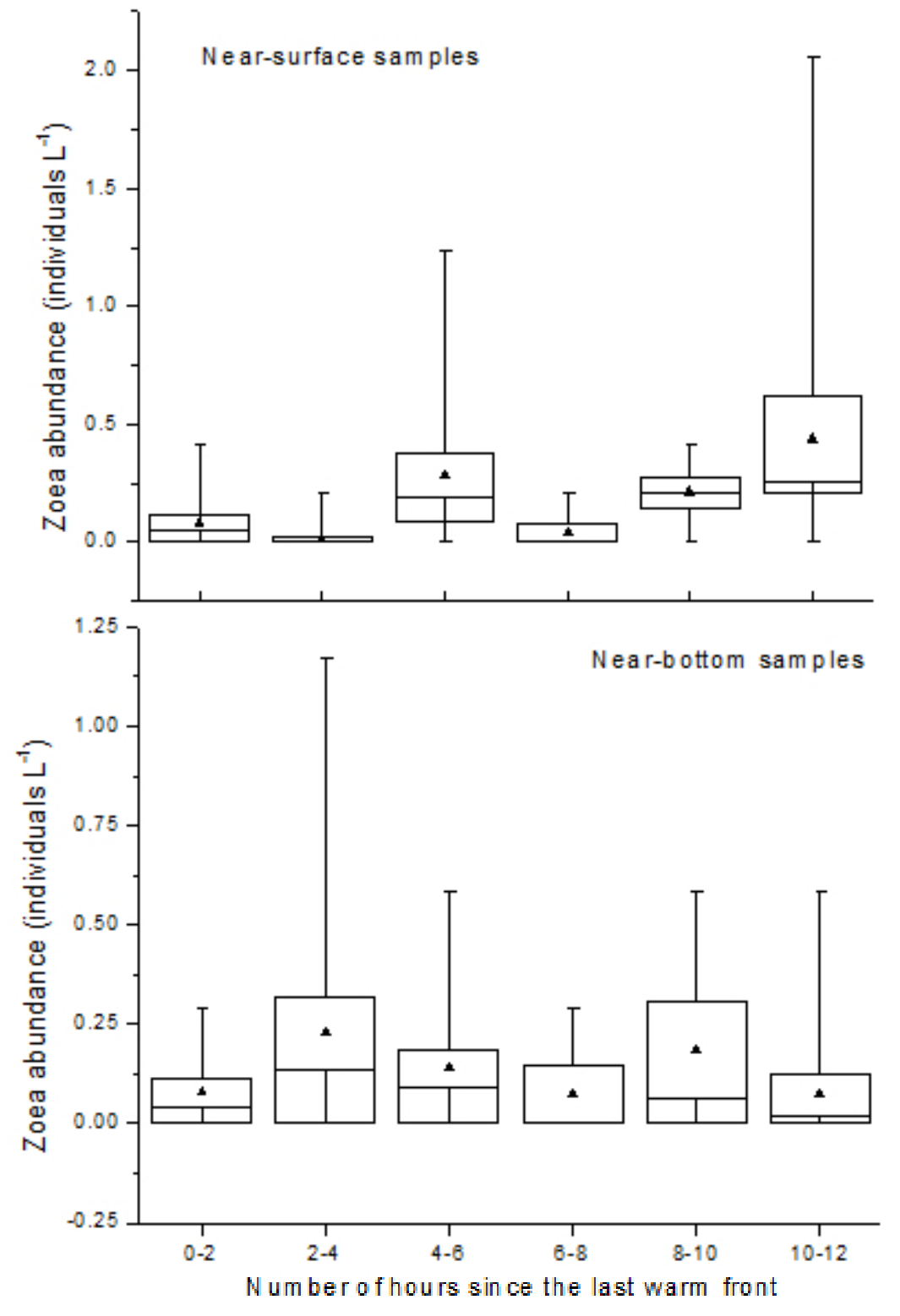

Figure 4.14. Abundance of Gecarcinus quadratus zoeas in relation to the phase of the internal tide. The zoea samples were collected over the course of three weeks and pooled together and averaged over 2-hour periods. Triangles represent the means, boxes represent the median and standard error of the mean, and whiskers represent the minimum and maximum values. 

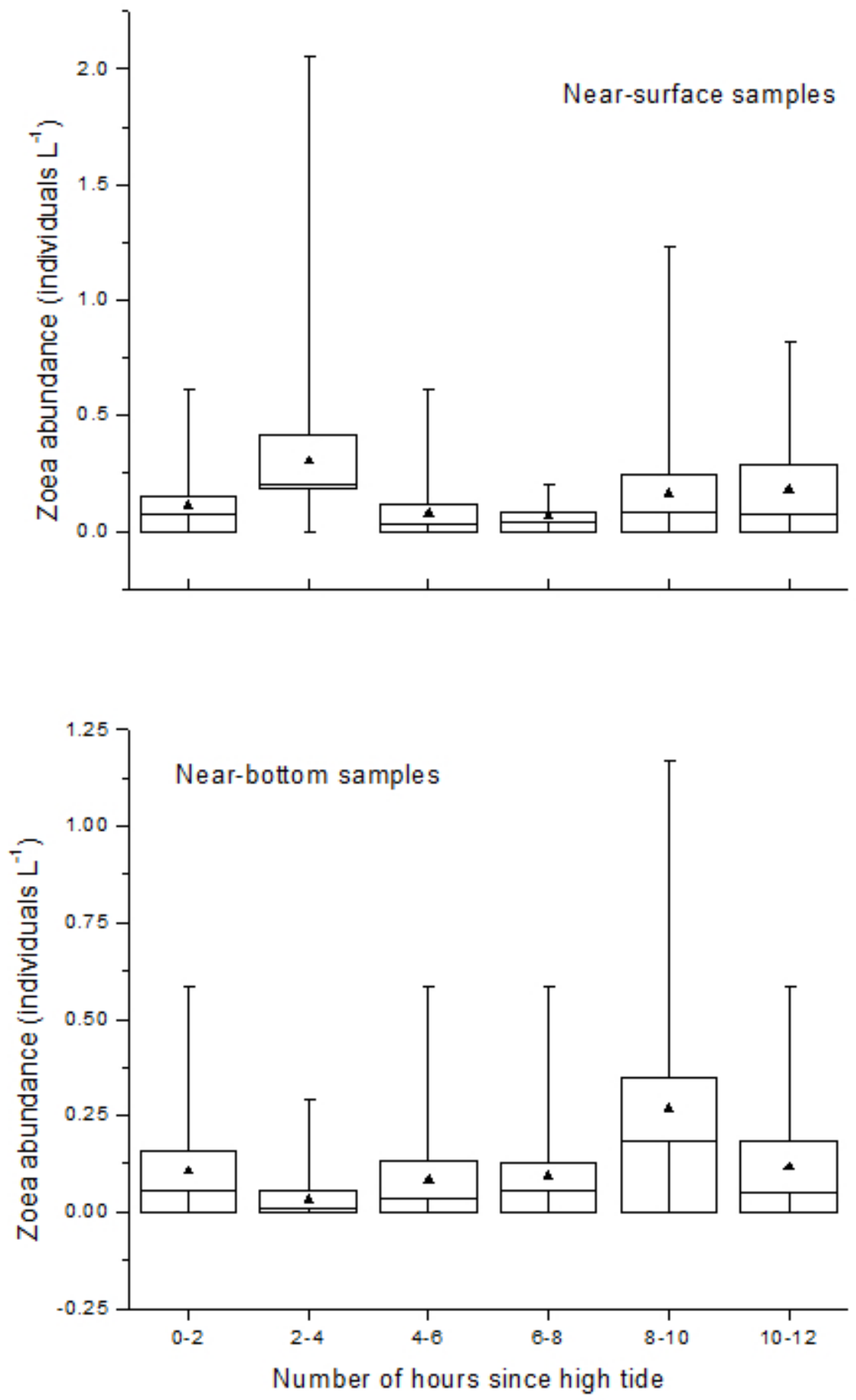

Figure 4.15. Abundance of Gecarcinus quadratus zoeas in relation to the phase of the surface tide. The zoea samples were collected over the course of three weeks and pooled together and averaged over 2-hour periods. Triangles represent the means, boxes represent the median and standard error of the mean, and whiskers represent the minimum and maximum values. 

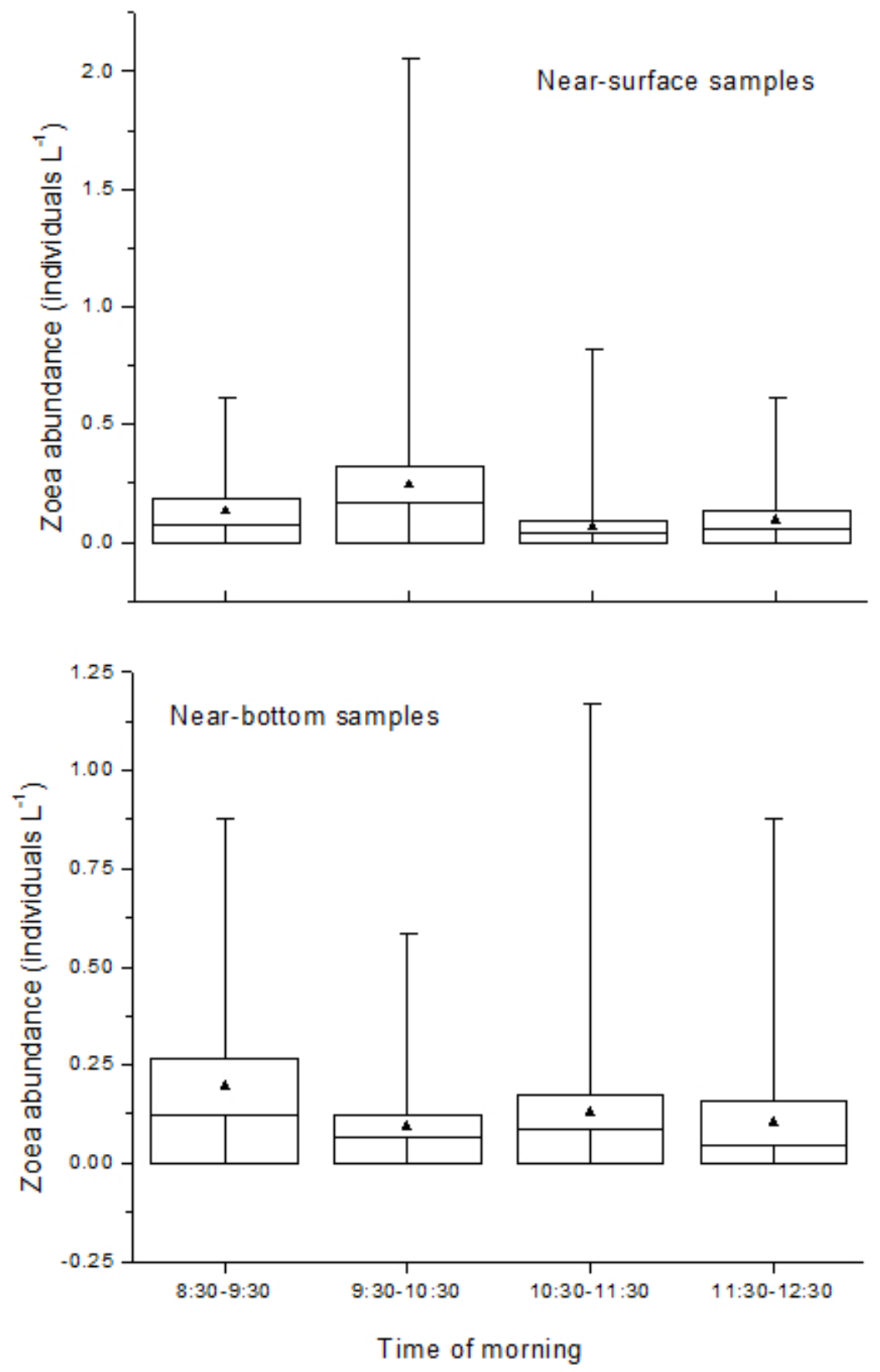

Figure 4.16. Abundance of Gecarcinus quadratus zoeas in relation to the time of sampling. The zoea samples were collected over the course of three weeks and pooled together weeks and pooled together and averaged over 1-hour periods. Triangles represent the means, boxes represent the median and standard error of the mean, and whiskers represent the minimum and maximum values. 
time of day, and tidal phase as cues. It is speculated here that the timing of egg release has been optimized to maximize survival of the adult, egg, and larval stages.

Rain prompts breeding migrations in G. quadratus. On Canales de Tierra, the crabs remained inside their burrows during the dry season and during periods of multiple rainless days at the beginning of the rainy season. The same pattern has been observed in all other terrestrial crabs studied to date (e.g., Gifford 1962; Bliss et al. 1978; Wolcott 1984; Hicks 1985). During the dry season, tropical land crabs tend to have limited access to fresh water, so desiccation poses a serious mortality risk. Wolcott (1984) found that the ghost crab Ocypode quadrata is capable of taking up water from damp sand, but two more highly terrestrial species (Gecarcinus lateralis and Cardisoma guanhumi) were much less capable of doing so. It appears that crabs of the genera Gecarcinus and Gecarcoidea maintain the water balance in their bodies in the dry season not through water uptake from substrates, but through behaviors that maximize water conservation (Wolcott 1984; Burggren and McMahon 1988). These behaviors include limiting physical activities to the nighttime, when evaporation rates are lowest (Burggren and McMahon 1988), and remaining inside the burrow during daytime and low-humidity conditions. The soil inside crab burrows is damp and humidity is high, so the rate of evaporative loss is low (Wolcott 1984). It is likely that G. quadratus undertakes its breeding migrations at the start of the rainy season because that is when the crabs are released from the locomotion restrictions imposed by desiccation.

Darkness is a second cue that triggers egg release in G. quadratus. After a rain shower, the crabs were observed walking outside their burrows, eating, and sometimes dipping their legs in tide pools. Like other land crabs, G. quadratus are likely to 
experience a large decrease in the osmolality of their hemolymph when they undertake migrations to the coast. By dipping their legs in salt water, they may restore the ion concentrations in their hemolymph to normal levels (Greenway 1994). Although the crabs were physically capable of making migrations down to the coast to engage in dipping behaviors in the daytime, no abdominal fanning leading to egg release was observed at that time. Instead, adult females waited until darkness to release their propagules. This is likely to be a predator-avoidance strategy that is common to many crabs. Morgan and Christy (1997) examined the timing of larval release relative to the light-dark cycle for 38 species of crabs, and they found that 32 of them (84\%) released larvae exclusively at night. It has been suggested that crabs release larvae nocturnally because there is reduced predation from planktivorous fish (e.g., Christy 1982; Forward et al. 1982; Morgan and Christy 1995; Hovel and Morgan 1997). Crab larvae with red or brown-black pigments are more vulnerable to visual predators than larvae with reflective blue-green pigments because the dark pigments contrast strongly with the yellow-green color of coastal waters during the day (Morgan and Christy 1997). Gecarcinus quadratus zoeas are highly pigmented with red-brown and black coloration, so being released at night might protect them from visual predation by diurnal fishes. However, recent work in a coral reef in the Red Sea has challenged the assumption that zooplankton are less vulnerable to predation from fishes at night. Holzman et al. (2007) showed that more than $60 \%$ of nocturnal fishes above the reef were planktivorous. Additional defenses may be required to contend with predation from nocturnal fishes.

The spines of G. quadratus zoeas may deter predation from both diurnal and nocturnal planktivorous fishes. Morgan (1989) showed that the spines of crab zoeas do 
not stabilize the larvae or reduce their sinking speed. Instead, it appears that the spines are an effective anti-predatory adaptation. Spines increase the size of the larva without substantially increasing its visibility, and this reduces predation from gape-limited fishes (Morgan 1989). Although the spines are frequently broken during fish attacks and must be regrown, the energetic costs are likely to be small, since spines consist merely of epidermis, hemolymph, and cuticle tissue (Freeman 1983; Morgan 1989). Zoeas with spines are more difficult to manipulate and ingest, and they can become lodged in the pharynxes of fish, resulting in death of the predator (Morgan 1989). In a laboratory experiment, small fish were capable of detecting zoeal spines, and they learned to seek out the experimentally de-spined zoeas among the unaltered zoeas (Morgan 1989). Depending on the species, brachyuran crab larvae can have two to four spines or pairs of spines, and they can be classified as long or short relative to body size (Morgan and Christy 1997). Gecarcinus quadratus zoeas have one dorsal, one rostral, and one pair of lateral spines that are relatively long relative to body size. This suggests that the larvae require substantial defense from planktivorous fishes.

An ebbing tide is the third cue that G. quadratus females use to time their egg release. G. quadratus zoea abundance in the nearshore was highest between high tide and low tide. Although not all the zoeas in the samples were verified as Stage I, it is likely that they were indeed newly hatched larvae, since light traps were used to capture them, and positive phototaxis in the laboratory-raised zoeas was much stronger immediately after hatching than at any other time (pers. obs.).

Releasing propagules at high or ebbing tide is a pattern common to many crabs. In a survey of 46 species from 9 families worldwide, Morgan and Christy (1997) found that 
27 of them (77\%) hatch within approximately one hour of nocturnal, large-amplitude high tides. This may be an additional measure for reducing fish predation for some crabs. In estuaries, larvae that hatch during this ebbing phase of the tidal cycle can be transported at maximum velocity away from the coast and toward deeper water (Zeng and Naylor 1996; Morgan and Christy 1997). Since planktivorous fish abundance tends to decrease with increasing distance from shore (Christy 1986; Morgan 1990; Morgan and Christy 1997; Holzman et al. 2007), zoeas may benefit from reduced predation risk by riding the ebb currents quickly out to deeper waters.

It is not entirely clear whether larvae released from an open coastline, as in the case of G. quadratus, would be transported offshore in the same way that estuarine larvae would be. Perhaps waves and alongshore currents would have a stronger influence than the cross-shore flow of an ebbing tide, which is usually negligible in open coastlines. However, a series of observations made by Zeng and Naylor (1996) showed that firststage larvae of the shore crab Carcinus maenas were abundant at the surface of coastal waters during ebbing tides. Only the first zoeal stage and the megalopa stage were common near shore. Intermediate stages were rare, suggesting that development occurred offshore. There is a need for more studies of the magnitude and direction of larval crab dispersal from open coastlines, and the idea that an ebbing tide disperses larvae away from the sure must be revisited. Future observations would benefit from measurements of current velocity at the surface near the site of release during ebbing tides to determine whether the predominant direction of water flow is offshore.

Another explanation for releasing during high tides could be that, since this is when water is deepest, larvae may be able to escape benthic predators more easily. G. 
quadratus zoeas have strong positive phototaxis at hatching, which may also keep them near the surface and away from the bottom. Alternatively, releasing during high tide may benefit adults. Since terrestrial crabs cannot breathe underwater, they tend to approach the shore cautiously to avoid getting washed away by waves (Wolcott and Wolcott 1982). Perhaps the likelihood of getting overcome by waves is less during high or ebbing tide.

The development time of Gecarcinus quadratus larvae in the laboratory from hatching to the megalopa stage was 21 days at $28^{\circ} \mathrm{C}$ and $31-34 \mathrm{ppt}$, although this is based on a single individual that survived to that stage. This development rate is comparable to that of other Gecarcinid crabs. Gecarcinus lateralis lateralis reaches the megalopa stage in $17-20$ days at $25^{\circ} \mathrm{C}$ and $35.9 \mathrm{ppt}$ (Willems 1982), Cardisoma guanhumi reaches it in 21-27 days at $25^{\circ} \mathrm{C}$ and $35 \mathrm{ppt}$ (Costlow and Bookhout 1968), Johngarthia planatus in approximately 31 days at $26^{\circ} \mathrm{C}$ and $34 \mathrm{ppt}$ (Cuesta et al. 2007), and Cardisoma armatum in approximately 35 days at $24^{\circ} \mathrm{C}$ and 25 ppt (Cuesta and Anger 2005). In the field, a mass migration of megalopae and juveniles onto land was observed 30 days after adult females migrated en masse to release eggs at the shore. Assuming that the juveniles originated from the local population, it appears that the duration of the planktonic stage in G. quadratus is approximately 30 days, and implies that the larvae spent about 9 days in the megalopa stage. Larval development rates of crabs are known to vary depending on temperature and salinity (Anger et al. 1998; García-Guerrero et al. 2003). Off the Pacific coast of Panama, nearshore water temperatures can vary by as much as $12^{\circ} \mathrm{C}$, and salinity can range from $0 \mathrm{ppt}$ (near land in the rainy season) to more than 34 ppt. Thus, more observations should be made in the 
laboratory and the field to determine how much variability there is in the development rate of G. quadratus larvae.

\subsubsection{Potential for accumulation and transport of zoeas by internal tidal bores}

Changes in the temperature structure of the water column suggested the presence of both internal tidal bores and high-frequency internal waves near the coast. These have been observed in the Gulf of Chiriquí before (Dana 1975; Pineda et al. 2009), and they are quite similar to those seen off the coast of California (Pineda 1991, 1994, 1999) and Florida (Leichter et al. 1998). Zoea abundance in the plankton pump samples was generally low. This could be either because the larvae were able to escape the suction of the pumps, or because the larvae were further offshore than the sampling location. Nevertheless, zoea abundance near the surface seemed to be highest around 5 and 11 hours after a warm front. At 5 hours after a warm front, the water column was usually in the cold phase of the internal tide. Leichter et al. (1998) found that crab zoea abundance over a coral reef was highest during the up-slope flow of colder water associated with internal tidal bores. Perhaps G. quadratus larvae also remain in colder, deeper waters during the day and are occasionally advected toward shore by internal tidal bores. At 11 hours after a warm front, zoeas near the surface would be concentrated just ahead of the next warm front as the cold water recedes, flowing down-slope away from shore, and the warm water moves shoreward to replace it. If zoeas remained in the cold water mass and swam upward, then perhaps they might become concentrated at the surface ahead of the warm front. The zoea abundance data from bottom waters do not support the 
concentration mechanisms proposed here, but perhaps this can be explained by the difference in the strength of the two pumps. While the surface pump averaged $4.82 \mathrm{~L}$ per sample, the bottom pump averaged $3.40 \mathrm{~L}$ per sample. Since larval abundance in the samples was low overall, it is possible that the bottom pump simply did not sample a sufficient volume to detect any patterns in zoea abundance. The mechanisms proposed here are thus highly tentative, but these hypotheses can be tested in future studies.

\subsection{Summary and conclusions}

The patterns of reproductive activity observed in Gecarcinus quadratus appear to be similar to those of other land crabs. Reproduction begins at the start of the rainy season, presumably to prevent adult mortality from desiccation during the breeding migration. Adults sometimes engage in dipping behavior during the day, but larval release occurs only at night. This probably helps larvae avoid visual diurnal predators. Adult females wait until the ebbing tide to release their eggs. It is not clear what the adaptive significance of this behavior might be. More observations are also needed to investigate whether the internal tide and internal waves could be an important source of transport for intermediate- and late-stage larvae. Since G. quadratus employs various physical and behavioral defenses against predation, it is likely that planktivory is an important source of mortality for their larvae. 


\section{Chapter 5}

\section{Conclusions}

The studies in this dissertation present observations and data that shed light on the reproductive ecology and larval biology of two crustacean species. Several conclusions can be drawn regarding the importance of scale in determining cues for reproduction; synchronous reproduction in crustaceans as a density-dependent or density-independent process; and the potential for climate change to alter reproductive patterns. The experiments and observations described in this thesis also generated several more questions for future inquiry.

\subsection{The importance of temporal scale in observations of marine invertebrate reproduction}

Marine invertebrates often rely on multiple cues to time their reproduction, and these cues can occur on widely different time scales. The timing of fertilization in the barnacle Semibalanus balanoides is linked mostly to photoperiod (Crisp 1959a; Davenport et al. 2005), presumably so that the embryos will be developmentally ready to be released by the time the winter-spring phytoplankton bloom begins a few months later. In the experiments and observations of this dissertation, larval release appears to be finetuned by an additional cue: turbidity. The timing of fertilization for these barnacles occurs on a seasonal scale, while the timing of release occurs on a scale of minutes to hours. Since high-turbidity events also last only minutes to hours, it would have been 
impossible to detect the relationship between turbidity and release without sampling on the scale of hours, as was done in Chapter 2 of this thesis.

Gecarcinus quadratus land crabs also rely on multiple cues to time their reproduction. First, they wait for rain, probably to ensure that both adult females and their eggs survive the migration to the ocean. Second, they wait until darkness, most likely to protect the eggs and larvae from visual predators. Finally, they seem to release their eggs when the tide is ebbing. These cues operate on seasonal, diurnal, and hourly scales, respectively. If studies of their reproduction had been limited to seasonal scales, only the relationship with rain would have been detected. Sampling a few times per day would have revealed the diurnal pattern. It was only by sampling on hourly scales that tidal patterns could be detected. A conclusion to be drawn from these studies is that when investigating the reproductive ecology of marine invertebrates, it is important to observe the animals on multiple time scales, since reproductive cues could be overlooked if the temporal scale of observation is too large or too small.

\subsection{Synchronous reproduction in crustaceans: predator swamping or predator avoidance?}

Synchronous reproduction is typically explained by hypotheses that fall into two main categories: predator swamping and predator avoidance hypotheses (Christy 2003). Predator swamping hypotheses suggest that propagules obtain density-dependent protection from predation (Ims 1990). Predators may become satiated quickly when a large number of propagules is available. Additionally, as the number of propagules in the 
water increases, the probability that an individual propagule will be consumed decreases. Predator swamping hypotheses generally assume that there is no advantage to reproducing under specific environmental conditions. Instead, organisms may synchronize reproduction according to lunar phase or tidal cycles simply because these are reliable cues that can be detected easily by all individuals in the population (Christy 2003).

Predator avoidance hypotheses suggest that organisms release propagules when predators are rare or inactive (Morgan and Christy 1997). Adults time their reproduction to coincide with environmental cues that are correlated with reduced predator abundance or activity, but the fitness benefits that their offspring gain do not depend on the number of other adults that are also reproducing at the same time. In his review, Christy (2003) reports evidence that intertidal crabs time their larval release to avoid, not swamp, predators. Nocturnal larval release helps larvae avoid some planktivorous fishes and release during ebbing tides may allow larvae to be transported rapidly to deeper waters, away from predators (Christy 2003).

Gecarcinus quadratus, a land crab, appears to follow the same strategy as intertidal crabs. They release larvae at night, and mostly during ebbing tides. However, they also time their reproduction to coincide with the beginning of the rainy season, presumably so that adults do not dehydrate during their migration to the ocean. Thus, a "predator avoidance" hypothesis does not fully explain all of the cues that they utilize, but a more general "density-independent" hypothesis is appropriate. It is concluded here that synchrony in Gecarcinus quadratus reproduction is a secondary result of behaviors 
that individuals undertake to maximize their own survival and that of their offspring, and so it falls in line most closely with the predator avoidance hypothesis.

Similarly, the benefits of synchronous larval release of Semibalanus balanoides appear to be density-independent. The timing of fertilization allows larvae to be developmentally ready by the onset of the winter-spring phytoplankton bloom. Larvae benefit from being released into such high concentrations of food. Release during turbid conditions aids larvae in avoiding predators, since their filter-feeding appendages can become temporarily clogged with other particles. If predator swamping was the main benefit of synchronous larval release, then the expectation is that all individuals in a local area would release at exactly the same time. Instead, some slight differences in timing of release have been observed in relation to the tidal height and wave exposure level of barnacles within spatial scales on the order of meters to kilometers (Crisp 1959b; Pineda et al. 2004). Moreover, multiple release events can be detected sometimes within relatively small areas (see Chapter 2 in this dissertation). It seems more likely that adults are reacting to environmental conditions that benefit the individual and its offspring, and that these conditions are not always experienced by all adults at exactly the same time. Since Semibalanus balanoides adults live in high densities over a wide vertical range of the intertidal zone, it is likely that many adults encounter the same conditions at the same time, and the resulting pattern of larval release appears to be synchronized among a large portion of the population. This suggests that the predator avoidance applies to the barnacles as well. 


\subsection{Potential impacts of climate change on the timing of reproduction}

Since Semibalanus balanoides does not depend on temperature as a cue for breeding, global warming is not likely to alter the timing of reproduction. However, cloud cover is expected to increase as the climate changes, and this "global dimming" could alter the photoperiod that barnacles experience (Davenport et al. 2005). Under these conditions, $S$. balanoides would be expected to undergo fertilization earlier in the year, since the perceived length of darkness would be longer. If predictions of increased storminess in the northern hemisphere are also accurate, then barnacles may be exposed to high turbidity levels frequently. Thus, they may also release larvae earlier in the year. An analysis of phytoplankton and zooplankton populations between 1958 and 2002 found that although peaks in meroplankton abundance are shifting to earlier dates, the timing of spring diatom blooms in the North Atlantic has remained relatively unchanged (Edwards and Richardson 2004). If S. balanoides begins to release larvae earlier in the year while diatom blooms remain fixed in time, then this could lead to a trophic mismatch. The larvae may not be able to find sufficient food, and perhaps barnacle recruitment would decline.

Changes in precipitation patterns in the tropics could alter the timing of reproduction for the land crab Gecarcinus quadratus. The most recent report from the Intergovernmental Panel on Climate Change states that there is high variability in the results of climate models for Central America. For the year 2050, precipitation predictions in the dry season range from a $12 \%$ decrease to a $5 \%$ increase, and in the rainy season it ranges from a $15 \%$ decrease to a $3 \%$ increase (IPCC 2007). The existing 
information about G. quadratus reproductive and larval ecology is too scant to make any predictions about the consequences of a change in reproductive timing. However, it is possible to speculate about some potential scenarios. If the length of the rainy season expands, then perhaps the reproductive season of G. quadratus would also expand and lead to a higher reproductive output. On the other hand, if the length of the dry season expands, then the reproductive season might be truncated, and reproductive output would decrease. As in S. balanoides, a change in the timing of reproduction could lead to a trophic mismatch between G. quadratus larvae and their prey or their predators, especially if the abundance of these organisms is not related to precipitation.

As mean global temperatures increase, sea levels are expected to increase due to melting of polar ice. Rises in sea level are not likely to affect the reproduction of the two crustaceans studied here. Although Semibalanus balanoides adults must remain cemented to a specific place in the intertidal zone, their offspring are capable of keeping pace with rising sea levels, thanks to the planktonic phase. As long as suitable hard substrates are available for larval settlement, the species should be able to cope with sea level rise. Gecarcinus quadratus is a terrestrial crab that only comes to the shore to restore its osmotic balance and to release propagules. As long as adults can move farther inland to dig their burrows, the vertical position of the sea surface is not likely to affect them.

\subsection{Suggestions for future research}

The results presented here raise questions that are worthy of future investigation. For example, this study confirmed a pattern that has been observed before: Semibalanus 
balanoides in Woods Hole, Massachusetts release larvae before individuals in Rhode Island, and they release before individuals in New Hampshire. What explains this pattern? Is it mostly genetic differences? The results also suggested that in three locations in a single winter, turbidity seemed to be the trigger for larval release. Is this pattern consistent from year to year? Does it apply to $S$. balanoides in Europe and the western coast of the United States? The laboratory experiments showed that adult predation on newly-released larvae was less under turbid conditions. Is this pattern also observed in the field?

The breeding season of Gecarcinus quadratus begins with the first rains of the rainy season, but it was not possible to observe them until the end of the rainy season, so it is unknown whether their breeding activities are limited to the beginning or whether they are sustained throughout it. Although a general description of the larval morphology for G. quadratus has been developed, it would be useful to conduct a more detailed study so that the morphology can be compared to that of other Gecarcinid species. The results suggested that adults release larvae mostly at ebbing tide. For estuarine crabs, this pattern has been shown to transport larvae quickly away from the site of release. However, it is not so clear that this pattern can be generalized to crabs that release on open coastlines. Studies of nearshore circulation and larval transport are needed to determine the distance, direction, and speed of larval dispersal from open coastlines. 


\section{Appendix 1: Filtering process for data from Little Harbor}

The chlorophyll (Fig 1a) and turbidity (Fig 2a) raw data in Little Harbor, Massachusetts exhibited some unrealistically high values, probably caused by a piece of macroalga that wrapped itself around the fluorometer. Since the instrument sampled at a high frequency and not all of the data seemed to be contaminated, we devised an ad-hoc method for filtering out bad data. It proceeded in three steps:

1. The instrument sampled once per second for 5 seconds every 5 minutes, so we computed the median for each of the 5-second sampling bursts. This eliminated bad data in situations when only some of the values in the sampling burst were contaminated (Fig 1b, 2b).

2. To remove bad data in instances when the entire sampling burst was contaminated, we divided the sampling period into 2-hour bins, and we filtered the data in each bin as follows: we calculated the mean and standard deviation of the values in the 2-hour bin. If the standard deviation of the mean was equal to or greater than half of the mean, then we eliminated the highest $1 / 3$ of values from the 2-hour bin (Fig 1c, 2c).

3. Finally, we calculated the median values for each 1-hour bin, and those are the values that we used in our analyses (Fig 1d, 2d, Fig 3). 

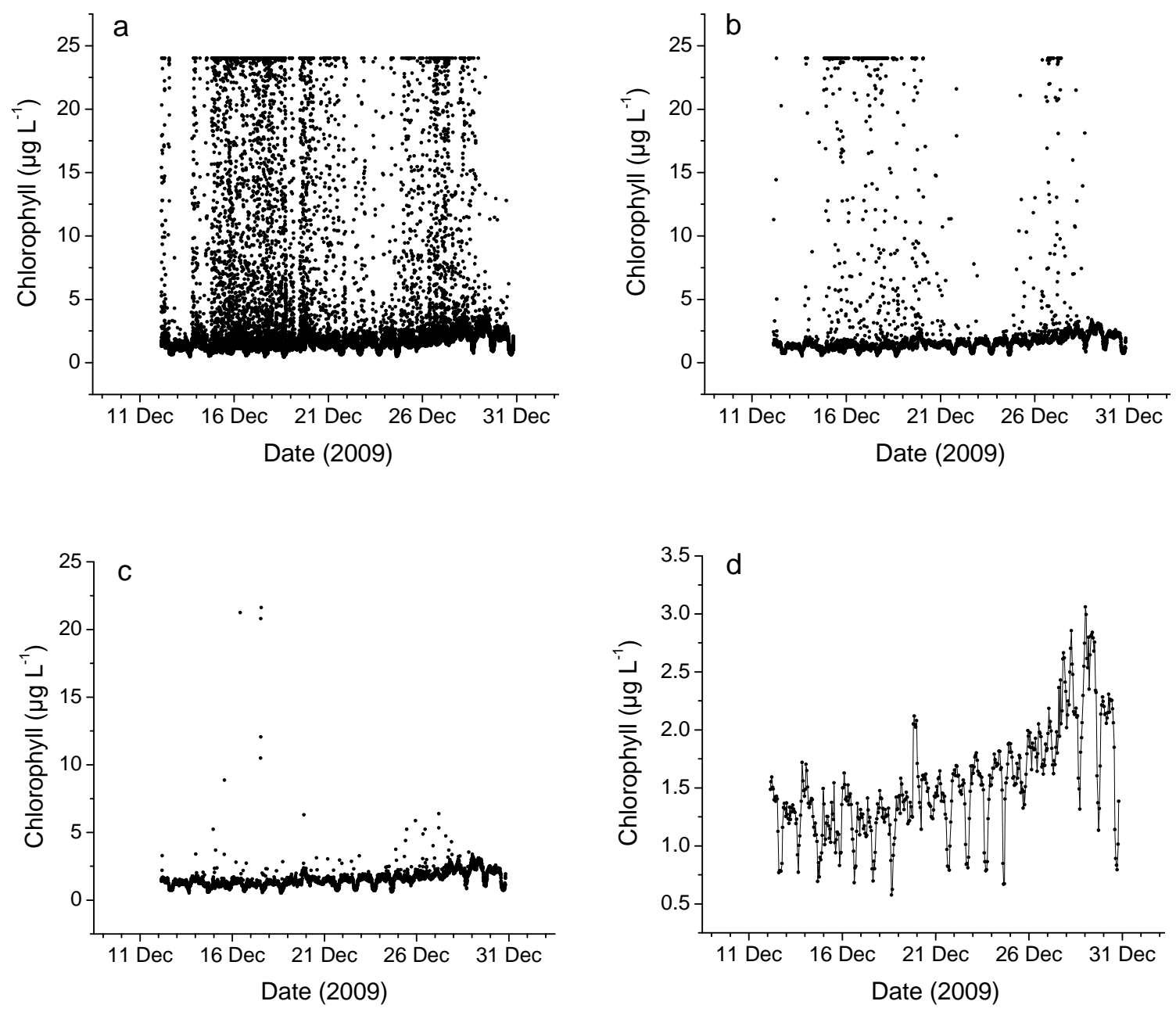

Figure 1. The process of data filtration for chlorophyll measurements from Little Harbor, Massachusetts. (a) Raw chlorophyll data (b) Median values for each 5-second sampling burst (c) Results of filtering data in 2-hour bins. (d) Median values for each 1-hour bin. Note that the $y$-axis scale differs from the other three plots. 

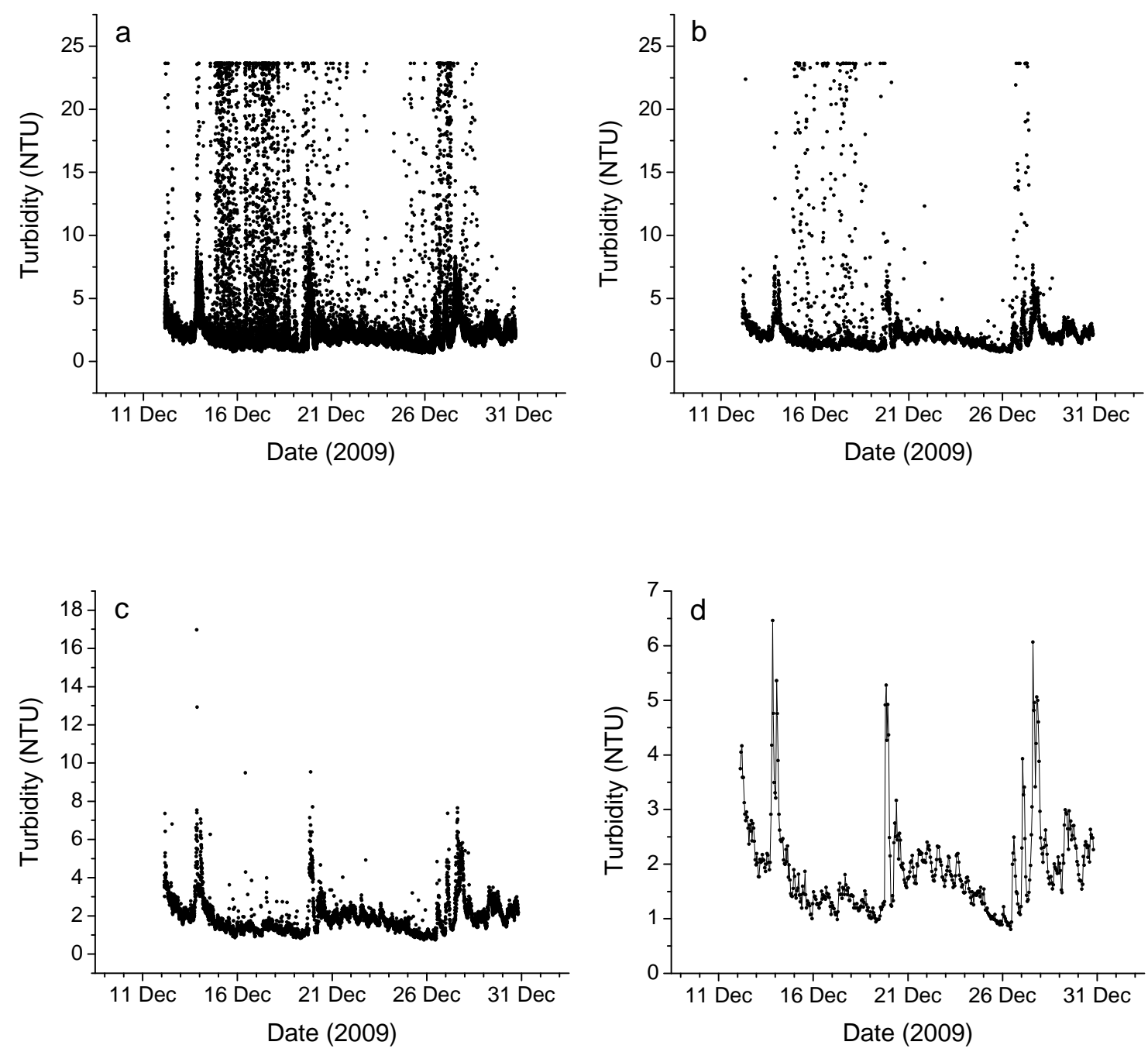

Figure 2. The process of data filtration for turbidity measurements from Little Harbor, Massachusetts. (a) Raw turbidity data (b) Median values for each 5-second sampling burst (c) Results of filtering data in 2-hour bins. (d) Median values for each 1-hour bin. Note that the y-axis scale differs among plots. 


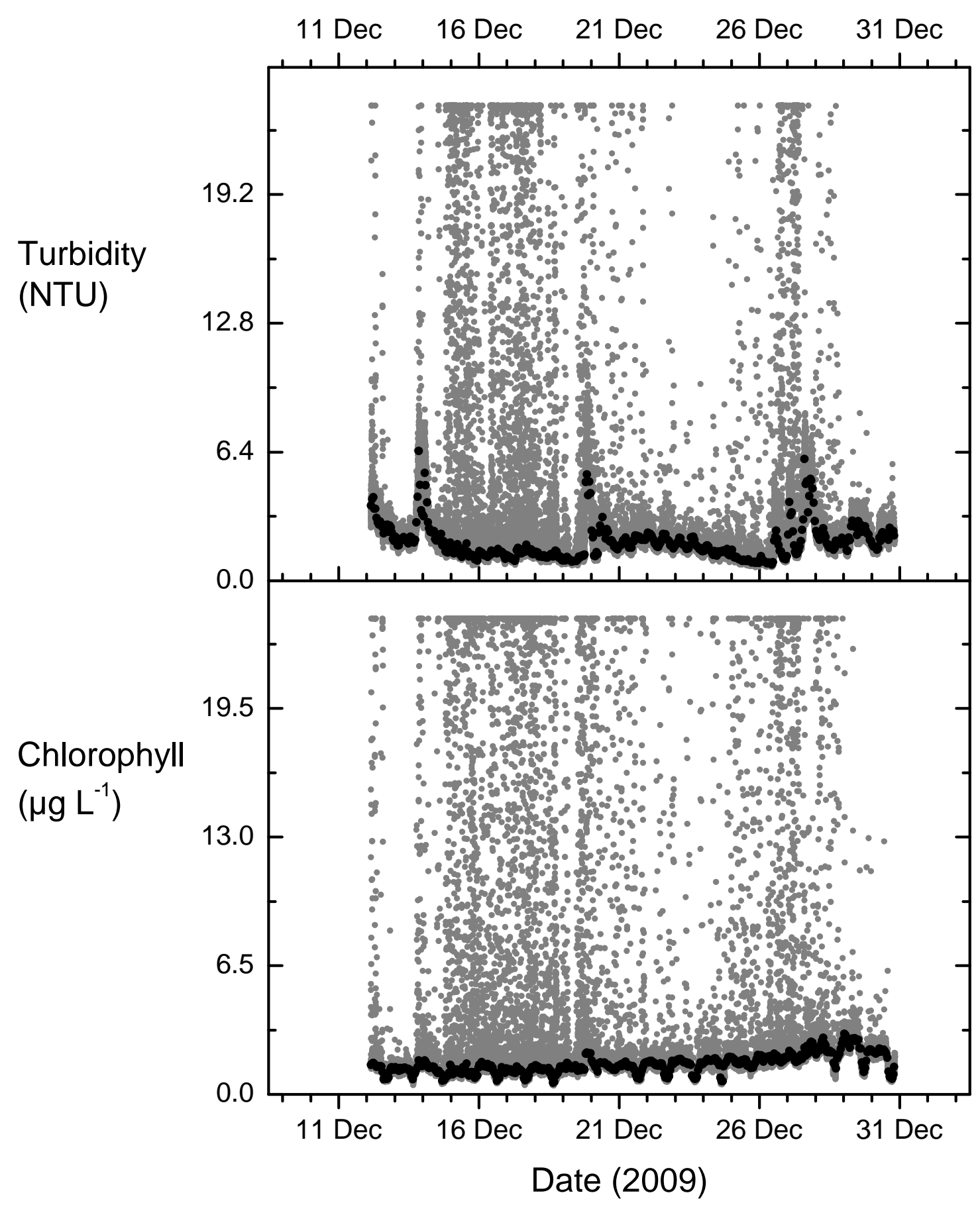

Figure 3. Raw turbidity and chlorophyll data are shown in gray dots. The black dots represent the data that have been processed via the filtering method described above. 


\section{Appendix 2: Observation of needlefish (Strongylura scapularis) spawning coinciding with the egg release of crabs (Gecarcinus quadratus)}

\section{Introduction}

While conducting the study on the reproductive ecology of the land crab, Gecarcinus quadratus (Chapter 4 of this thesis), a needlefish spawning event was observed to coincide with the beginning of the crab breeding season. A study was conducted to determine which species of needlefish had spawned and whether the fish larvae were potential predators of crab eggs and larvae.

\section{Material and Methods}

On March 4, 2008 at approximately 22:00 local time, it rained over Canales de Tierra and many hundreds of needlefish were observed swimming agitatedly near the water surface in Service Marina (Fig 4.1). The fish swam very close to the rocky shore. The following day at low tide, the rocks were covered with eggs that adhered to surfaces with tendrils. Approximately 30 of these eggs were taken back to the laboratory and placed in a 1-L glass beaker filled with seawater obtained with a bucket from a beach. The seawater was filtered through $100-\mu \mathrm{m}$ mesh and sterilized with ultraviolet light. The water temperature throughout the culturing period was approximately $28^{\circ} \mathrm{C}$, and the salinity was 31-34 ppt. The glass beaker was positioned near a window but away from 
direct sunlight. An air pump connected to a diffuser provided a gentle current and aeration. Once the fish larvae hatched, they were fed brine shrimp nauplii and brine shrimp adults, and half of the beaker water was changed daily. The larvae were photographed and measured several times throughout development. The night after the needlefish spawned, there was a mass migration of female G. quadratus crabs to the shore, where they released their eggs.

\section{Results}

Needlefish spawning took place three days before new moon during the rising tide. The eggs hatched in the laboratory 3 days after they were collected from the intertidal. The fish larvae were heavily pigmented and approximately $7 \mathrm{~mm}$ long three days after hatching (Fig 1). After 29 days in the laboratory, the fish had grown to $7.2 \mathrm{~cm}$ in length (from the tip of the lower jaw to the tip of the tail). The jaws were both short at hatching,

but by the $29^{\text {th }}$ day the larvae were in the 'half-beak phase' that has been reported for other belonid fishes (Tmski and Leis 2000). In this phase, the lower jaw is longer than the upper jaw. The larvae had 10 pectoral fin rays, 13 dorsal fin rays, and 14 anal fin rays, which are indicative of Strongylura scapularis (Collette et al. 1984; Collette 1995; Tmski and Leis 2000).

\section{Discussion}

Little information is available on the reproductive and larval ecology of needlefishes. To our knowledge, there is no literature describing the spawning frequency 

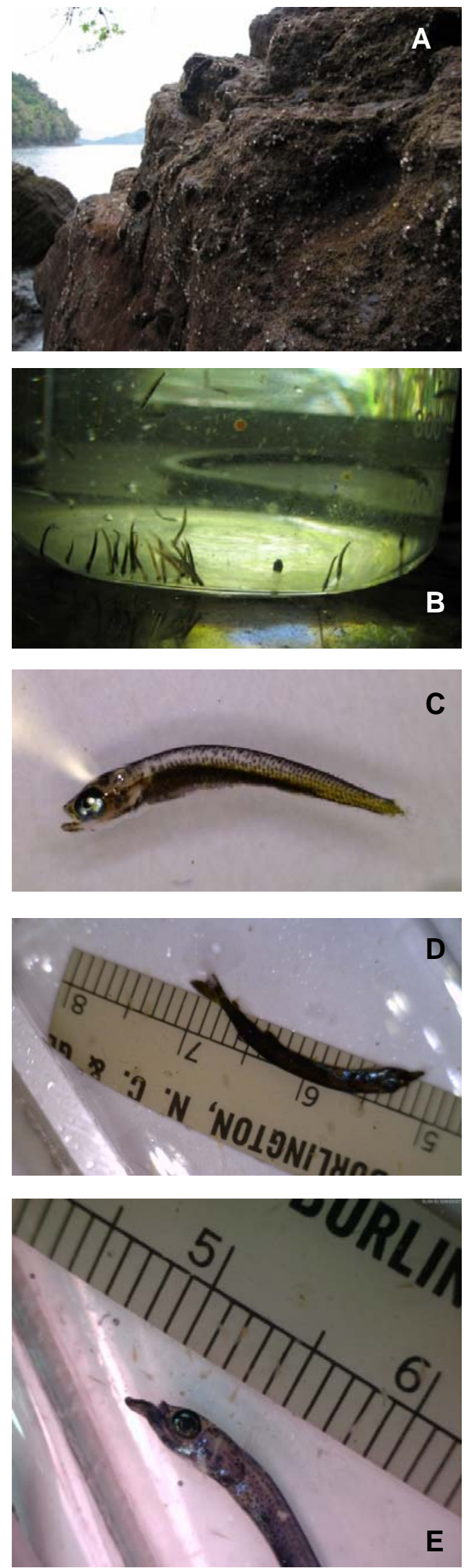

Figure 1. Eggs and larvae of the needlefish Strongylura scapularis from the Pacific coast of Panama. (A) Eggs remain attached to the benthos via tendrils and are exposed at low tide. (B) Newly hatched larvae in the laboratory exhibited a near-constant downward swimming behavior. (C) Three days after hatching, the larva was approximately 7 $\mathrm{mm}$ long and had upper and lower jaws that were approximately equal in length. (D) Larvae were approximately $7.2 \mathrm{~cm}$ long 29 days after hatching. (E) At 29 days, the larvae were in the "half-beak" stage, in which the lower jaw is longer than the upper jaw. 
or seasonality of Strongylura scapularis. The spawning event that took place at the beginning of the land crab reproductive season, in the month of March, took place three days before new moon, during the flood tide, and while it was raining. Thus, needlefish are hypothesized to use rain as a cue to spawn so that their reproduction will coincide with that of Gecarcinus quadratus.

Rain initiates the reproductive season of land crabs, so if zoeas are a good source of food for Strongylura scapularis larvae, then it might benefit these fish to synchronize their reproduction with the beginning of the rainy season. S. scapularis is a coastal fish that attaches its eggs to rocks along the shore. Thus, when the larvae hatch, they are in close proximity to the same areas where the land crabs release their eggs. S. scapularis eggs hatched in three days, which is much faster than the one to two weeks reported for other needlefishes (Breder and Rosen 1966; Collette 1984; Ambrose and Moser 1988). If the needlefish are attempting to synchronize their reproduction with that of the crabs, then the brevity of the egg stage might ensure that the fish larvae hatch when the crab larvae are still plentiful in the nearshore.

Strongylura scapularis larvae were raised successfully for 29 days on a diet consisting solely of brine shrimp nauplii and adults. Ambrose and Moser (1988) raised larvae of the California needlefish, Strongylura exilis, on the same diet. Previous work has shown that needlefish larvae in the halfbeak stage feed on detritus and zooplankton, and when they reach the needlenose stage (i.e., when both jaws are equally long), they become piscivorous (Breder 1932; Foster 1974; Boughton et al. 1991). Carr and Adams (1973) found that Strongylura marina juveniles (35 to $50 \mathrm{~mm}$ long) feed on small crustaceans, including small shrimp, mysids, and amphipods. This suggests that small 
crustaceans can be an adequate food item for $S$. scapularis larvae, and supports the hypothesis that the fish may be timing their spawning to coincide with the propagule release of Gecarcinus quadratus crabs. Future work should test this hypothesis by noting the timing of reproduction for both species and determining whether S. scapularis larvae feed on G. quadratus zoeas. Fish such as Strongylura scapularis may time their reproduction with that of the crabs so that their young may feed on the crab larvae. If that is the case, then G. quadratus might be an important but temporary link in the marine food web. 


\section{Bibliography}

Ambrose, A. and H.G. Moser, 1988. Rearing, development, and early life history of the California Needlefish, Strongylura exilis. Revue française d'aquariologie, 15: 4348.

Amend, M. and A. Shanks, 1999. Timing of larval release in the mole crab Emerita talpoida. Mar Ecol Prog Ser 183: 295-300.

Anger, K., E. Spivak, and T. Luppi, 1998. Effects of reduced salinity on development and bioenergetics of early larval shore crab Carcinus maenas. Journal of Experimental Marine Biology and Ecology, 220: 287-304.

Ashjian, C.J., S.L. Smith, C.N. Flagg, and C. Wilson, 1998. Patterns and occurrence of diel vertical migration of zooplankton biomass in the Mid-Atlantic Bight described by an acoustic Doppler current profiler. Continental Shelf Research, 18: 831-858.

Barnes, H., 1955. The hatching process in some barnacles. Oikos, 6: 114-123.

Barnes, H., 1956. Balanus balanoides (L.) in the Firth of Clyde: The developmental and annual variation of the larval population, and the causative factors. J Anim Ecol 25: $72-84$.

Barnes, H., 1957. Processes of restoration and synchronization in marine ecology. The spring diatom increase and the "spawning" of the common barnacle Balanus balanoides (L.). Annales Biologiques, 33: 67-85.

Barnes, H., 1962. Note on the variations in the release of nauplii of Balanus balanoides with special reference to the spring diatom outburst. Crustaceana, 4: 118-122.

Barnes, H. and M. Barnes, 1958. The rate of development of Balanus balanoides (L.) larvae. Limnol Oceanogr, 3: 29-32.

Barry, J.P., 1989. Reproductive response of a marine annelid to winter storms: an analog to fire adaptation in plants? Mar Ecol Prog Ser, 54: 99-107.

Bertness, M.D., S.D. Gaines, and R.A. Wahle, 1996. Wind-driven settlement patterns in the acorn barnacle Semibalanus balanoides. Mar Ecol Prog Ser, 137: 103-110.

Best, D.J., and P.G. Gipps, 1974. An improved gamma approximation to the negative binomial. Technometrics, 16: 621-624.

Bigelow, H.B., I.C. Lillick, and M. Sears, 1940. Phytoplankton and planktonic protozoa 
of the offshore waters of the Gulf of Maine. Part I. Numerical distribution. Transactions of the American Philosophical Society, 21: 149-191.

Bliss, D.E., J. Van Montfrans, M. Van Montfrans, and J.R. Boyer, 1978. Behavior and growth of the land crab Gecarcinus lateralis (Fréminville) in southern Florida. Bulletin of the American Museum of Natural History, 160: 111-152.

Boughton, D.A., B.B. Collette, A.R. McCune, 1991. Heterochrony in jaw mophology of needlefishes (Teleostei: Belonidae). Systematic Zoology, 40: 329-354.

Bousfield, E.L., 1955. Ecological control of the occurrence of barnacles in the Miramichi Estuary. Bull Nat Mus Can, 137: 1-69.

Breder, C.M., 1932. On the habits and development of certain Atlantic Synentognathi. Carnegie Institute of Washington Publications, 435: 1-35.

Breder, C.M. and D.E. Rosen, 1966. Modes of Reproduction in Fishes. New York, Natural History Press.

Bright, D.B. and C.L. Hogue, 1972. A synopsis of the burrowing land crabs of the world and list of their arthropod symbionts and burrow associates. Contributions in Science, Los Angeles County Natural History Museum, 220: 1-58.

Burggren, W.W. and B.R. McMahon, 1988. Biology of the Land Crabs. Cambridge University Press, Cambridge, U.K.

Carr, W.E.S, and C.A. Adams, 1973. Food habits of juvenile marine fishes occupying seagrass beds in the estuarine zone near Crystal River, Florida. Transactions of the American Fisheries Society, 102: 511-540.

Cebrián, J. and I. Valiela, 1999. Seasonal patterns in phytoplankton biomass in coastal ecosystems. Journal of Plankton Research, 21: 429-444.

Chree, C., 1912. Some phenomena of sunspots and of terrestrial magnetism, at Kew observatory. Philos Trans R Soc London Ser A, 212: 75.

Christy, J.H., 1982. Adaptive significance of semilunar cycles of larval release in fiddler crabs (Genus Uca): Test of an hypothesis. Biological Bulletin, 163: 251-263.

Christy, J.H., 1986. Timing of larval release by intertidal crabs on an exposed shore. Bulletin of Marine Science, 39: 176-191.

Collette, B.B., G.E. McGowen, N.V. Parin, and S. Mito, 1984. Beloniformes: development and relationships. In: H.G. Moser (ed.) Ontogeny and systematics of fishes. American Society of Ichthyologists and Herpetologists. Spec. Publ. no. 1. Pp. 335-354. 
Collette, B.B., 1995. Belonidae. In: W. Fischer, F. Krupp, W. Schneider, C. Sommer, K.E. Carpenter, and V.H. Niem (eds.). Guía FAO para la identificación de especies para los fines de la pesca. Pacifico centro-oriental, Volumen II. (FAO, Rome, Italy). Pp. 919-926.

Costlow, J., and C. Bookhout, 1968. The complete larval development of the land crab Cardisoma guanhumi Latreille in the laboratory. Crustaceana Supplements, 2: 259-270.

Crisp, D.J., 1956. A substance promoting hatching and liberation of young in cirrepedes. Nature, 178: 263.

Crisp, D.J., 1959a. The rate of development of Balanus balanoides (L.) embryos in vitro. J Anim Ecol, 28: 119-132.

Crisp, D.J., 1959b. Factors influencing the time of breeding of Balanus balanoides. Oikos, 10: $275-289$.

Crisp, D.J., 1962. The planktonic stages of the Cirripedia Balanus balanoides (L.) and Balanus balanus (L.) from north temperate waters. Crustaceana, 3: 207-221.

Crisp, D.J., 1964. Racial differences between North American and European forms of Balanus balanoides. J Mar Biol Assoc UK, 44: 33-45.

Crisp, D.J. and B.S. Patel, 1960. The moulting cycle in Balanus balanoides (L.). Biological Bulletin, 118: 31-47.

Crisp, D.J., and D.A. Ritz, 1973. Responses of Cirripede larvae to light. I. Experiments with white light. Mar Biol 23: 327-335.

Crisp, D.J. and C.P. Spencer, 1958. The control of the hatching process in barnacles. Proceedings of the Royal Society of London, B149: 278-299.

Cuesta, J., and K. Anger, 2005. Larval morphology and salinity tolerance of a land crab from West Africa, Cardisoma armatum (Brachyura: Grapsoidea: Gecarcinidae). Journal of Crustacean Biology 25: 640-654.

Cuesta, J.A., M.U. García-Guerrero, and M.E. Hendrickx, 2007. The complete larval development of Johngarthia planatus (Brachyura: Grapsoidea: Gecarcinidae) described from laboratory rearred material, with notes on the affinity of Gecarcinus and Johngarthia. Journal of Crustacean Biology, 27: 263-277.

Cushing, C.H., 1951. The vertical migration of planktonic organisms. Biological Review, 26: $158-192$. 
D’Croz, L. and D.R. Robertson, 1997. Coastal oceanographic conditions affecting coral reefs on both sides of the Isthmus of Panama. Proceedings of the $8^{\text {th }}$ International Coral Reef Symposium, 2: 2053-2058.

Dana, T.F., 1975. Development of contemporary Eastern Pacific coral reefs. Marine Biology, 33: 355-374.

Dandonneau, Y. and J. Neveux, 1997. Diel variations of in vivo fluorescence in the eastern equatorial Pacific: and unvarying pattern. Deep-Sea Research II, 44: 1869-1880.

Davenport, J., M.S. Berggren, T. Brattegard, N. Brattenborg, M. Burrows, S. Jenkins, D. McGrath, R. MacNamara, J.-A. Sneli, G. Walker, and S. Wilson, 2005. Doses of darkness control latitudinal differences in breeding date in the barnacle Semibalanus balanoides. Journal of the Marine Biological Association of the U.K., 85: 59-63.

Dayton, P.K. and E. Sala, 2001. Natural History: the sense of wonder, creativity and progress in ecology. Scientia Marina, 65 (Suppl. 2): 199-206.

Fish, C.J., 1925. Seasonal distribution of the plankton of the Woods Hole region. Bull US Bur Fish, 41: 91-179.

Foale, S., 1999. Local ecological knowledge and biology of the land crab Cardisoma hirtipes (Decapoda: Gecarcinidae) at West Nggela, Solomon Islands. Pacific Science, 53: 37-49.

Forward, R.B., K. Lohmann, and T.W. Cronin, 1982. Rhythms in larval release by an estuarine crab (Rhithropanopeus harrisii). Biological Bulletin, 163: 287-300.

Foster, N.R., 1974. Behavior, development, and early life history of the Asian needlefish, Xenentodon cancila. Proceedings of the Academy of Natural Science of Philadelphia, 125: 77-88.

Freeman, J.A., 1983. Spine regeneration in larvae of the crab, Rhiithropanopeus harrisii. Journal of Experimental Zoology, 225: 443-448.

Frolander, H.T., 1955. "The biology of the zooplankton of the Narragansett Bay area." Ph.D. Thesis, Brown University, 94 pp.

Fromentin, J.-M. and B. Planque, 1996. Calanus and environment in the eastern North Atlantic. II. Influence of the North Atlantic Oscillation on C. finmarchicus and $C$. helgolandicus. Marine Ecology Progress Series, 134: 111-118.

García-Guerrero, M., H. Villarreal, and I. Racotta, 2003. Effect of temperature on lipids, proteins, and carbohydrates levels during development from egg extrusion to 
juvenile stage of Cherax quadricarcinatus (Decapoda: Parastacidae).

Comparative Biochemistry and Physiology Part A, 135: 147-154.

Giese, A.C. and H. Kanatani, 1987. Maturation and spawning. In: A.C. Giese, J.S. Pearse, and V.B. Pearse (eds.). Reproduction of marine invertebrates. Vol. 9. Blackwell Scientific, Palo Alto, California. Pp. 251-329.

Gifford, C.A., 1962. Some observations on the general biology of the land crab, Cardisoma guanhumi (Latreille), in south Florida. Biological Bulletin, 123: 207223.

Greenaway, P., 1994. Salt and water balance in field populations of the terrestrial crab Gecarcoidea natalis. Journal of Crustacean Biology, 14: 438-453.

Gyory, J. and J. Pineda. High-frequency observations of early-stage larval abundance: Do storms trigger synchronous larval release in Semibalanus balanoides? Submitted.

Harms, J., 1984. Influence of water temperature on larval development of Elminius modestus and Semibalanus balanoides (Crustacea, Cirripedia). Helgol Meeresunters 38: 123-134.

Harrison, P.L, R.C. Babcock, G.D. Bull, J.K. Oliver, C.C. Wallace, and B.L. Willis, 1984. Mass spawning in tropical reef corals. Science, 223: 1186-1189.

Haury, L.R., J.A. McGowan, and P.H. Wiebe, 1978. Patterns and processes in the timespace scales of plankton distributions. Pages 277-328 in J.H. Steele, ed. Spatial Pattern in Plankton Communities, NATO Conference Series, IV: Marine Sciences, Vol. 3. Plenum, New York.

Harrison, P.L, R.C. Babcock, G.D. Bull, J.K. Oliver, C.C. Wallace, and B.L. Willis, 1984. Mass spawning in tropical reef corals. Science, 223: 1186-1189.

Hicks, J.W., 1985. The breeding behaviour and migrations of the terrestrial crab Gecarcoidea natalis (Decapoda: Brachyura). Australian Journal of Zoology, 33: $127-142$.

Hicks, J.W., H. Rumpff, and H. Yorkston, 1990. Christmas Crabs. (Christmas Island Natural History Association, Christmas Island, Indian Ocean). Pp. 1-81.

Hitchcock, G.L. and T.J. Smayda, 1977. The importance of light in the initiation of the 1972-1973 winter-spring diatom bloom in Narragansett Bay. Limnology and Oceanography, 22: 126-131.

Holzman, R., M. Ohavia, R. Vaknin, and A. Genin, 2007. Abundance and distribution of nocturnal fishes over a coral reef during the night. Marine Ecology Progress Series, 342: 205-215. 
Horner, R.A., 2002. A taxonomic guide to some common marine phytoplankton. BioPress Ltd, Dorset Press, Dorchester, UK.

Hovel, K.A. and S.G. Morgan, 1997. Planktivory as a selective force for reproductive synchrony and larval migration. Marine Ecology Progress Series, 157: 79-95.

Hutchinson, G.E., 1961. The paradox of the plankton. The American Naturalist, 95: 137145.

Hutchinson, G.E., 1967. A Treatise on Limnology, Vol. II:Introduction to Lake Biology and the Limnoplankton. Wiley, New York.

Ims, R.A., 1990. The ecology and evolution of reproductive synchrony. Trends in Ecology and Evolution, 5: 135-140.

Keller, A.A., C. Taylor, C. Oviatt, T. Dorrington, G. Holcombe, and L. Reed, 2001. Phytoplankton production patterns in Massachusetts Bay and the absence of the 1998 winter-spring bloom. Marine Biology, 138: 1051-1062.

Ladah, L.B., F.J. Tapia, J. Pineda, and M. Lopez, 2005. Spatially heterogeneous, synchronous settlement of Chthamalus spp. larvae in northern Baja California. Marine Ecology Progress Series, 302: 177-185.

Lampert, W., 1989. The adaptive significance of diel vertical migration of zooplankton. Functional Ecology, 3: 21-27.

Lang, W.H. and A. Ackenhusen-Johns, 1981. Seasonal species composition of barnacle larvae (Cirripedia: Thoracica) in Rhode Island waters, 1977-1978. Journal of Plankton Research, 3: 567-575.

Leichter, J.J., G. Shellenbarger, S.J. Genovese, and S.R. Wing, 1998. Breaking internal waves on a Florida (USA) coral reef: a plankton pump at work? Marine Ecology Progress Series, 166: 83-97.

Licandro, P., F. Ibañez, and M. Etienne, 2006. Long-term fluctuations (1974-1999) of the salps Thalia democratica and Salpa fusiformis in the northwestern Mediterranean Sea: Relationships with hydroclimatic variability. Limnology and Oceanography, 51: 1832-1848.

Lindquist, E.S. and C. R. Carroll, 2004. Differential seed and seedling predation by crabs: impacts on tropical coastal forest composition. Oecologia, 141: 661-671.

Liu, H.-C. and M.-S. Jeng, 2007. Some reproductive aspects of Gecarcoidea lalandii (Brachyura: Gecarcinidae) in Taiwan. Zoological Studies, 46: 347-354. 
Loftus, M.E. and H.H. Seliger, 1975. Some limitations of the in vivo fluorescence technique. Chesapeake Science, 16: 79-92.

Macho, G., J. Molares, and E. Vazquez, 2005. Timing of larval release by three barnacles from the NW Iberian Peninsula. Marine Ecology Progress Series, 298: 251-260.

Martin, J.H., 1965. Phytoplankton-zooplankton relationships in Narragansett Bay. Limnology and Oceanography, 10: 185-191.

Martin, J.H., 1970. Phytoplankton-zooplankton relationships in Narragansett Bay. IV. The seasonal importance of grazing. Limnology and Oceanography, 15: 413-418.

McGowan, J.A., D.R. Cayan, and L.M. Dorman, 1998. Climate-ocean variability and ecosystem response in the Northeast Pacific. Science, 281: 210-217.

Meekan, M.G., P.J. Doherty, and L. White Jr., 2000. Recapture experiments show the low sampling efficiency of light traps. Bulletin of Marine Science, 67: 875-885.

Meekan, M.G., S.G. Wilson, A. Halford, and A. Retzel, 2001. A comparison of catches of fishes and invertebrates by two light trap designs in tropical NW Australia. Marine Biology, 139: 373-381.

Moore, H.B., 1935. The biology of Balanus balanoides. III. The soft parts. J Mar Biol Assoc UK, 20: 263-277.

Morgan, S.G., 1995. Life and death in the plankton: larval mortality and adaptation. In: Ecology of marine invertebrate larvae. McEdward LR, ed. Boca Raton: CRC Press. 279-321.

Morgan, S.G., 1989. Adaptive significance of spination in estuarine crab zoeae. Ecology, 70: $464-482$.

Morgan, S.G. and J.H. Christy, 1995. Adaptive significance of the timing of larval release by crabs. The American Naturalist, 145: 457-479.

Morgan, S.G. and J.H. Christy, 1996. Survival of marine larvae under the countervailing selective pressures of photodamage and predation. Limnology and Oceanography, 41: 498-504.

Morgan, S.G. and J.H. Christy, 1997. Planktivorous fishes as selective agents for reproductive synchrony. Journal of Experimental Marine Biology and Ecology, 209: 89-101.

Müller, P., X.-P. Li, and K.K. Niyogi, 2001. Non-photochemical quenching. A response to excess light energy. Plant Physiology, 125: 1558-1566. 
Navarrete, S.A. and E.A. Wieters, 2000. Variation in barnacle recruitment over small scales: larval predation by adults and maintenance of community pattern. Journal of Experimental Marine Biology and Ecology. 253: 131-148.

NOAA, 2009. Tide Predictions: Bahia Honda. http://tidesandcurrents.noaa.gov/get predictions.shtml?year=2009\&stn=1113+Balboa\&se

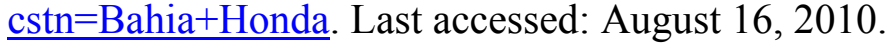

NOAA, 2010a. Tidal station locations and ranges.

http://tidesandcurrents.noaa.gov/tides06/tab2ec1b.html\#12. Accessed on March 10, 2010.

NOAA, 2010b. Climatic wind data for the United States.

http://www.ncdc.noaa.gov/oa/mpp/wind1996.pdf. Accessed on March 10, 2010.

Ohman, M.D., B.W. Frost, and E.B. Cohen, 1983. Reverse diel vertical migration: an escape from invertebrate predators. Science, 220: 1404-1407.

Onitsuka, T., T. Kawamura, T. Horii, N. Takiguchi, H. Takami, and Y. Watanabe, 2007. Synchronized spawning of abalone Haliotis diversicolor triggered by typhoon events in Sagami Bay, Japan. Marine Ecology Progress Sereies, 351: 129-138.

Ottersen, G., B. Planque, A. Belgrano, E. Post, P.C. Reid, and N.C. Stenseth, 2001. Ecological effects of the North Atlantic Oscillation. Oecologia, 128: 1-14.

Oviatt, C., A. Keller, and L. Reed, 2002. Annual primary production in Narragansett Bay with no bay-wide winter-spring phytoplankton bloom. Estuarine, Coastal, and Shelf Science, 54: 1013-1026.

Parmenter, C.M., M.H. Bothner, and B. Butman, 1983. Characteristics of resuspended sediment from Georges Bank collected with a sediment trap. Esuar Coast Shelf Sci, 17: 521-533.

Pineda, J., 1991. Predictable upwelling and the shoreward transport of planktonic larvae by internal tidal bores. Science, 253: 548-551.

Pineda, J., 1994. Internal tidal bores in the nearshore: Warm-water fronts, seaward gravity currents and the onshore transport of neustonic larvae. Journal of Marine Research, 52: 427-458.

Pineda, J., 1999. Circulation and larval distribution in internal tidal bore warm fronts. Limnology and Oceanography, 44: 1400-1414.

Pineda J., V. Starczak, and C. DiBacco, 2004. Biocomplexity: regional variability in reproductive timing, settlement and recruitment of an intertidal barnacle in the US northeast coast. Abstract. ASLO/TOS Ocean research conference. Honolulu, HI Feb 2004. 
Pineda, J., N.B. Reyens, and V.R. Starczak, 2009. Complexity and simplification in understanding recruitment in benthic populations. Population Ecology, 51: 17-32.

PLUTO (Panama LJL Underwater Tropical Observatory), 2010. http://4dgeo.whoi.edu/panama/. Last accessed: July 072010.

Prager, M.H. and J.M. Hoenig, 1989. Superposed Epoch Analysis: A randomization test of environmental effects on recruitment with application to chub mackerel. Transactions of the American Fisheries Society, 118: 608-618.

Pratchett, M.S., N. Gust, G. Goby, and S.O. Klanten, 2001. Consumption of coral propagules represents a significant trophic link between corals and reef fish. Coral Reefs, 20: 13-17.

Pratt, D.M., 1965. The winter-spring flowering in Narragansett Bay. Limnology and Oceanography, 10: 173-184.

Richerson, P., R. Armstrong, and C.R. Goldman, 1970. Contemporaneous disequilibrium, a new hypothesis to explain the "Paradox of the Plankton". Proceedings of the National Academy of Science, 67: 1710-1714.

Roberts, J., 1975. Internal Gravity Waves in the Ocean. Marcel Dekker, Inc.

Rumrill, S.S., 1990. Natural mortality of marine invertebrate larvae. Ophelia 32::163-98.

Shanks, A.L. 1983. Surface slicks associated with tidally forced internal waves may transport pelagic larvae of benthic invertebrates and fishes shoreward. Marine Ecology Progress Series, 13: 311-315.

Sherman, P.M., 2002. Effects of land crabs on seedling densities and distributions in a mainland neotropical rain forest. Journal of Tropical Ecology, 18: 67-89.

Sherman, P.M., 2003. Effects of land crabs on leaf litter distributions and accumulations in a mainland tropical rainforest. Biotropica, 35: 365-374.

Sherman, P.M., 2006. Influence of land crabs Gecarcinus quadratus (Gecarcinidae) on distributions of organic carbon and roots in a Costa Rican rain forest. International Jounral of Tropical Biology, 54: 149-161.

Singarajah, K.V., J. Moyse, and E.W. Knight-Jones, 1967. The effect of feeding upon the phototactic behaviour of Cirrepede nauplii. Journal of Experimental Marine Biology and Ecology, 1: 144-153.

Singh, Y.P., and Badruddin, 2006. Statistical considerations in superposed epoch analysis and its applications in space research. J Atmos Sol Terr Phys, 68: 803-813. 
Smayda, T.J., 1998. Patterns of variability characterizing marine phytoplankton, with examples from Narragansett Bay. ICES Journal of Marine Science, 55: 562-573.

Sokal, R.R. and F.J. Rohlf, 1995. Biometry: the Principles and Practices of Statistics in Biological Research, $3^{\text {rd }}$ ed., W.H. Freeman, New York.

Starr, M., J.H. Himmelman, and J.-C. Therriault, 1990. Direct coupling of marine invertebrate spawning with phytoplankton blooms. Science, 247: 1071-1074.

Starr, M., J.H. Himmelman, and J.-C. Therriault, 1991. Coupling of nauplii release in barnacles with phytoplankton blooms: a parallel strategy to that of spawning in urchins and mussels. Journal of Plankton Research, 13: 561-571.

Stone, C.J., 1989. A comparison of algal diets for cirripede nauplii. Journal of Experimental Marine Biology and Ecology, 132: 17-40..

Stubbings, H.G., 1975. Balanus balanoides. Liverpool University Press.

Thorson, G., 1950. Reproductive and larval ecology of marine bottom invertebrates. Biological Reviews, 25: 1-45.

Tmski, T. and J.M. Leis, 2000. Belonidae (Needlefishes, Long-Toms). In: Leis, J.M. and B.M. Carson-Ewart (eds.). The Larvae of Indo-Pacific Coastal Fishes: An Identification Guide to Marine Fish Larvae (Brill, Leiden, the Netherlands). Pp. 149-153.

Tomas, C.R. (ed), 1997. Identifying marine phytoplankton. Academic Press, San Diego, CA.

Townsend, D.W., L.M Cammen, P.M. Holligan, D.E. Campbell, and N.R. Pettigrew, 1994. Causes and consequences of variability in the timing of spring phytoplankton blooms. Deep-Sea Research I, 41: 747-765.

University of Rhode Island Graduate School of Oceanography 2010. Phytoplankton of Narragansett Bay. http://www.gso.uri.edu/phytoplankton/ . Last accessed on June 242010.

Vaughn, D. and J.D. Allen, 2010. The peril of the plankton. Integrative and Comparative Biology, pp. 1-19.

Willems, K.A., 1982. Larval development of the land crab Gecarcinus lateralis lateralis (Fréminville, 1835) (Brachyura, Gecarcinidae) reared in the laboratory. Journal of Crustacean Biology, 2: 180-201.

Wolcott, T.G., 1984. Uptake of interstitial water from soil: Mechanisms and ecological 
significance in the Ghost Crab Ocypode quadrata and two Gecarcinid land crabs. Physiological Zoology, 57: 161-184.

Wolcott, T.G. and D.L. Wolcott, 1982. Larval loss and spawning behavior in the land crab Gecarcinus lateralis (Fréminville). Journal of Crustacean Biology, 2: 477485.

Young C.M., Chia F.S., 1987. Abundance and distribution of pelagic larvae as influenced by predation, behavior and hydrographic factors. In: Reproduction of marine invertebrates - Giese AC, Pearse JS, Pearse VB, eds. Vol. 9:. seeking unity in diversity. Palo Alto (CA): Blackwell/Boxwood Press. 385-463.

Zeng, C. and E. Naylor, 1996. Endogenous tidal rhythms of vertical migration in field collected zoea-1 larvae of the shore crab Carcinus maenas: implications for ebb tide offshore dispersal. Marine Ecology Progress Series, 132: 71-82. 